Prepared in cooperation with National Oceanic and Atmospheric Administration, National Marine Fisheries Service

Effects of the Proposed California WaterFix North Delta Diversion on Survival of Juvenile Chinook Salmon (Oncorhynchus tshawytscha) in the Sacramento-San Joaquin River Delta, Northern California

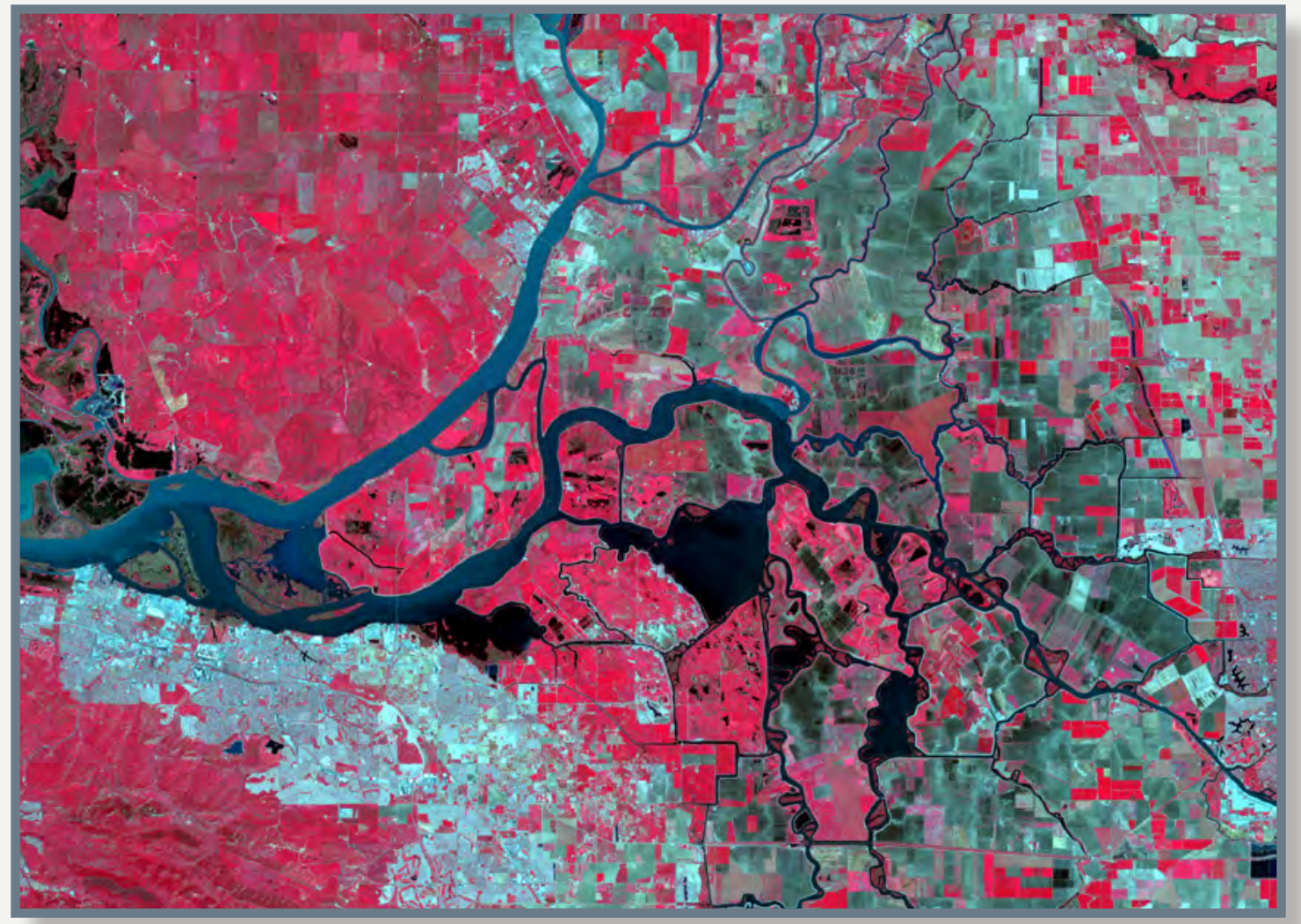

Open-File Report 2018-1078 
Cover: Landsat image of the Sacramento-San Joaquin River Delta in central California. Landsat imagery courtesy of NASA Goddard Space Flight Center and U.S. Geological Survey. 


\section{Effects of the Proposed California WaterFix North Delta Diversion on Survival of Juvenile Chinook Salmon (Oncorhynchus tshawytscha) in the Sacramento-San Joaquin River Delta, Northern California}

By Russell W. Perry and Adam C. Pope

Prepared in cooperation with National Oceanic and Atmospheric Administration, National Marine Fisheries Service

Open-File Report 2018-1078

U.S. Department of the Interior

U.S. Geological Survey 


\section{U.S. Department of the Interior \\ RYAN K. ZINKE, Secretary}

\section{U.S. Geological Survey \\ William H. Werkheiser, Deputy Director \\ exercising the authority of the Director}

U.S. Geological Survey, Reston, Virginia: 2018

For more information on the USGS-the Federal source for science about the Earth, its natural and living resources, natural hazards, and the environment-visit https://www.usgs.gov/ or call 1-888-ASK-USGS (1-888-275-8747).

For an overview of USGS information products, including maps, imagery, and publications, visit https:/store.usgs.gov.

Any use of trade, firm, or product names is for descriptive purposes only and does not imply endorsement by the U.S. Government.

Although this information product, for the most part, is in the public domain, it also may contain copyrighted materials as noted in the text. Permission to reproduce copyrighted items must be secured from the copyright owner.

\section{Suggested citation:}

Perry, R.W., and Pope, A.C., 2018, Effects of the proposed California WaterFix North Delta Diversion on survival of juvenile Chinook salmon (Oncorhynchus tshawytscha) in the Sacramento-San Joaquin River Delta, northern California: U.S. Geological Survey Open-File Report 2018-1078, 94 p. plus appendixes,

https://doi.org/10.3133/ofr20181078. 


\section{Contents}

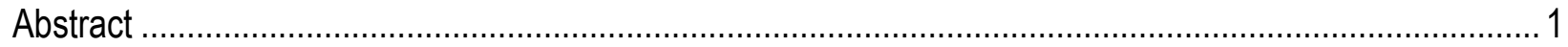

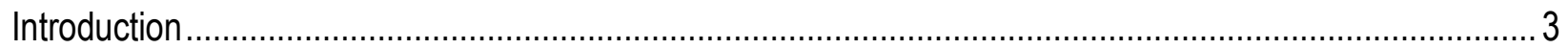

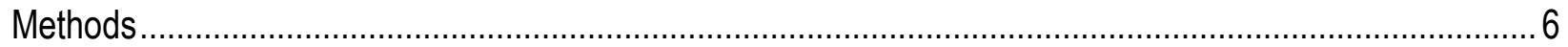

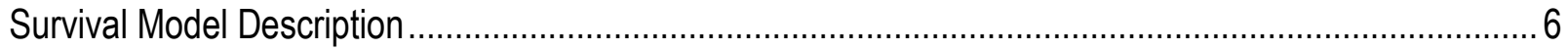

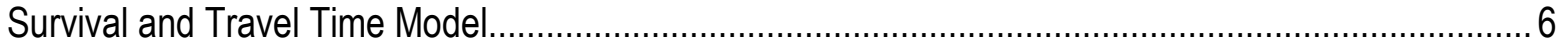

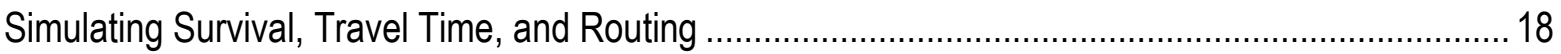

Evaluating the North Delta Diversion Bypass Rules......................................................................... 19

Comparing the Proposed Action and No Action Alternative ............................................................... 19

Using Survival Criteria for Shaping North Delta Diversion Rule Curves ............................................. 22

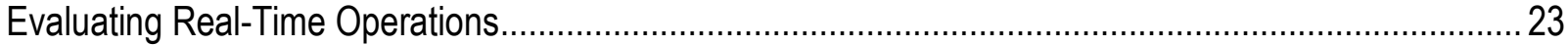

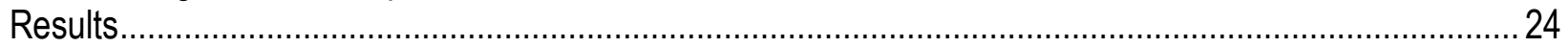

Evaluating the North Delta Diversion Bypass Rules.......................................................................... 24

Comparing the Proposed Action and No Action Alternative ............................................................. 38

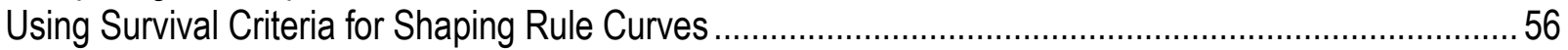

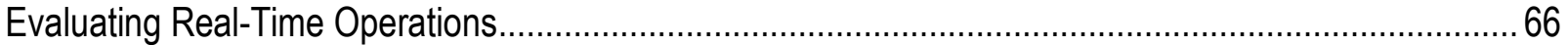

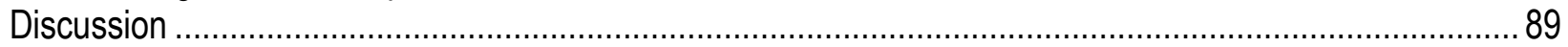

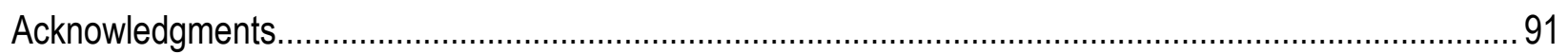

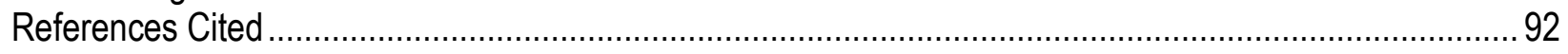

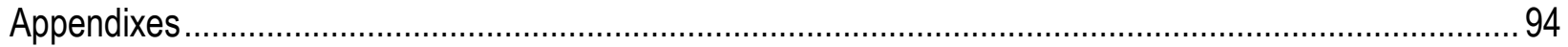

Appendix 1. Simulated Daily Survival by Year, No Action Alternative Compared to Proposed

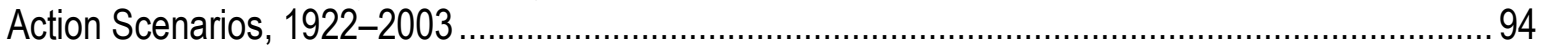

Appendix 2. Simulated Daily Travel Time by Year, No Action Alternative Compared to Proposed

Action Scenarios, 1922-2003 .............................................................................................. 94

Appendix 3. Simulated Daily Routing by Year, No Action Alternative Compared to Proposed

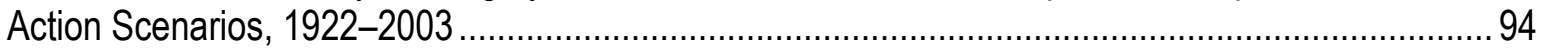

Appendix 4. Simulated Route-Specific Survival by Year, No Action Alternative Compared to

PA Scenarios, 1922-2003 .............................................................................................. 94

Appendix 5. Simulated Route-Specific Travel Time by Year, No Action Alternative Compared to

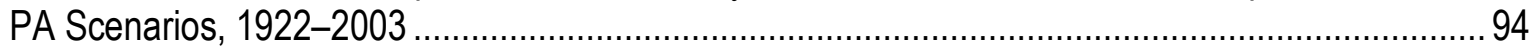

Appendix 6. Simulated Daily Survival by Year, No Action Alternative Compared to Level 1

Scenarios, 1922-2003 ......................................................................................................... 94

Appendix 7. Simulated Daily Travel Time by Year, No Action Alternative Compared to Level 1

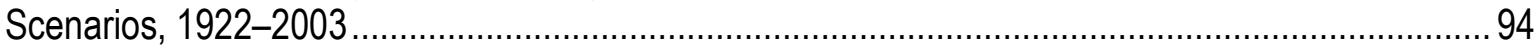

Appendix 8. Simulated Daily Routing by Year, No Action Alternative Compared to Level 1

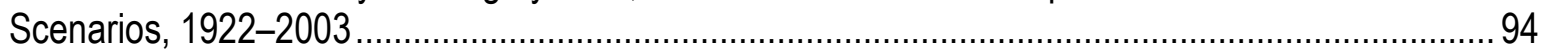

Appendix 9. Simulated Route-Specific Survival by Year, No Action Alternative Compared to

Level 1 Scenarios, 1922-2003 ................................................................................................ 94

Appendix 10. Simulated Route-Specific Travel Time by Year, No Action Alternative Compared

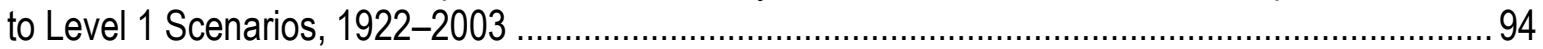

Appendix 11. North Delta Diversion Rule Curve Optimization.......................................................... 94 


\section{Figures}

Figure 1. Map showing location of acoustic telemetry receiving stations (filled black circles) used to detect acoustic-tagged juvenile Chinook salmon as they migrated through the Sacramento-San Joaquin River Delta, northern California.

Figure 2. Summary of posterior distributions of parameters estimating the effects of river flow and Delta Cross Channel (DCC) gate position on travel time and survival of juvenile Chinook salmon, Sacramento-San Joaquin River Delta, northern California.

Figure 3. Graphs showing reach-specific relations between median travel time of juvenile Chinook salmon and inflow to the Sacramento-San Joaquin River Delta as measured at the Sacramento River at Freeport

Figure 4. Graphs showing reach-specific relations between survival of juvenile Chinook salmon and inflow to the Sacramento-San Joaquin River Delta as measured at the Sacramento River at Freeport

Figure 5. Graphs showing route-specific survival of juvenile Chinook salmon between Freeport and Chipps Island (see fig. 1), through the Sacramento-San Joaquin River Delta, northern California...

Figure 6. Graphs showing route-specific travel time distributions of juvenile Chinook salmon at the 5th (top graph) and 95th (bottom graph) percentiles of discharge based on the historical flow record $(8,290$ and $47,910 \mathrm{ft} 3 / \mathrm{s})$, between Freeport and Chipps Island (see fig. 1), Sacramento-San Joaquin River Delta, northern California......... 13 Figure 7. Graphs of fitted logistic regression model (heavy line) showing the probability of juvenile Chinook salmon entering Sutter and Steamboat Sloughs as a function of the ratio of Sutter plus (+) Steamboat discharge to Sacramento River dishcarge at Freeport

Figure 8. Daily entrainment probability into Georgiana Slough and the Delta Cross Channel (DCC) as a function of discharge of the Sacramento River at Freeport

Figure 9. Graphs showing effect of the North Delta Diversion (NDD) bypass rules on the difference in throughSacramento-San Joaquin River Delta survival with and without implementation of the NDD, in northern California.

Figure 10. Graphs showing effect of the North Delta Diversion on bypass discharge (top graph), and survival (S $S_{\text {Delta) }}$ with and without the diversion for the Delta Cross Channel (DCC) closed (middle graphs) and open (bottom graphs) for constant low-level pumping as defined in the NDD bypass rules, Sacramento-San Joaquin River Delta, northern California. 26

Figure 11. Graphs showing effect of the North Delta Diversion on bypass discharge (top graph), and survival (S $S_{\text {Delta) }}$ with and without the diversion for the Delta Cross Channel (DCC) closed (middle graphs) and open (bottom graphs) for October-November bypass rules, Sacramento-San Joaquin River Delta, northern California.

Figure 12. Graphs showing effect of the North Delta Diversion on bypass discharge (top graph), and survival ( $S_{\text {Delta) }}$ with and without the diversion for the Delta Cross Channel (DCC) closed (middle graphs) and open (bottom graphs) for Level 1 post-pulse operations for December-April, Sacramento-San Joaquin River Delta, northern California.

Figure 13. Graphs showing effect of the North Delta Diversion on bypass discharge (top graph), and survival (S Delta) with and without the diversion for the Delta Cross Channel (DCC) closed (middle graphs) and open (bottom graphs) for Level 2 post-pulse operations for December-April, Sacramento-San Joaquin River Delta, northern California.

Figure 14. Graphs showing effect of the North Delta Diversion on bypass discharge (top graph), and survival (S $S_{\text {Delta) }}$ with and without the diversion for the Delta Cross Channel (DCC) closed (middle graphs) and open (bottom graphs) for Level 3 post-pulse operations for December-April, Sacramento-San Joaquin River Delta, northern California.

Figure 15. Graphs showing effect of the North Delta Diversion on bypass discharge (top graph), and survival (S $S_{\text {Delta) }}$ with and without the diversion for the Delta Cross Channel (DCC) closed (middle graphs) and open (bottom graphs) for Level 1 post-pulse operations in May, Sacramento-San Joaquin River Delta, northern California. 
Figure 16. Graphs showing effect of the North Delta Diversion on bypass discharge (top graph), and survival $\left(S_{\text {Delta }}\right)$ with and without the diversion for the Delta Cross Channel (DCC) closed (middle graphs) and open (bottom graphs) for Level 2 post-pulse operations in May, Sacramento-San Joaquin River Delta, northern California....... 32 Figure 17. Graphs showing effect of the North Delta Diversion on bypass discharge (top graph), and survival (S $S_{\text {Delta) }}$ with and without the diversion for the Delta Cross Channel (DCC) closed (middle graphs) and open (bottom graphs) for Level 3 post-pulse operations in May, Sacramento-San Joaquin River Delta, northern California. 33 Figure 18. Graphs showing effect of the North Delta Diversion on bypass discharge (top graph), and survival $\left(S_{\text {Delta }}\right)$ with and without the diversion for the Delta Cross Channel (DCC) closed (middle graphs) and open (bottom graphs) for Level 1 post-pulse operations in June, Sacramento-San Joaquin River Delta, northern California....... 34 Figure 19. Graphs showing effect of the North Delta Diversion on bypass discharge (top graph), and survival $\left(S_{\text {Delta }}\right.$ ) with and without the diversion for the Delta Cross Channel (DCC) closed (middle graphs) and open (bottom graphs) for Level 2 post-pulse operations in June, Sacramento-San Joaquin River Delta, northern California....... 35 Figure 20. Graphs showing effect of the North Delta Diversion on bypass discharge (top graph), and survival (S $S_{\text {Delta }}$ ) with and without the diversion for the Delta Cross Channel (DCC) closed (middle graphs) and open (bottom graphs) for Level 1 post-pulse operations in June, Sacramento-San Joaquin River Delta, northern California.

Figure 21. Graphs showing effect of the North Delta Diversion on bypass discharge (top graph), and survival (S $S_{\text {Delta) }}$ with and without the diversion for the Delta Cross Channel (DCC) closed (middle graphs) and open (bottom graphs) for July-September bypass rules, Sacramento-San Joaquin River Delta, northern California.

Figure 22. Graphs showing simulated daily bypass flows and Delta Cross Channel (DCC) gate operations for water year 1979 (top graph), median of simulated mean daily survival through the Sacramento-San Joaquin River Delta, northern California (middle graph), and the difference in survival between the Proposed Action (PA) and No Action Alternative (NAA) scenarios (bottom graph).

Figure 23. Graphs showing simulated daily bypass flows and Delta Cross Channel (DCC) gate operations for water year 1979 (top graph), simulated median daily travel time of juvenile Chinook salmon through the Sacramento-San Joaquin River Delta, northern California (middle graph), and the difference in travel time between the Proposed Action (PA) and No Action Alternative (NAA) scenarios (bottom graph).....

Figure 24. Graphs showing simulated daily bypass flows and Delta Cross Channel (DCC) gate operations for water year 1990 (top graph), median of simulated mean daily survival through the Sacramento-San Joaquin River Delta, northern California (middle graph), and the difference in survival between the Proposed Action (PA) and No Action Alternative (NAA) scenarios (bottom graph).

Figure 25. Graphs showing simulated daily bypass flows and Delta Cross Channel (DCC) gate operations for water year 1990 (top graph), median of simulated mean route-specific survival through the Sacramento-San Joaquin River Delta, northern California (middle graph), and the difference in route-specific survival between the Proposed Action (PA) and No Action Alternative (NAA) scenarios (bottom graph).

Figure 26. Graphs showing simulated daily bypass flows and Delta Cross Channel (DCC) gate operations for water year 1990 (top graph), simulated median daily travel time through the Sacramento-San Joaquin River Delta, northern California (middle graph), and the difference in travel time of juvenile Chinook salmon between the Proposed Action (PA) and No Action Alternative (NAA) scenarios (bottom graph).

Figure 27. Graphs showing simulated daily bypass flows and Delta Cross Channel (DCC) gate operations for water year 1990 (top graph), simulated median route-specific travel time of juvenile Chinook salmon through the Sacramento-San Joaquin River Delta, northern California (middle graph), and the difference in route-specific travel time between the Proposed Action (PA) and No Action Alternative (NAA) scenarios (bottom graph).....

Figure 28. Graphs showing simulated daily bypass flows and Delta Cross Channel (DCC) gate operations for water year 1990 (top graph), and stacked line plots showing the daily cumulative migration route probabilities for the Proposed Action (PA, middle graph) and No Action Alternative (NAA, bottom graph) scenarios, Sacramento-San Joaquin River Delta, northern California. 
Figure 29. Graphs showing simulated daily bypass flows and Delta Cross Channel (DCC) gate operations for water year 1979 (top graph), and stacked line plots showing the daily cumulative migration route probabilities for the Proposed Action (PA, middle graph) and No Action Alternative (NAA, bottom graph) scenarios, Sacramento-San Joaquin River Delta, northern California.

Figure 30. Graphs showing simulated daily bypass flows and Delta Cross Channel (DCC) gate operations for water year 1979 (top graph), simulated median route-specific travel time of juvenile Chinook salmon through the Sacramento-San Joaquin River Delta, northern California (middle graph), and the difference in route-specific travel time between the Proposed Action (PA) and No Action Alternative (NAA) scenarios (bottom graph).

Figure 31. Graphs showing simulated daily bypass flows and Delta Cross Channel (DCC) gate operations for water year 1979 (top graph), median of simulated mean route-specific survival through the Sacramento-San Joaquin River Delta, northern California (middle graph), and the difference in route-specific survival between the Proposed Action (PA) and No Action Alternative (NAA) scenarios (bottom graph).

Figure 32. Daily boxplots showing the distribution of the probability that through-Sacramento-San Joaquin River Delta survival for either the Level 1 (L1) or Proposed Action (PA) scenarios is less than survival for the No Action Alternative (NAA) scenario, in northern California.

Figure 33. Daily boxplots showing the distribution of the probability that the difference in median travel time of juvenile Chinook salmon through the Sacramento-San Joaquin River Delta between the No Action Alternative (NAA) and either the Level 1 (L1) or Proposed Action (PA) scenarios is greater than 0 , in northern California....... 51 Figure 34. Daily boxplots showing daily median differences in through-Sacramento-San Joaquin River Delta survival between the No Action Alternative (NAA), Proposed Action (PA), and Level 1 (L1) scenarios, in northern California.

Figure 35. Daily boxplots showing median differences in median travel time of juvenile Chinook salmon between the No Action Alternative (NAA), Proposed Action (PA), and Level 1 (L1) scenarios, in the Sacramento-San Joaquin River Delta, northern California............................................................................................... 53 Figure 36. Daily boxplots showing median differences in median through-Sacramento-San Joaquin River Delta survival between the Proposed Action (PA) and No Action Alternative (NAA) scenarios by water year type, in northern California.

Figure 37. Daily boxplots showing median differences in median travel time of juvenile Chinook salmon between the Proposed Action (PA) and No Action Alternative (NAA) scenarios by water year type, in the Sacramento-San Joaquin River Delta, northern California.

Figure 38. Graph showing North Delta Diversion (NDD) flow rates as a functions of Sacramento River discharge required to achieve a $90 \%$ probability of a given relative decrease in survival assuming 0 near-field mortality, in the Sacramento-San Joaquin River Delta, northern California.

Figure 39. Graph showing North Delta Diversion (NDD) rates as a functions of Sacramento River discharge required to achieve a $90 \%$ probability of a given relative decrease in survival assuming near-field mortality of 0.03 , in the Sacramento-San Joaquin River Delta, northern California.................................................................. 58 Figure 40. Graph showing North Delta Diversion (NDD) rates as a functions of Sacramento River discharge required to achieve a $90 \%$ probability of a given relative decrease in survival assuming near-field mortality of 0.05 , in the Sacramento-San Joaquin River Delta, northern California.

Figure 41. Graph showing North Delta Diversion (NDD) rates as a functions of Sacramento River discharge required to achieve a $90 \%$ probability of a given absolute decrease in survival assuming 0 near-field mortality, in the Sacramento-San Joaquin River Delta, northern California.

Figure 42. Graph showing North Delta Diversion (NDD) rates as a functions of Sacramento River discharge required to achieve a $90 \%$ probability of a given absolute decrease in survival assuming near-field mortality of 0.03 , in the Sacramento-San Joaquin River Delta, northern California. 
Figure 43. Graph showing North Delta Diversion (NDD) rates as a functions of Sacramento River discharge required to achieve a $90 \%$ probability of a given absolute decrease in survival assuming near-field mortality of 0.05 , in the Sacramento-San Joaquin River Delta, northern California.

Figure 44. Graphs showing posterior distributions for the relative (top graph) and absolute (bottom graph) difference in survival between no diversion and diversion at rates based on the Level 1, December-April bypass rule.

Figure 45. Graphs showing posterior distributions for the relative (top graph) and absolute (bottom graph) difference in survival between no diversion and diversion at rates based on a criterion of a $90 \%$ probability of a relative difference in survival of $<0.06$ with 0 near-field mortality.

Figure 46. Graphs showing posterior distributions for the relative (top graph) and absolute (bottom graph) difference in survival between no diversion and diversion at rates based on a criterion of a $90 \%$ probability of an absolute difference in survival of $<0.03$ with 0 near-field mortality.

Figure 47. Graphs showing Level 1 (L1) real-time operations (top graph), revised Unlimited Pulse Protection (UPP) real-time operations (second graph from top), median daily through-Sacramento-San Joaquin River Delta survival probability (third graph from top), and median daily difference in survival of each real-time scenario relative to the no diversion scenario (bottom graph), for water year 2003.

Figure 48. Violin plots showing posterior distributions of annual survival probability for Level 1 (L1) real-time operations and revised Unlimited Pulse Protection (UPP) real-time operations (top graph), and the difference in annual survival of each real-time scenario relative to the no diversion scenario (bottom graph), for water year 2003

Figure 49. Graphs showing Level 1 (L1) real-time operations (top graph), revised Unlimited Pulse Protection (UPP) real-time operations (second graph from top), median daily through-Sacramento-San Joaquin River Delta survival probability (third graph from top), and median daily difference in survival of each real-time scenario relative to the no diversion scenario (bottom graph), for water year 2004.

Figure 50. Violin plots showing posterior distributions of annual survival probability for Level 1 (L1) real-time operations and revised Unlimited Pulse Protection (UPP) real-time operations (top graph), and the difference in annual survival of each real-time scenario relative to the no diversion scenario (bottom graph),

for water year 2004

Figure 51. Graphs showing Level 1 (L1) real-time operations (top graph), revised Unlimited Pulse Protection (UPP) real-time-operations (second graph from top), median daily through-Sacramento-San Joaquin River Delta survival probability (third graph from top), and median daily difference in survival of each real-time scenario relative to the no diversion scenario (bottom graph), for water year 2005 .

Figure 52. Violin plots showing posterior distributions of annual survival probability for Level 1 (L1) real-time operations and revised Unlimited Pulse Protection (UPP) real-time operations (top graph), and the difference in annual survival of each real-time scenario relative to the no diversion scenario (bottom graph),

for water year 2005.

Figure 53. Graphs showing Level 1 (L1) real-time operations (top graph), revised Unlimited Pulse Protection (UPP) real-time operations (second graph from top), median daily through-Sacramento-San Joaquin River Delta survival probability (third graph from top), and median daily difference in survival of each real- time scenario relative to the no diversion scenario (bottom graph), for water year 2006

Figure 54. Violin plots showing posterior distributions of annual survival probability for Level 1 (L1) real-time operations and revised Unlimited Pulse Protection (UPP) real-time operations (top graph), and the difference in annual survival of each real-time scenario relative to the no diversion scenario (bottom graph), for water year 2006.

Figure 55. Graphs showing Level 1 (L1) real-time operations (top graph), revised Unlimited Pulse Protection (UPP) real-time operations (second graph from top), median daily through-Sacramento-San Joaquin River Delta survival 
probability (third graph from top), and median daily difference in survival of each real-time scenario relative to the no diversion scenario (bottom graph), for water year 2007.

Figure 56. Violin plots showing posterior distributions of annual survival probability for Level 1 (L1) real-time operations and revised Unlimited Pulse Protection (UPP) real-time operations (top graph), and the difference in annual survival of each real-time scenario relative to the no diversion scenario (bottom graph), for water year 2007

Figure 57. Graphs showing Level 1 (L1) real-time operations (top graph), revised Unlimited Pulse Protection (UPP) real-time operations (second graph from top), median daily through-Sacramento-San Joaquin River Delta survival probability (third graph from top), and median daily difference in survival of each real-time scenario relative to the no diversion scenario (bottom graph) for water year 2008.

Figure 58. Violin plots showing posterior distributions of annual survival probability for Level 1 (L1) real-time operations and revised Unlimited Pulse Protection (UPP) real-time operations (top graph), and the difference in annual survival of each real-time scenario relative to the no diversion scenario (bottom graph),

for water year 2008.

Figure 59. Graphs showing Level 1 (L1) real-time operations (top graph), revised Unlimited Pulse Protection (UPP) real-time operations (second graph from top;), median daily through-Sacramento-San Joaquin River Delta survival probability (third graph from top), and median daily difference in survival of each real-time scenario relative to the no diversion scenario (bottom graph), for water year 2009.

Figure 60. Violin plots showing posterior distributions of annual survival probability for Level 1 (L1) real-time operations and revised Unlimited Pulse Protection (UPP) real-time operations (top graph), and the difference in annual survival of each real-time scenario relative to the no diversion scenario (bottom graph),

for water year 2009

Figure 61. Graphs showing Level 1 (L1) real-time operations (top graph), revised Unlimited Pulse Protection (UPP) real-time operations (second graph from top), median daily through-Sacramento-San Joaquin River Delta survival probability (third graph from top), and median daily difference in survival of each real-time scenario relative to the no diversion scenario (bottom graph), for water year 2010.

Figure 62. Violin plots showing posterior distributions of annual survival probability for Level 1 (L1) real-time operations and revised Unlimited Pulse Protection (UPP) real-time operations (top graph), and the difference in annual survival of each real-time scenario relative to the no diversion scenario (bottom graph), for water year 2010

Figure 63. Graphs showing Level 1 (L1) real-time operations (top graph), revised Unlimited Pulse Protection (UPP) real-time operations (second graph from top), median daily through-Sacramento-San Joaquin River Delta survival probability (third graph from top), and median daily difference in survival of each real-time scenario relative to the no diversion scenario (bottom graph), for water year 2011.

Figure 64. Violin plots showing posterior distributions of annual survival probability for Level 1 (L1) real-time operations and revised Unlimited Pulse Protection (UPP) real-time operations (top graph,) and the difference in annual survival of each real-time scenario relative to the no diversion scenario (bottom graph),

for water year 2011.

Figure 65. Graphs showing Level 1 (L1) real-time operations (top graph), revised Unlimited Pulse Protection (UPP) real-time operations (second graph from top), median daily through-Sacramento-San Joaquin River Delta survival probability (third graph from top), and median daily difference in survival of each real-time scenario relative to the no diversion scenario (bottom graph), for water year 2012.

Figure 66. Violin plots showing posterior distributions of annual survival probability for Level 1 (L1) real-time operations and revised Unlimited Pulse Protection (UPP) real-time operations (top graph), and the difference in annual survival of each real-time scenario relative to the no diversion scenario (bottom graph), 
Figure 67. Graphs showing Level 1 (L1) real-time operations (top graph), revised Unlimited Pulse Protection (UPP) real-time operations (second graph from top), median daily through-Sacramento-San Joaquin River Delta survival probability (third graph from top), and median daily difference in survival of each real-time scenario relative to the no diversion scenario (bottom graph), for water year 2014.

Figure 68. Violin plots showing posterior distributions of annual survival probability for Level 1 (L1) real-time operations and revised Unlimited Pulse Protection (UPP) real-time operations (top graph), and the difference in annual survival of each real-time scenario relative to the no diversion scenario (bottom graph),

for water year 2014

\section{Tables}

Table 1. Parameter estimates for the logistic regression model describing the relation between the proportion of juvenile Chinook salmon entering Sutter and Steamboat Sloughs and the ratio of discharge entering Sutter and Steamboat Sloughs relative to discharge of the Sacramento River at Freeport, Sacramento-San Joaquin River

Delta, northern California.

Table 2. Parameter estimates for linear regressions relating mean daily entrainment probabilities to Sacramento River discharge at Freeport (U.S. Geological Survey streamgage 11447650), Sacramento-San Joaquin River Delta, northern California.

\section{Conversion Factors}

Inch/Pound to International System of Units

\begin{tabular}{ccc}
\hline Multiply & By & To obtain \\
\hline & Volume & \\
\hline acre-foot $($ acre- $\mathrm{ft})$ & 1,233 & cubic meter $\left(\mathrm{m}^{3}\right)$ \\
\hline & Flow rate & \\
\hline cubic foot per second $\left(\mathrm{ft}^{3} / \mathrm{s}\right)$ & 0.02832 & cubic meter per second $\left(\mathrm{m}^{3} / \mathrm{s}\right)$ \\
\hline
\end{tabular}

International System of Units to Inch/Pound

\begin{tabular}{lcc}
\hline Multiply & By & To obtain \\
\hline & Length & \\
\hline kilometer $(\mathrm{km})$ & 0.6214 & mile (mi) \\
\hline
\end{tabular}

\section{Abbreviations}

$\begin{array}{ll}\text { DCC } & \text { Delta Cross Channel } \\ \text { DSM-2 } & \text { Delta Simulation Model 2 } \\ \text { MCMC } & \text { Markov Chain Monte Carlo } \\ \text { NAA } & \text { No Action Alternative } \\ \text { NDD } & \text { North Delta Diversion } \\ \text { L1 } & \text { Level 1 } \\ \text { PA } & \text { Proposed Action } \\ \text { UPP } & \text { Unlimited Pulse Protection } \\ \text { USGS } & \text { U.S. Geological Survey } \\ \text { WY } & \text { water year } \\ \text { WYI } & \text { water year index }\end{array}$


This page left intentionally blank 


\title{
Effects of the Proposed California WaterFix North Delta Diversion on Survival of Juvenile Chinook Salmon (Oncorhynchus tshawytscha) in the Sacramento-San Joaquin River Delta, Northern California
}

\author{
By Russell W. Perry and Adam C. Pope
}

\begin{abstract}
The California Department of Water Resources and Bureau of Reclamation propose new water intake facilities on the Sacramento River in northern California that would convey some of the water for export to areas south of the Sacramento-San Joaquin River Delta (hereinafter referred to as the Delta) through tunnels rather than through the Delta. The collection of water intakes, tunnels, pumping facilities, associated structures, and proposed operations are collectively referred to as California WaterFix. The water intake facilities, hereinafter referred to as the North Delta Diversion (NDD), are proposed to be located on the Sacramento River downstream of the city of Sacramento and upstream of the first major river junction where Sutter Slough branches from the Sacramento River. The NDD can divert a maximum discharge of 9,000 cubic feet per second $\left(\mathrm{ft}^{3} / \mathrm{s}\right)$ from the Sacramento River, which reduces the amount of Sacramento River inflow into the Delta.

In this report, we conduct four analyses to investigate the effect of the NDD and its proposed operation on survival of juvenile Chinook salmon (Oncorhynchus tshawytscha). All analyses used the results of a Bayesian survival model that allowed us to simulate travel time, migration routing, and survival of juvenile Chinook salmon migrating through the Delta in response to NDD operations, which affected both inflows to the Delta and operation of the Delta Cross Channel (DCC).

For the first analysis, we evaluated the effect of the NDD bypass rules on salmon survival. The NDD bypass rules are a set of operational rule curves designed to provide adaptive levels of fish protection by defining allowable diversion rates as a function of (1) Sacramento River discharge as measured at Freeport, and (2) time of year when endangered runs requiring the most protection are present. We determined that all bypass rule curves except constant low-level pumping (maximum diversion of $900 \mathrm{ft}^{3} / \mathrm{s}$ ) could cause a sizeable decrease in survival by as much as $6-10$ percentage points. The maximum decrease in survival occurred at an intermediate Sacramento River flow of about $20,000-30,000 \mathrm{ft}^{3} / \mathrm{s}$. Diversion rates increased rapidly as Sacramento River flows increased from $20,000 \mathrm{ft}^{3} / \mathrm{s}$ to $30,000 \mathrm{ft}^{3} / \mathrm{s}$, until a maximum diversion rate was reached at $9,000 \mathrm{ft}^{3} / \mathrm{s}$. Because through-Delta survival increases sharply over this range of Sacramento River flow before beginning to level off with further flow increases, increasing diversion rates over this flow range causes a large decrease in survival relative to no diversion.
\end{abstract}


For the second analysis, we applied the survival model to 82 years of daily simulated flows under the Proposed Action (PA) and No Action Alternative (NAA). The PA includes operation of the Central Valley Project/State Water Project with implementation of the NDD and its operations prescribed by the NDD bypass rules, whereas the NAA assumes system operations without implementation of the NDD. We also evaluated a "Level 1" (L1) scenario, which was similar to the PA scenario but applied the most protective bypass rule known as Level 1 post-pulse operations. We noted a high probability that survival under the PA scenario was lower than under the NAA scenario, and that travel time was longer under PA relative to NAA in most simulation years. However, the largest survival differences between the PA and NAA scenarios occurred during October-November and May-June. Although bypass rules are less restrictive during these periods, we determined that more frequent use of the DCC under PA led to the largest differences in survival between the two scenarios. Additionally, we noted no difference in median survival decreases between the PA and L1 scenarios, although in some years the L1 scenario had a lower survival decrease than the PA scenario.

For the third analysis, we proposed a quantitative approach for developing NDD rule curves (that is, prescribed diversion flows for given inflows) by using the survival model to identify diversion rates that meet a criterion of a having a small probability of exceeding a given decrease in survival. We examined diversion rates that led to a $10 \%$ chance of exceeding a given decrease in survival for a range of absolute and relative decreases in survival. To maintain a given constant level of protection across the range of river flows, our analysis indicated that diversions had to increase at a much slower rate with respect to Sacramento River flow relative to the rule curves defined in the NDD bypass table. Additionally, we determined that diversion rates could be higher than under the bypass table rule curves at river flows less than $20,000 \mathrm{ft}^{3} / \mathrm{s}$, but diversions had to be less than defined by NDD bypass rules at higher flows.

For the fourth analysis, we simulated the effect of "real-time operations" on salmon survival, where bypass flow rates were determined by the presence of juvenile salmon entering the Delta, as indicated by juvenile salmon catch in a rotary screw trap upstream of the Delta. For this analysis, we evaluated NDD operations as defined by the L1 scenario and an additional scenario (Unlimited Pulse Protection [UPP]) that provided protection to an unlimited number of fish pulses. This analysis indicated that the highest catches occurred during flow pulses when daily survival was high, which caused annual survival to be weighted towards periods of high daily survival, resulting in a high annual survival. We determined that the mean annual survival decreased by $1-4$ percentage points, and annual survival decreases were more frequently smaller for the UPP scenario. Additionally, because the UPP scenario protected an unlimited number of fish pulses, decreases in daily survival under the UPP scenario were less than under the L1 scenario. 


\section{Introduction}

The California Department of Water Resources and Bureau of Reclamation propose new water intake facilities on the Sacramento River in northern California that would convey some of the water for export to areas south of the Sacramento-San Joaquin River Delta (hereinafter referred to as the Delta) through tunnels rather than through the Delta. The collection of water intakes, tunnels, pumping facilities, associated structures, and proposed operations are collectively referred to as California WaterFix (ICF International, 2016). The water intake facilities, hereinafter referred to as the North Delta Diversion (NDD), are proposed to be located on the Sacramento River downstream of the city of Sacramento and upstream of the first major river junction where Sutter Slough branches from the Sacramento River (near $A_{2}$ in fig. 1). The NDD can divert a maximum discharge of $9,000 \mathrm{ft}^{3} / \mathrm{s}$ from the Sacramento River, which reduces the amount of Sacramento River inflow into the Delta.

In this report, we conduct four analyses to evaluate the potential effect of the NDD on survival of juvenile Chinook salmon (Oncorhynchus tshawytscha) emigrating from the Sacramento River through the Delta. All analyses used the results of a Bayesian mark-recapture model that jointly estimated reach-specific travel time and survival of juvenile Chinook salmon. Statistical methods for this analysis are described in detail in Perry and others (in press). This model extended the work of Perry and others (2010) to estimate the effect of the Delta Cross Channel (DCC; see $\mathrm{C}_{4}$ in fig. 1) and Delta inflows as measured in the Sacramento River at Freeport (U.S. Geological Survey [USGS] streamgage 11447650; see $\mathrm{A}_{2}$ in fig. 1) on survival and travel time of juvenile Chinook salmon in eight reaches of the Delta (fig. 1). Perry and others (in press) determined that median travel time was related to inflow in all reaches of the Delta, but that survival was strongly related to inflow in only three reaches that transitioned from tidally influenced, bidirectional flow at low inflows to unidirectional downstream flow as inflows increased. These three reaches caused overall route-specific survival through the Delta to increase with flow, yet fish that entered the interior Delta (reach 8 in fig. 1) through Georgiana Slough or the DCC had lower survival than through other migration routes. Overall survival decreased further through lower survival of fish entering the interior Delta through Georgiana Slough or the DCC, combined with a higher proportion of fish entering the interior Delta as inflows decreased to less than about 25,000 $\mathrm{ft}^{3} / \mathrm{s}$ and when the Delta Cross Channel gate was opened (Perry and others, in press).

Because decreasing survival is associated with decreasing river flow, the NDD will reduce survival to some extent. However, the NDD bypass rules (table 3.4.1-2 in California Department of Water Resources, 2013) are a set of operational rule curves designed to provide adaptive levels of fish protection. One goal of the NDD bypass rules is to provide bypass flows that prevent an increase in upstream transport of fish into Georgiana Slough and the DCC. Bypass flows are defined as flow remaining in the Sacramento River downstream of the NDD. These rules were developed based on previous research and understanding of reverse-flow hydrodynamics at this river junction. Research has shown that the entrainment probability of juvenile Chinook salmon into Georgiana Slough and the DCC is highest during reverse-flow flood tides (Perry and others, 2015). Furthermore, the daily proportion of fish entrained into Georgiana Slough increases with the fraction of the day in a reverse flow condition at the Sacramento River downstream of Georgiana Slough (Perry, 2010). Therefore, diverting water from the Sacramento River could increase the frequency and duration of reverse-flow conditions, thereby reducing survival by increasing the proportion of fish entrained into the interior Delta where survival probabilities are lower than in the Sacramento River (Perry and others, 2010, 2013). 
The NDD bypass rules also are designed to provide more protection during times of the year when juvenile salmon populations are actively migrating through the Delta (primarily October-June) and during pulse flow events when endangered winter-run Chinook salmon are likely to initiate downstream migration into the Delta (del Rosario and others, 2013). To accommodate adaptive levels of protection, the NDD bypass rules prescribe a series of minimum allowable bypass flows that vary depending on (1) month of the year, and (2) progressively decreasing levels of protection following a pulse flow event. For flow modeling purposes, pulse events are defined based on discharge of the Sacramento River at Wilkins Slough, and minimum bypass levels are based on varying fractions of discharge of the Sacramento River arriving at the NDD (see table 3.4.1-2 in California Department of Water Resources, 2013, for details). For operational purposes, pulse events will be based on monitoring for the presence of winter-run-sized fish entering the reach.

Although the effect of river flow on migration routing and overall survival through the Delta has been established for some time (Newman and Rice, 2002; Newman, 2003; Perry, 2010), our goal was to use the recently developed survival and travel time relationships (Perry and others, in press) to better understand the potential magnitude of the effect of the NDD on juvenile salmon survival and travel time. For our first analysis, we evaluated the NDD bypass rules directly by evaluating the effect of each rule curve on salmon survival relative to no diversion at a given Delta inflow. For the second analysis, we applied the survival model to 82 years of daily simulated flows under the Proposed Action (PA) and No Action Alternative (NAA). The proposed action included operation of the Central Valley Project/State Water Project with implementation of the NDD and its operations prescribed by the NDD bypass rules, whereas the No Action Alternative assumed system operations without implementation of the NDD (ICF International, 2016). The third analysis proposed a method for quantifying rule curves (that is, prescribed diversion flows for given inflows) based on satisfying the criterion of meeting a maximum allowable decrease in survival with a given level of confidence. The fourth analysis simulated the effect of "real-time operations" on survival, where bypass flow rates were determined by the presence of juvenile salmon entering the Delta, as indicated by juvenile salmon catch in a rotary screw trap upstream of the Delta. 


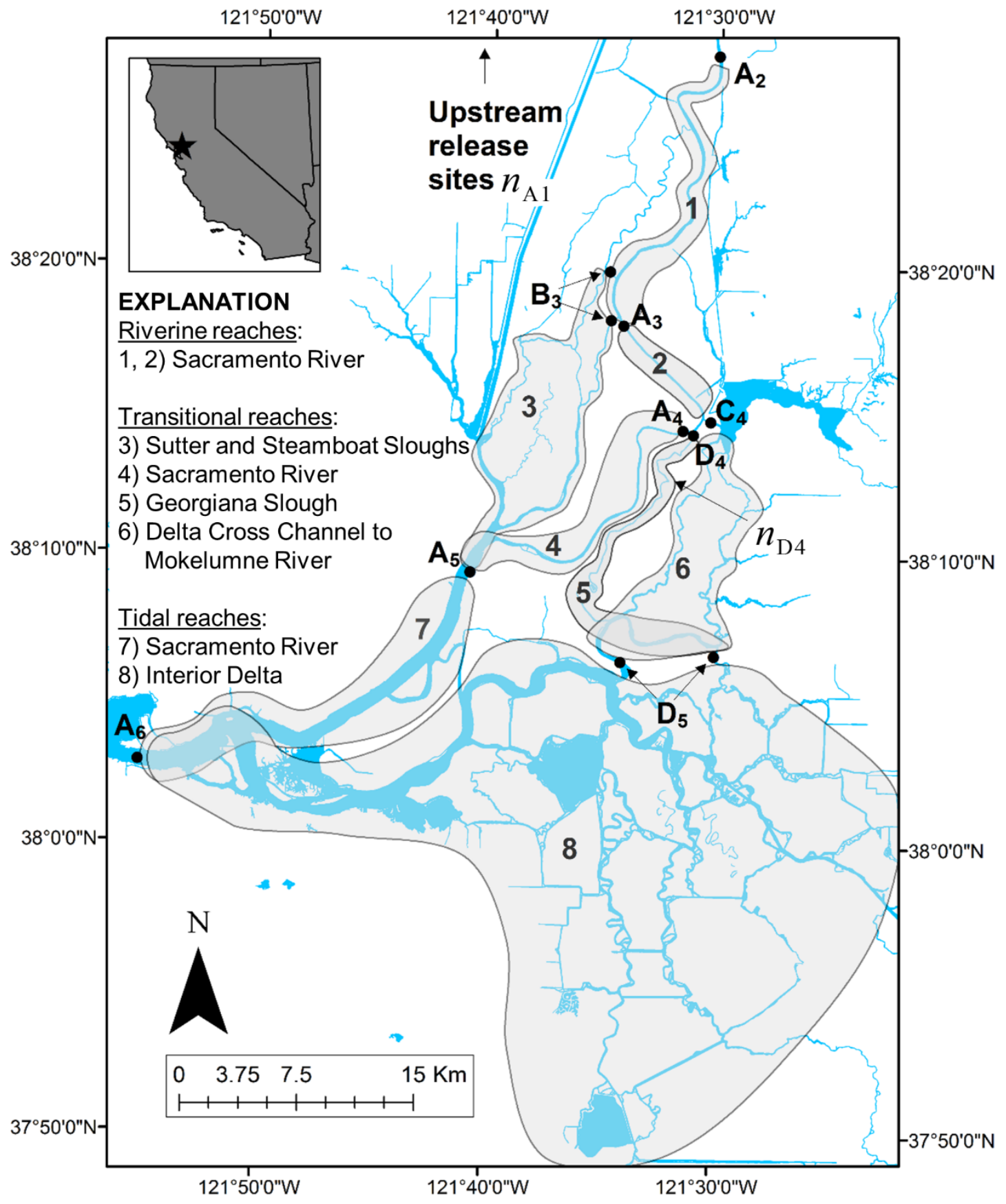

Figure 1. Map showing location of acoustic telemetry receiving stations (filled black circles) used to detect acoustic-tagged juvenile Chinook salmon as they migrated through the Sacramento-San Joaquin River Delta, northern California. Telemetry stations are labeled by migration route (A, Sacramento River; B, Sutter and Steamboat Sloughs; C, Delta Cross Channel; D, Georgiana Slough) and sampling occasion (1-7). These telemetry stations divide the Delta into eight discrete reaches (shown by numbered shaded regions), with an additional reach upstream of telemetry station $\mathrm{A}_{2}$ (Reach 0 ) used as an acclimation reach to allow fish to recover from post-release handling. Route-specific survival begins at $A_{2}$ (Freeport) and ends at $A_{6}$ (Chipps Island). Release sites are labeled as $n_{\mathrm{A} 1}$ and $n_{\mathrm{D} 4}$. 


\section{Methods}

\section{Survival Model Description}

Here we provide a summary of the statistical model we used to simulate survival, travel time, and migration routing. Although our analysis in this report used a slightly different version of the model presented in Perry and others (in press), the telemetry dataset and statistical methods were identical. The primary difference is that Perry and others (in press) estimated flow-routing relations simultaneously with survival and travel time, whereas, in this report, we combined two separate models - (1) a Bayesian statistical model that estimated survival and travel time relations, and (2) regression models that estimated flow-routing relations. Routing relations were then combined with the survival and travel time model from Perry and others (in press) to simulate travel time, routing, and survival through the Delta.

\section{Survival and Travel Time Model}

Fitted models from a joint statistical analysis of travel time and survival in eight discrete reaches of the Delta (fig. 1) was used for simulating travel time and survival. The data for the analysis consisted of 2,170 acoustic-tagged late-fall Chinook salmon released during a 5-year period (2007-11) over a wide range of Sacramento River inflows $\left(6,800-77,000 \mathrm{ft}^{3} / \mathrm{s}\right.$ at Freeport). This analysis was based on acoustic telemetry data from several published studies where details of each study are available (Perry and others, 2010, 2013; Michel and others, 2015).

Although numerous studies have identified a relation between Delta inflows and survival at the Delta-wide scale, the goal of the Perry and others (in press) analysis was to quantify how the flowsurvival relation varied spatially among different regions of the Delta. To quantify the reach-specific relation between river inflows and survival, the analysis used time-varying individual covariates where an individual's covariate value was defined as the flow of the Sacramento River at Freeport on the day that $i$ th fish entered the $m$ th reach. Owing to missing covariate values for undetected fish, the analysis implemented the multistate mark-recapture model of Perry and others (2010) using a complete data likelihood approach in a Bayesian framework (King and others, 2010). To account for missing covariate values, the analysis jointly modeled reach-specific travel times and survival. Estimated parameters of a log-normal travel time distribution for each reach were used to impute travel times of undetected fish, which in turn allowed missing covariate values to be defined based on the imputed arrival time in a given reach. Markov Chain Monte Carlo (MCMC) techniques were used to integrate over the missing covariate values by drawing missing travel times on each iteration of the Markov chain. 
Reach-specific survival was modeled as functions of river inflow and DCC gate position using the following logistic model:

$$
\operatorname{logit}\left(S_{i, m}\right)=\beta_{0, m}+\beta_{1, m} Q_{i, m, d}+\beta_{2, m} I\left(\mathrm{DCC}_{i, m, d}=\text { open }\right)+\varepsilon_{S, g, m} \text {, }
$$

where $m$ indexes reach $0, \ldots, 8$ (fig. 1),

$\operatorname{logit}(\cdot) \quad$ is the logit link function,

$\beta_{0, m} \quad$ is the intercept,

$\beta_{1, m} \quad$ is the slope for the effect of discharge on survival,

$\beta_{2, m} \quad$ is the effect of Delta Cross Channel position on survival,

$Q_{i, m, d} \quad$ is the discharge of the Sacramento River at Freeport on day $d$ that individual $i$ entered reach $m$,

$I\left(\mathrm{DCC}_{i, m, d}=\right.$ open $)$ is an indicator function resolving to 1 if the DCC is open on day $d$ that individual $i$ entered reach $m$, and

$\varepsilon_{S, g, m} \quad$ is a normally distributed deviation for the $g$ th release group in reach $m$ with mean 0 and standard deviation $\xi_{S, m}$.

Median travel time was expressed as a function of covariates in a manner similar to survival:

$$
\mu_{i, m}=\alpha_{0, m}+\alpha_{1, m} Q_{i, m, d}+\alpha_{2, m} I\left(\mathrm{DCC}_{i, m, d}=\text { open }\right)+\varepsilon_{\mu, g, m}
$$

where $\mu_{i, m} \quad$ is the mean of log-normal travel time distribution for the $i$ th individual in the $m$ th

$$
\begin{aligned}
\exp \left(\mu_{i, m}\right) & \text { is the median travel time, and } \\
\alpha_{i, m} & \text { are slope and intercept coefficients. }
\end{aligned}
$$

In this model, survival is constant among individuals that enter a given reach on a particular day but varies among release groups according to the random effect term $\varepsilon_{S, g, m}$. Travel time influences survival only through its effect on arrival times to a given telemetry station, which determines the discharge that individuals experienced when they entered a given reach. The standard deviations of the random effects, $\xi_{S, m}$ and $\xi_{\mu, m}$, estimates variation in mean travel time and survival among release groups over that explained by covariates. This term can be thought of as a measure of process error for unmeasured factors that vary among release groups migrating through a given reach (for example, predator density). The DCC gate position is included as a covariate because the effect of opening the DCC gate is to reduce discharge in downstream reaches. Therefore, $\alpha_{2, m}$ and $\beta_{2, m}$ were set to 0 for reaches located upstream of the Delta Cross Channel (that is, for $m=0, \ldots, 3$ ). Parameter estimates used for all analyses are shown in figure 2. 

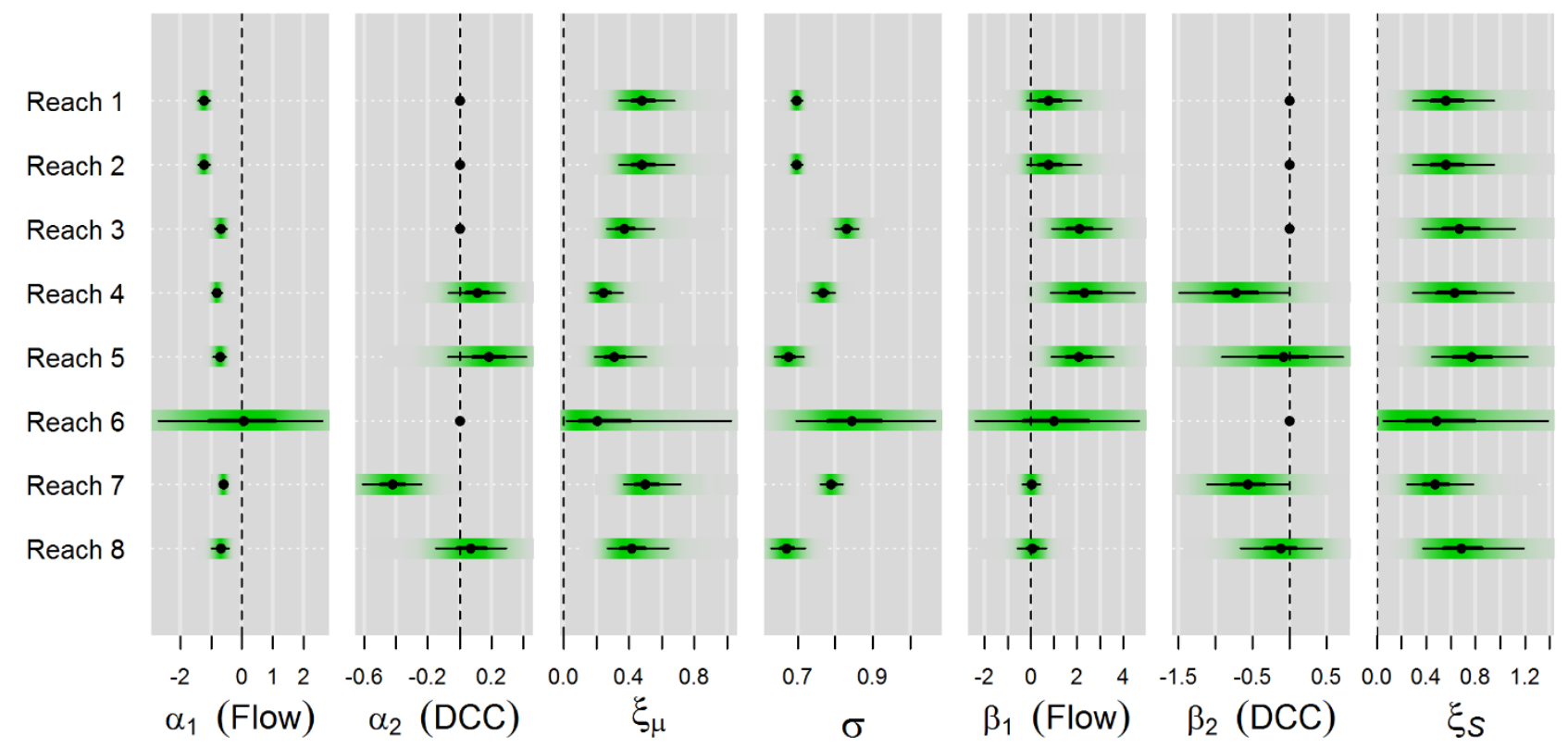

Figure 2. Summary of posterior distributions of parameters estimating the effects of river flow and Delta Cross Channel (DCC) gate position on travel time and survival of juvenile Chinook salmon, Sacramento-San Joaquin River Delta, northern California. Points show the median of the posterior distribution, heavy lines show 25th-75th percentile, and thin lines show 5th-95th percentile. Shaded horizontal bars are density strips with darker segments indicating higher posterior density than lighter segments. Parameters are defined as follows: $\alpha_{1}$, slope for effect of discharge on mean of log-travel time; $\alpha_{2}$, slope for effect of an open DCC gate on mean of log-travel time; $\xi_{\mu}$, standard deviation of release group random effect on $\mu ; \sigma$, variance parameter of the lognormal travel time distribution; $\beta_{1}$, slope for effect of discharge on survival; $\beta_{2}$, slope for effect of an open DCC gate on survival; $\xi_{S}$, standard deviation of release group random effect on survival. 
Our analysis identified a relation between river inflows and median travel times in all reaches of the Delta (fig. 3). In contrast, the flow-survival relation among reaches varied considerably (fig. 4). In the upper reaches of the Delta (reaches 1 and 2 in fig. 4), survival was consistently high regardless of inflows, whereas in the strongly tidal reaches (reaches 7 and 8 in fig. 4), there was no significant relation between river inflows and reach-specific survival despite a relation between inflow and travel time (fig. 3). The strongest flow-survival relations were identified in the three reaches that transition from river-dominated to tidally dominated flows (reaches 3, 4, and 5 in fig. 4).

The product of reach-specific survival for a given migration pathway between Freeport $\left(\mathrm{A}_{2}\right.$ in fig. 1) and Chipps Island ( $\mathrm{A}_{6}$ in fig. 1) yields the probability of surviving through each migration route at a given river discharge. Route-specific survival for all routes increased with river discharge but approached an asymptote, leveling off at about 0.75 for the Sacramento River and Sutter and Steamboat Sloughs, and at about 0.35 for fish entering Georgiana Slough when river discharges increase to more than $30,000-40,000 \mathrm{ft}^{3} / \mathrm{s}$ (fig. 5). The reach-specific survival relations indicate that the asymptote in route-specific survival was driven by the survival in the strongly tidal reaches (reaches 7 and 8) since survival for all other reaches approached 1 as flow increased, but remained constant with flow for the strongly tidal reaches (fig. 4). Expected travel time distributions through each migration route decreased as river flow increased, with migration routes leading to the interior Delta (Georgiana Slough and the Delta Cross Channel) having longer travel times than other routes (fig. 6). 


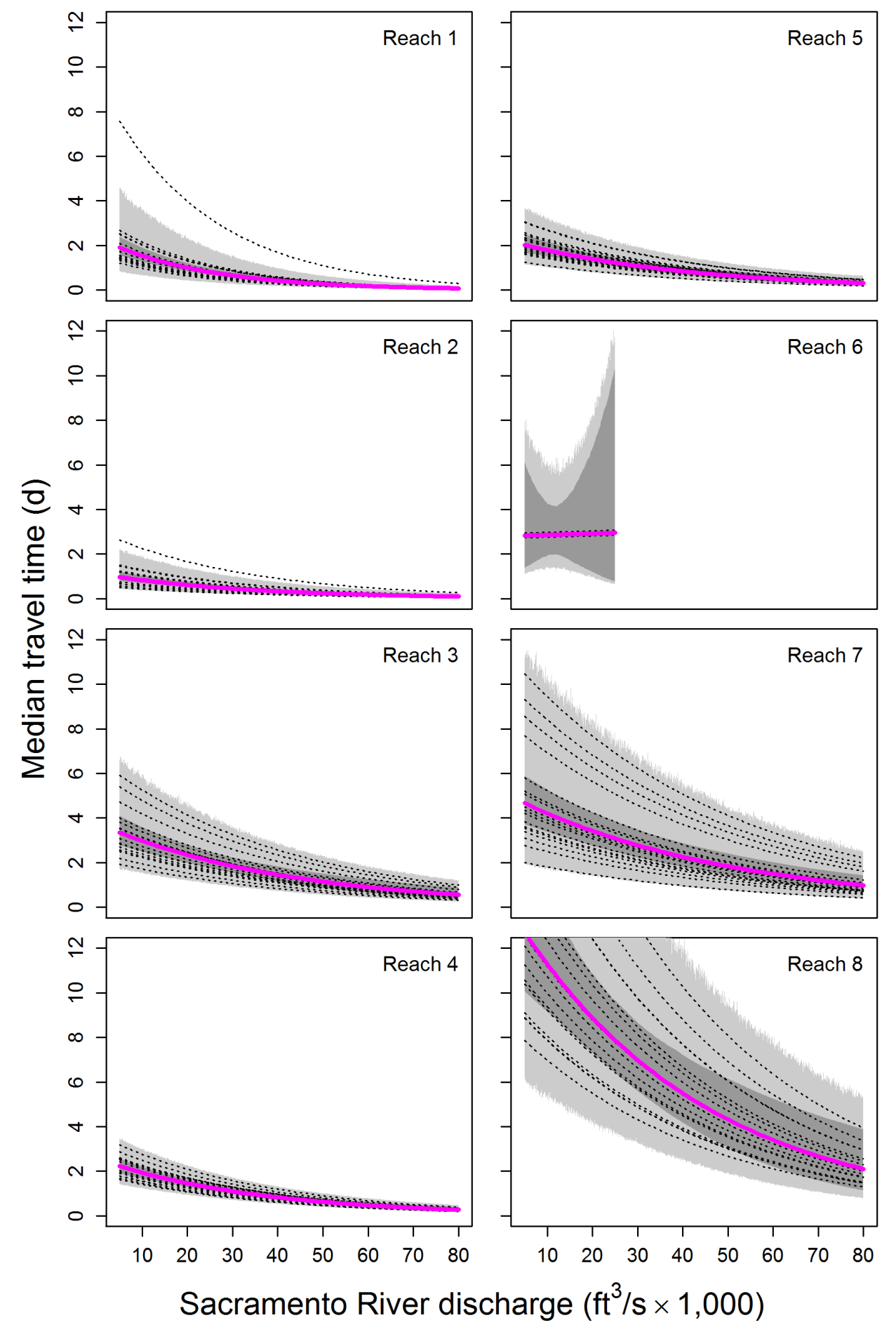

Figure 3. Graphs showing reach-specific relations between median travel time of juvenile Chinook salmon and inflow to the Sacramento-San Joaquin River Delta as measured at the Sacramento River at Freeport (U.S. Geological Survey streamgage 11447650; shown for closed Delta Cross Channel gates and plotted at the mean fork length), northern California. The heavy solid lines show the mean relations and the dotted lines show the random effect estimates for each release group based on medians of the joint posterior distribution. The dark gray regions show $95 \%$ credible intervals about the mean relations. The light gray regions show the 95 confidence interval among release groups. $d$, days; $\mathrm{ft}^{3} / \mathrm{s} \times 1,000$, thousands of cubic feet per second. 

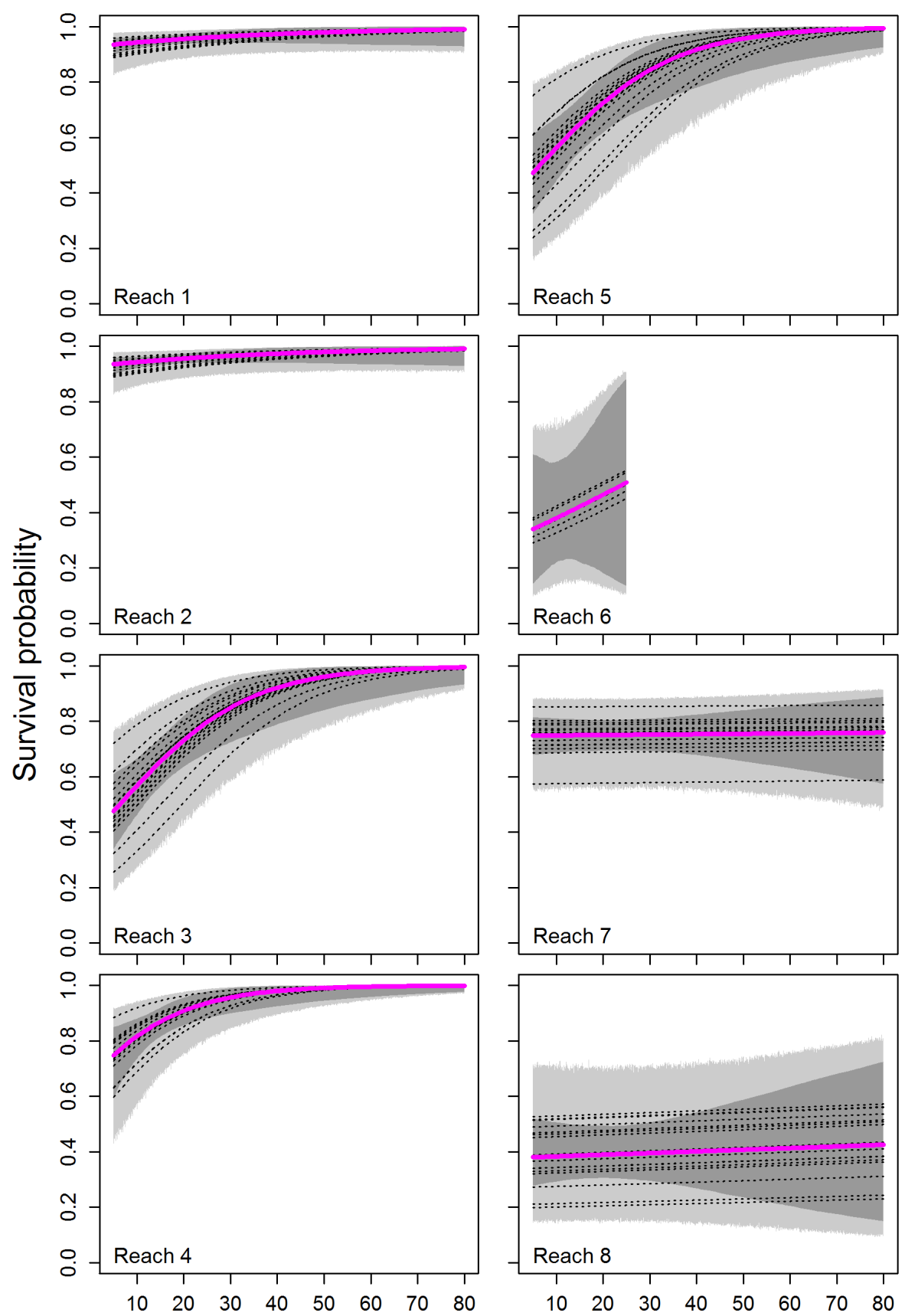

Sacramento River discharge $\left(\mathrm{ft}^{3} / \mathrm{s} \times 1,000\right)$

Figure 4. Graphs showing reach-specific relations between survival of juvenile Chinook salmon and inflow to the Sacramento-San Joaquin River Delta as measured at the Sacramento River at Freeport (U.S. Geological Survey streamgage 11447650; shown for closed Delta Cross Channel gates and plotted at the mean fork length), northern California. The heavy solid lines show the mean relations and dotted lines show the random effect estimates for each release group based on medians of the joint posterior distribution. The dark gray regions show $95 \%$ credible intervals about the mean relations. The light gray regions show the $95 \%$ confidence interval among release groups. $d$, days; $\mathrm{ft}^{3} / \mathrm{s} \times 1,000$, thousands of cubic feet per second. 

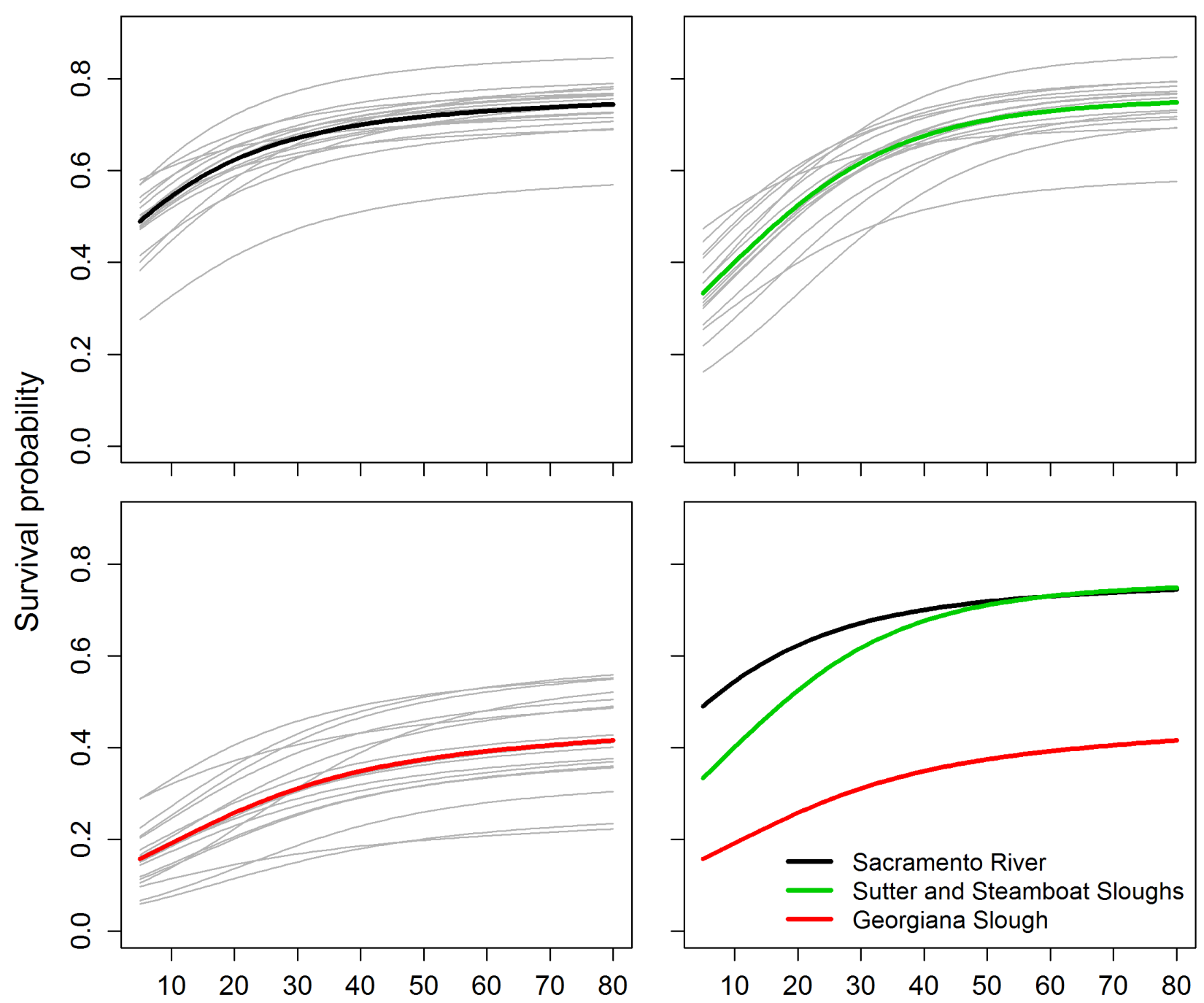

\section{Sacramento River discharge $\left(\mathrm{ft}^{3} / \mathrm{s} \times 1,000\right)$}

Figure 5. Graphs showing route-specific survival of juvenile Chinook salmon between Freeport and Chipps Island (see fig. 1), through the Sacramento-San Joaquin River Delta, northern California. Route-specific survival based on posterior median parameter values was calculated as the product of reach-specific survival for reaches that trace each unique migration route through the Delta (shown for closed Delta Cross Channel gates). Top graphs and bottom left graph show the mean relation for each route, with thin gray lines showing the random effect estimates for each release group. Bottom right graph compares the route-specific survival relations. $\mathrm{ft}^{3} / \mathrm{s} \times 1,000$, thousands of cubic feet per second. 


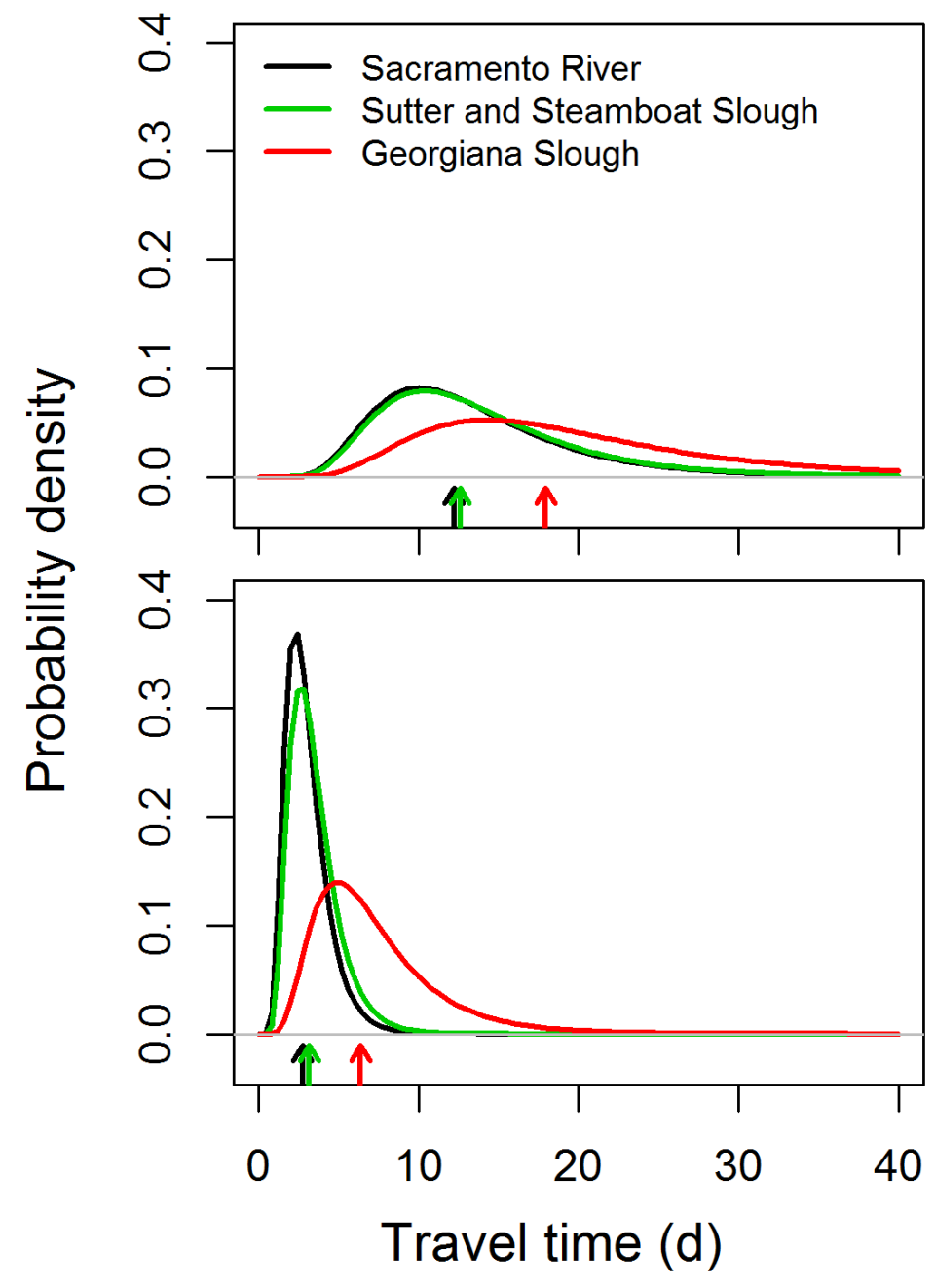

Figure 6. Graphs showing route-specific travel time distributions of juvenile Chinook salmon at the 5th (top graph) and 95th (bottom graph) percentiles of discharge based on the historical flow record $(8,290$ and $47,910 \mathrm{ft} / \mathrm{s})$, between Freeport and Chipps Island (see fig. 1), Sacramento-San Joaquin River Delta, northern California. Graphs were based on posterior medians of parameters for reach-specific travel time distributions assuming closed Delta Cross Channel gates. d, days; $\mathrm{ft}^{3} / \mathrm{s}$, cubic foot per second. 


\section{Routing Models}

To simulate overall survival through the Delta as a function of inflows, a model is required showing how river inflows affect the proportion of fish using each of the four primary migration routes through the Delta. Fish first enter Sutter and Steamboat Sloughs at their junctions with the Sacramento River (fig. 1). Fish that remain in the Sacramento River may then enter the DCC and Georgiana Slough further downstream (fig. 1). Although the Perry and others (in press) analysis included flowrouting relations, the earlier version of their Bayesian model used here did not relate routing to flow. Therefore, we conducted separate analyses to relate daily proportions of fish entering each route to daily river discharge at Freeport.

For Sutter and Steamboat Sloughs, we analyzed acoustic telemetry on late-fall Chinook salmon from a study done in 2014 (California Department of Water Resources, 2016; Romine and others, 2017). During this study, 3,418 acoustic-tagged fish were detected at this river junction over a 58-d period. We conducted a logistic regression analysis that related the daily fraction of discharge entering Sutter and Steamboat Sloughs to the daily proportion of fish entering this route. Because fish were released daily at Sacramento, daily sample sizes averaged 58 fish (interquartile range $=43-83$ fish), providing adequate sample sizes for the analysis. Tidally averaged daily river discharge of the Sacramento River at Freeport varied from 9,146 to $28,051 \mathrm{ft}^{3} / \mathrm{s}$ over the 58 -d period. Although initial analysis indicated a direct relation between discharge at Freeport and the probability of entering Sutter and Steamboat Sloughs, extending this relation beyond the range of flow measured in the study suggested that entrainment increased in a linear manner with flow. In contrast, the fraction of discharge entering Sutter and Steamboat Sloughs increases at low flows owing to tidal forcing, but then stabilizes to a constant fraction as river inflow dampens tidal forcing. Thus, by using the ratio of Sutter Slough (USGS streamgage 11447830) and Steamboat Slough (USGS streamgage 11447850) discharges relative to the Freeport discharge as a covariate, extending this relation beyond the range of measured flows leads to an asymptotic relation of entrainment with respect to discharge at Freeport (fig. 7, table 1). Although the analysis did not include high river flows, subsequent analysis by Perry and others (in press) supports this asymptotic relation.

Table 1. Parameter estimates for the logistic regression model describing the relation between the proportion of juvenile Chinook salmon entering Sutter and Steamboat Sloughs and the ratio of discharge entering Sutter and Steamboat Sloughs relative to discharge of the Sacramento River at Freeport, Sacramento-San Joaquin River Delta, northern California.

\begin{tabular}{lrll}
\hline \multicolumn{1}{c}{ Parameter } & Estimate & Standard error & 95\% confidence interval \\
\hline Intercept & -4.70 & 0.67 & -0.601 to -3.39 \\
Slope & 9.21 & 1.66 & $5.95-12.46$ \\
\hline
\end{tabular}




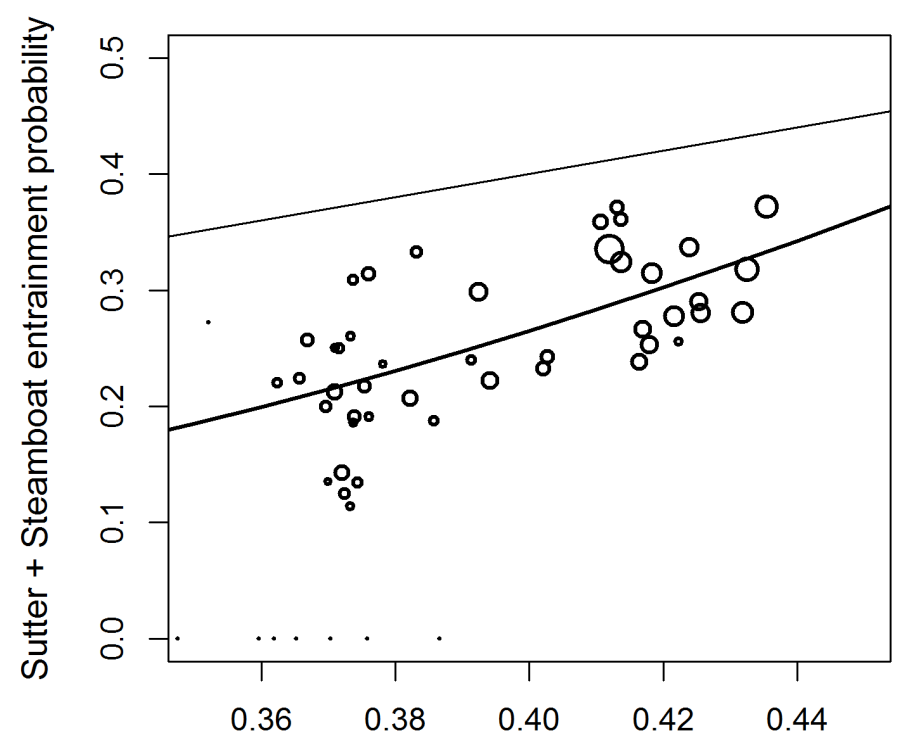

Sutter + Steamboat discharge / Freeport discharge

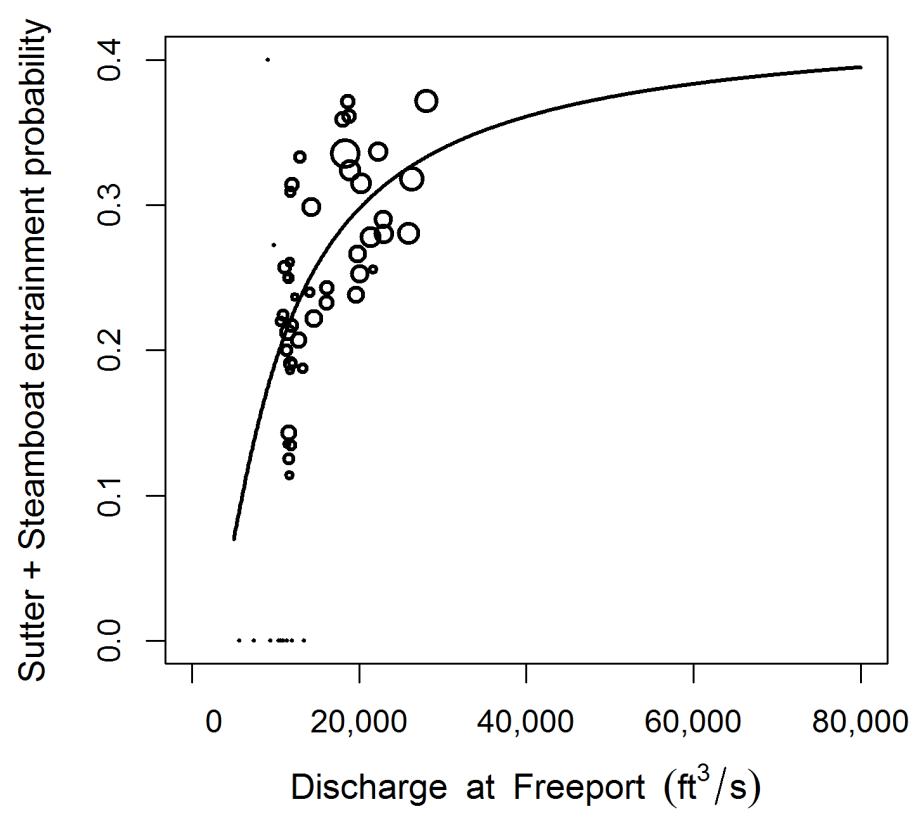

Figure 7. Graphs of fitted logistic regression model (heavy line) showing the probability of juvenile Chinook salmon entering Sutter and Steamboat Sloughs as a function of the ratio of Sutter plus (+) Steamboat discharge to Sacramento River dishcarge at Freeport (U.S. Geological Survey [USGS] streamgages 11447830, 11447850, and 11447650, respectively; top graph), and discharge of the Sacramento River at Freeport (USGS streamgage 11447650; bottom graph), Sacramento-San Joaquin River Delta, northern California. In the top graph, the thin line shows where the proportion of fish entering Sutter and Steamboat Sloughs is equal to the proportion of flow entering the sloughs. Size of the symbols is scaled proportionately to the daily sample size of fish passing the river junction. $\mathrm{ft} 3 / \mathrm{s}$, cubic foot per second; /, divided by; +, plus. 
For Georgiana Slough and the DCC, we summarize results of the multinomial regression model of Perry and others (2015) to predict daily entrainment probabilities. This river junction has tidally reversing flows when inflows at Freeport are less than about 23,000 $\mathrm{ft}^{3} / \mathrm{s}$ at Freeport (Perry and others, 2018). Perry and others (2015) showed that entrainment into these migration routes depended on the tidal conditions when fish arrived at the river junction. Because the model predicts the probability of an individual entering each route as a function of the "instantaneous" river discharge (that is, discharge measured at 15-min intervals) at the time of fish arrival, we used this model to calculate entrainment probabilities based on 15-min discharge records occurring during the time period in which the study was done (December-February 2007-09). We then averaged entrainment probabilities over each day and related the mean daily entrainment probability to daily discharge at Freeport. Specifically, we used a segmented linear regression model to relate the daily probability of entering Georgiana Slough with the DCC gate closed to Freeport discharge. For the DCC gate open, we used a linear regression to relate the daily probability of entering the DCC and Georgiana Slough to Freeport discharge. The segmented regression indicated that daily entrainment probabilities into Georgiana Slough initially decreased with increasing discharge, but then changed little as discharge increased to more than about $20,000 \mathrm{ft}^{3} / \mathrm{s}$ (fig. 8; table 2). Although the maximum discharge for this analysis was about 40,000 $\mathrm{ft}^{3} / \mathrm{s}$, the expected entrainment into Georgiana Slough at $80,000 \mathrm{ft}^{3} / \mathrm{s}$ was 0.33 , and is consistent with empirical evidence that showed entrainment into Georgiana Slough ranged from 0.244 to 0.299 at a Freeport discharge of $80,000 \mathrm{ft}^{3} / \mathrm{s}$ (Perry and others, 2014). Furthermore, this relation was consistent with subsequent analysis by Perry and others (in press).

Table 2. Parameter estimates for linear regressions relating mean daily entrainment probabilities to Sacramento River discharge at Freeport (U.S. Geological Survey streamgage 11447650), Sacramento-San Joaquin River Delta, northern California.

\begin{tabular}{|c|c|c|c|}
\hline Parameter & Estimate & Standard error & $95 \%$ confidence Interval \\
\hline \multicolumn{4}{|c|}{ Segmented linear regression-Georgiana Slough with Delta Cross Channel closed } \\
\hline Intercept & 0.505 & 0.008 & $0.488-0.521$ \\
\hline Segment 1 slope & $-7.28 \times 10^{-06}$ & $6.72 \times 10^{-07}$ & $-8.601 \times 10^{-06}--5.967 \times 10^{-06}$ \\
\hline Segment 2 slope difference from segment 1 & $6.832 \times 10^{-06}$ & $8.354 \times 10^{-07}$ & $5.195 \times 10^{-06}-8.469 \times 10^{-06}$ \\
\hline Break point & 19,530 & 1,137 & $17,302-21,758$ \\
\hline \multicolumn{4}{|c|}{ Linear regression-Georgiana Slough with Delta Cross Channel open } \\
\hline Intercept & 0.083 & 0.007 & $0.074-0.103$ \\
\hline Slope & $1.248 \times 10^{-05}$ & $6.338 \times 10^{-07}$ & $1.124 \times 10^{-05}-1.372 \times 10^{-05}$ \\
\hline \multicolumn{4}{|c|}{ Linear regression-Delta Cross Channel } \\
\hline Intercept & 0.550 & 0.013 & $0.527-0.576$ \\
\hline Slope & $-2.178 \times 10^{-05}$ & $1.168 \times 10^{-06}$ & $-2.407 \times 10^{-05}--1.949 \times 10^{-05}$ \\
\hline
\end{tabular}




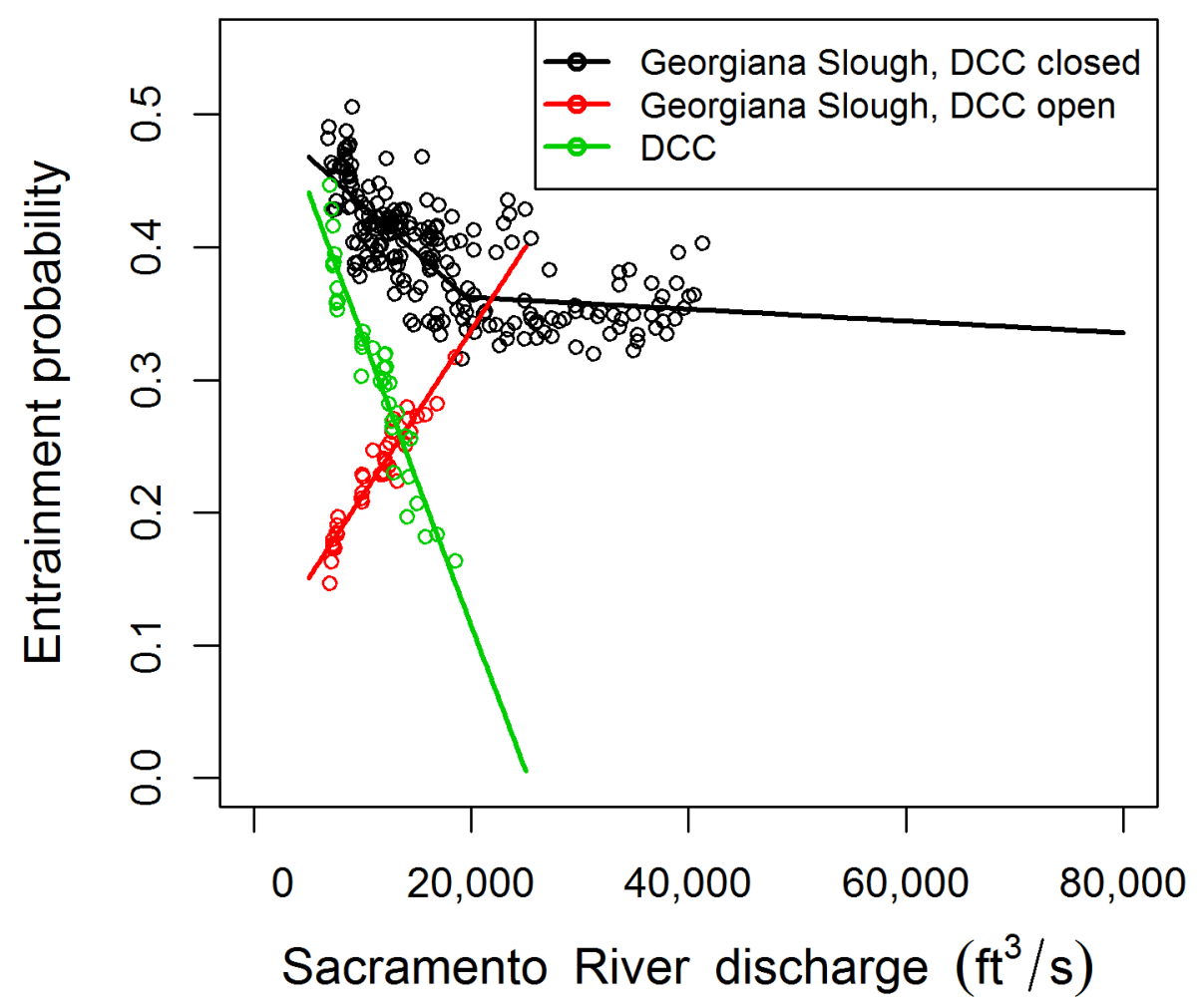

Figure 8. Daily entrainment probability into Georgiana Slough and the Delta Cross Channel (DCC) as a function of discharge of the Sacramento River at Freeport (U.S. Geological Survey streamgage 11447650), SacramentoSan Joaquin River Delta, northern California. Daily routing probabilities were estimated by fitting linear models to daily entrainment probabilities that were calculated using the entrainment model of Perry and others (2015). $\mathrm{ft}^{3} / \mathrm{s}$, cubic foot per second. 


\section{Simulating Survival, Travel Time, and Routing}

To simulate survival, travel time, and routing, we combined results from the Bayesian markrecapture model with the routing regression models. To incorporate measures of uncertainty in our simulations, we used the joint posterior distribution of the survival and travel time parameters from the Bayesian analysis. However, we used the point estimates of the parameters from the routing regression models. Therefore, all simulation results show statistical and process uncertainty associated with survival and travel time, but not routing.

We used the combined model in either a "time-varying" mode or "steady-state" mode. Survival of a cohort of fish that enters the Delta on a given day depends on the subsequent time series of daily inflows because daily inflows affect reach-specific travel times, and travel times affect the flow conditions when fish arrive in each reach. To simulate survival under time-varying flow conditions, we developed an individual-based simulation model that emulated the migration, routing, and survival process. We then used this model to simulate daily survival, travel time, and routing for the 82-year time series of simulated river flows under the PA and NAA scenarios (See details in section, "Comparing the Proposed Action and No Action Alternative").

All other analyses in this report used the model in steady-state mode. This approach assumes that daily flows entering the Delta remain constant over the migration of a cohort through the Delta. As such, simulation of individual travel times can be excluded from the simulation of routing and survival because the flows that fish experience in each reach do not depend on arrival times in each reach. Using this simplified model allows for a better understanding of the underlying interrelationships between river inflows, NDD operations, and juvenile salmon survival under steady-state conditions.

For steady-state and time-varying models, uncertainty was propagated by doing one simulation for each MCMC draw forming the joint posterior distribution of the parameters. The random-effect terms in this joint posterior distribution ( $\varepsilon_{S, g, m}$ and $\varepsilon_{\mu, g, m}$ in eqs. 1 and 2, respectively) estimated the deviation of each release cohort from the average survival and travel time relation. However, because we were interested in simulating new cohorts of fish, we drew new random effects for each posterior draw from a normal distribution with mean 0 and standard deviation of $\xi_{S}$ and $\xi_{\mu}$ (see fig. 2). In this way, each draw of the joint posterior distribution represents a possible state of nature for how river flow and DCC gate operations affect travel time, routing, and survival of a given cohort of fish. When comparing alternative scenarios (for example, PA and NAA), we used the same set of random effect draws for both scenarios because we envisioned that the same cohort of fish was migrating through the Delta, but under two possible alternative operational scenarios. For steady-state and time-varying models, this simulation approach produced a posterior distribution for all parameters of interest, which we summarized by using the median of the posteriors. We focused on uncertainty when comparing the difference in survival or travel time between alternative scenarios, and formed a $90 \%$ credible interval from the 5th and 95th percentiles of the posterior distribution of the difference in a given statistic between scenarios. 


\section{Evaluating the North Delta Diversion Bypass Rules}

We simulated through-Delta survival ( $\left.S_{\text {Delta }}\right)$ under each bypass rule over a range of Sacramento River discharges $\left(5,000-60,000 \mathrm{ft}^{3} / \mathrm{s}\right)$, which bracketed flows in which survival increased sharply at low flows and leveled off at higher flows (fig. 5). We compared $S_{\text {Delta }}$ assuming no diversion and diversion under the NDD bypass rules with the DCC open or closed. We then calculated the difference in $S_{\text {Delta }}$ between no diversion and diversion prescribed under the NDD bypass rules to assess the magnitude of the survival difference. Specifically, we did this comparison for the 12 scenarios described under the NDD bypass rules:

1. Constant low-level pumping

2. October-November bypass rules

3. Level 1, 2, and 3 post-pulse operations for December-April

4. Level 1,2, and 3 post-pulse operations for May

5. Level 1,2, and 3 post-pulse operations for June

6. July-September bypass rules

The conditions under which each bypass rule is implemented are outlined in California Department of Water Resources (2013, table 3.4.1-2). Constant low-level pumping generally is implemented following a flow pulse sufficient to initiate movement of juvenile salmon. Over time following a flow pulse, NDD operations transition from constant low-level pumping to Level 1,2, and 3 post-pulse bypass rules. Level 1,2, and 3 post-pulse operations also depend on time of year to provide more protection when the most juvenile salmon are emigrating through the Delta.

\section{Comparing the Proposed Action and No Action Alternative}

To understand the effect of the North Delta Diversion on survival and travel time of juvenile late-fall Chinook salmon, we simulated travel time, survival, and migration routing for the CalSim and Delta Simulation Model 2 (DSM-2) model runs for the NAA and PA scenarios (ICF International, 2016). We also simulated survival, routing, and travel time for a secondary scenario referred to as the "Level 1" or "L1" scenario. Whereas the proposed action implemented the bypass rules with three levels of post-pulse operations, the L1 scenario was intended to be more protective by eliminating Level 2 and 3 post-pulse operations and implementing only Level 1 post-pulse operations. We focus primarily on the NAA and PA scenarios in the main body of this report, but include all results from the PA and L1 scenarios in appendixes 1-10.

Because our model relied on daily inflows to the Delta and daily DCC gate operations, we combined the output of the CalSim and DSM-2 hydrodynamic models to construct the inputs required for our simulation model. For each scenario, the CalSim model produced an 82-year time series of daily bypass flows (flows of the Sacramento River downstream of the NDD), and the DSM-2 model produced an 82-year time series of 15-min flows and DCC gate operations. We used daily flows from the CalSim model and summarized daily gate operations from DSM-2 model output. 
Our simulation model produces through-Delta survival and travel time distributions for a cohort of fish entering the Delta at Freeport on each day of the 82-year daily time series of Delta inflows. For each day of the 82-year time series, travel time, routing, and survival were simulated as follows:

1. Select parameter set $i$ from the joint posterior parameter distribution.

2. Initiate the simulation with 500 fish at Freeport on day $t$.

3. Calculate survival in reach 1 using equation 1 , given bypass discharge on day $t$ and parameter set $i$.

4. Draw individual travel times through reach 1 from a log-normal distribution where the mean of the distribution depends on parameter set $i$ and bypass discharge on day $t$ (eq. 2). This yields a distribution of arrival times at the junction of Sutter and Steamboat Sloughs with the Sacramento River ( $\mathrm{A}_{3}$ and $\mathrm{B}_{3}$ in fig. 1$)$.

5. Draw the route taken by each fish from a Bernoulli distribution where the probability of entering Sutter and Steamboat Sloughs is a function of parameters in table 1 and bypass discharge on the day each fish arrives at the junction.

6. Calculate the survival probability of each individual for the next reach downstream (Sacramento River or Sutter and Steamboat Sloughs) given bypass discharge on the day each fish entered the reach.

7. Draw travel times for each individual for the next downstream reach given the bypass flows on the day each fish entered the reach.

8. For fish remaining in the Sacramento River, draw the route taken by fish at the junction of the Sacramento River with the DCC and Georgiana Slough $\left(\mathrm{A}_{4}, \mathrm{C}_{4}\right.$, and $\mathrm{D}_{4}$ in fig. 1$)$ from a multiple Bernoulli distribution where the probability of entering each route depends on the parameters in table 2, the position of the DCC gates, and bypass flows on the day each fish arrived at the junction.

9. Repeat steps 4 and 5 for all remaining reaches.

10. Repeat steps 2-9 for all days in the 82-year time series.

11. Repeat steps 1-10 for all iterations of the joint posterior distribution.

This simulation yields a posterior distribution of reach-specific survival probabilities, reachspecific travel times, and routing histories for a cohort of 500 individuals entering the Delta at Freeport on each day of the 82-year time series. By using this approach, our simulation emulates the effect of daily flow variation on through-Delta survival and travel time for a cohort of fish that enter the Delta on a given day. For example, although two cohorts may enter the Delta under identical flows at Freeport, survival and travel time of these cohorts would differ if one cohort entered during an ascending hydrograph and another cohort entered during a descending hydrograph.

The simulation output for each day was then summarized to provide many useful statistics for each daily cohort:

- The daily proportion of fish using each unique migration route.

- The mean daily survival from Freeport to Chipps Island for each unique migration route, calculated by first taking the product of reach-specific survival between Freeport and Chipps Island for each individual and then taking the mean survival over all individuals.

- Overall survival through the Delta, calculated as the mean survival over all individuals that entered the Delta on day $t$. Because routing for each individual was randomly drawn at each river junction, the mean survival is weighted by the proportion of fish that used each route. 
- Median travel time by route and over all routes for individuals that entered the Delta on day $t$. Median travel time was calculated by first summing reach-specific travel times for each individual between Freeport and Chipps Island and then taking the exponent of the mean of the logarithm of travel times (by route and over all routes).

- Daily difference in survival and median travel time between PA and NAA scenarios.

To display model output, we generated annual graphs of:

- Daily bypass flows for each scenario,

- Daily overall through-Delta survival ( $\left.S_{\text {Delta }}\right)$ and median travel time,

- Daily route-specific survival and median travel time,

- Daily routing probabilities, and

- The difference in $S_{\text {Delta }}$ and median travel time between scenarios.

For these graphs, we plotted the posterior medians and $90 \%$ credible intervals on the difference in survival and travel time between scenarios. We selected two water years ${ }^{1}$ to present in the body of the report to represent model output; graphs for all 82 years are provided in appendixes 1-10.

To summarize the 82 -year time series, we use boxplots to examine the probability of a difference and the magnitude of the difference in the daily survival or travel time between scenarios. For survival, we calculated the probability that survival for the PA or L1 scenarios was less than for the NAA scenario. This probability was calculated as the fraction of the posterior distribution of the daily difference in survival between scenarios that was less than 0 . For travel time, we calculated the probability that survival for the PA or L1 scenarios was greater than for the NAA scenario. This approach produced a daily time series of probabilities for the 82-year simulation, which we summarize using boxplots for each day of the year.

To examine the magnitude of the difference in survival or travel time, we used boxplots to display the distribution of posterior median differences for all years combined and by water-year type. The California Department of Water Resources uses five classifications for water year type in the Sacramento Valley that are based on water year index value (WYI) in millions of acre-feet (MAF):

1. W=Wet, WYI greater than or equal to $(\geq) 9.2$;

2. $\mathrm{AN}=$ Above Normal, 7.8 less than or equal to $(\leq) \mathrm{WYI} \leq 9.2$;

3. $\mathrm{BN}=$ Below Normal, $6.5 \leq \mathrm{WYI} \leq 7.8$;

4. $\mathrm{D}=$ Dry, $5.4 \leq \mathrm{WYI} \leq 6.5$; and

5. $\mathrm{C}=$ Critical, $\mathrm{WYI} \leq 5.4$ (Kapahi and others, 2006).

${ }^{1}$ The 12-month period from October 1, for any given year, through September 30, of the following year. The water year is designated by the calendar year in which it ends. 


\section{Using Survival Criteria for Shaping North Delta Diversion Rule Curves}

Although we use our Bayesian survival model to quantify the effect of bypass rules on survival, another way to use the survival model is to design bypass flow rules that maintain specific survival criteria to minimize effects on salmon populations. Such criteria can take into account a magnitude of difference in survival and uncertainty about the difference. For example, one such criterion might ask the question, "What diversion rates will ensure a 90\% probability that the reduction in survival is no more than $x$ percent?" The shaping of NDD operations using such a criterion links NDD operations directly to an expected maximum effect on survival and explicitly incorporates uncertainty in the survival estimates by ensuring a low probability of exceeding a given reduction in survival.

To answer this question, we developed a set of NDD operational "rule curves" using criterion based on an absolute and a relative change in survival. Each rule curve was developed using the following methods:

1. Select whether the criterion is based on an absolute $\left(S_{\text {no NDD }}-S_{\mathrm{NDD}}\right)$ or relative difference in survival $\left[\left(S_{\mathrm{no} \mathrm{NDD}}-S_{\mathrm{NDD}}\right) / S_{\mathrm{no} N D D}\right]$.

2. Select the maximum percent-change in survival in which we wish no more than a $10 \%$ chance of exceeding (for example, $90 \%$ probability of an $x$-percent difference or less). We selected an absolute difference of 1-5 percent and a relative difference of 4-9 percent, both in 1-percent increments.

3. Select the magnitude of near-field mortality caused by the NDD $(0,0.03$, and 0.05$)$. In this analysis, near-field mortality is defined as the potential decrease in survival caused by the presence of diversion structures (for example, screens or increase in predation) over and above that caused by a decrease in bypass flow. In these scenarios, survival is calculated as the $S_{\mathrm{NDD}}(1-m)$, where $m$ is the near-field mortality that we set to $0,0.03$, and 0.05 .

4. For a given discharge at Freeport, identify the NDD flow that satisfies the criterion identified in steps 1 and 2. The NDD flow that satisfies this criterion was determined using an optimization routine by:
A. Inputting a starting value for NDD flow,
B. Calculating the difference in survival between that NDD flow and no diversion for each iteration in the joint posterior distribution of the parameters,
C. Calculating the 90th percentile of the difference in survival from the posterior distribution of the difference in survival between the given NDD flow and no diversion, and
D. Changing the NDD flow in a direction that moves closer to the desired x-percent difference.

5. Repeat steps 4A-D until reaching the NDD flow that achieves the desired criterion. Repeat steps 1-3 over the range of Freeport discharges. We ran the optimization for Freeport discharge ranging from 5,000 to $80,000 \mathrm{ft}^{3} / \mathrm{s}$ in increments of $2,000 \mathrm{ft}^{3} / \mathrm{s}$.

The only other constraint that we imposed was a minimum bypass flow of $5,000 \mathrm{ft}^{3} / \mathrm{s}$, which is consistent with the current bypass rules. The outcome of this analysis is a "rule curve" that defines NDD flows that satisfy the specified survival criterion as a function of Freeport discharge. 


\section{Evaluating Real-Time Operations}

The purpose of this analysis was to evaluate real-time operations of the NDD that propose to implement reduced diversion based on a trap catch index of spring- and winter-run sized juvenile Chinook salmon at a rotary screw trap at Knights Landing, located about $53 \mathrm{~km}$ upriver of the City of Sacramento. We evaluated two real-time operation scenarios - the Level 1 (L1) and Unlimited Pulse Protection (UPP) scenarios. Under Level 1 pulse protection, a daily catch index of 5 or greater triggers constant low-level pumping operations as defined under the bypass rules in California Department of Water Resources (2013, table 3.4.1-2), but only the first pulse of fish in the season receives protection under the Level 1 operations. Thus, the UPP scenario implements constant low-level pumping for all pulses of fish that exceeded a catch index of 5 or greater. Additionally, the UPP instituted what is referred to as "offramp" where additional pumping is allowed as long as a minimum bypass flow $35,000 \mathrm{ft}^{3} / \mathrm{s}$ is maintained. Simulated bypass flows under these two scenarios were constructed based on historical catch and flow data for water years (WYs) 2003-12 and 2014 and provided to us by the National Marine Fisheries Service. Further detail on development of these scenarios is available in National Marine Fisheries Service (2017).

The goal of our analysis was to evaluate the effect of the L1 and UPP scenarios on daily and annual survival relative to the historical operations that occurred in each water year. We used the posterior distributions from our Bayesian survival model to do this analysis. For each draw of the posterior distribution, we calculated through-Delta survival for each day of each simulated water year (WYs 2003-12 and 2014) for no diversion, L1 real-time operations, and Revised real-time operations. We ran the model in the "steady state" form (described in section, "Simulating Survival, Travel Time, and Routing"), which assumed that flows remained constant as fish migrated through the Delta. In addition to daily survival, posterior distributions were calculated for the difference in daily survival of each scenario relative to no diversion. Posterior distributions of annual survival were calculated by weighting each daily survival by the fraction of the total Knights Landing Catch Index for each day. Additionally, posterior distributions were calculated for the difference in annual survival of each scenario relative to no diversion.

Assumptions associated with this analysis include the following:

1. Knights Landing Catch Index represents the passage distribution of winter- and spring-run sized fish passing Knights Landing. This is an important assumption because days with 0 catch receive 0 weight in the annual survival estimate even though fish likely are passing Knights Landing on many of these days owing to low trap efficiency.

2. Fish passing Knights Landing on a given day experience bypass flows on that day; that is, (1) no lag time was applied to account for travel time from Knights Landing to the North Delta Diversion, and (2) no travel times were applied to different reaches within the Delta to account for flow variation over a given cohort of fish.

3. The Delta Cross Channel was assumed closed. 


\section{Results}

\section{Evaluating the North Delta Diversion Bypass Rules}

We determined that the NDD bypass rules, as implemented under the assumptions of our simulation, decreased through-Delta survival, with the magnitude of decrease varying among scenarios (figs. 9-21). Constant low-level pumping, the most protective bypass rule, led to the smallest decrease in survival (figs. 9-10). For example, survival with the diversion was less than 2 percentage points lower than without the diversion. In contrast, all other bypass rules showed sizeable decreases in survival. For example, during December-April, when most populations of juvenile salmon are migrating through the Delta, post-pulse NDD operations caused median decreases in survival ranging from 0.06 to 0.09 , depending on the particular post-pulse level (figs. 9, 12-14). These maximum decreases in survival occurred at flows ranging from about 20,000-30,000 $\mathrm{ft}^{3} / \mathrm{s}$. For all bypass rules, the maximum decrease in survival occurred as diversion discharge increased to as much as the point of maximum diversion discharge $\left(9,000 \mathrm{ft}^{3} / \mathrm{s}\right)$. After this point, diversion discharge remained constant while survival continued to increase with bypass discharge, thereby decreasing the difference in survival with and without diversion (figs. 11-21). Juvenile salmon also are present in the Delta, albeit at lower abundances, during other periods with less restrictive bypass rules (for example, during May, and October-November). Under October-November bypass rules (fig. 11) or level 3 post-pulse operations in May (fig. 17), the maximum decrease in survival was about 10 percentage points. Operation of the DCC led to slightly larger differences in survival relative to closed DCC gates, but survival differences with the DCC were more uncertain than with gates closed (figs. 11-21). 

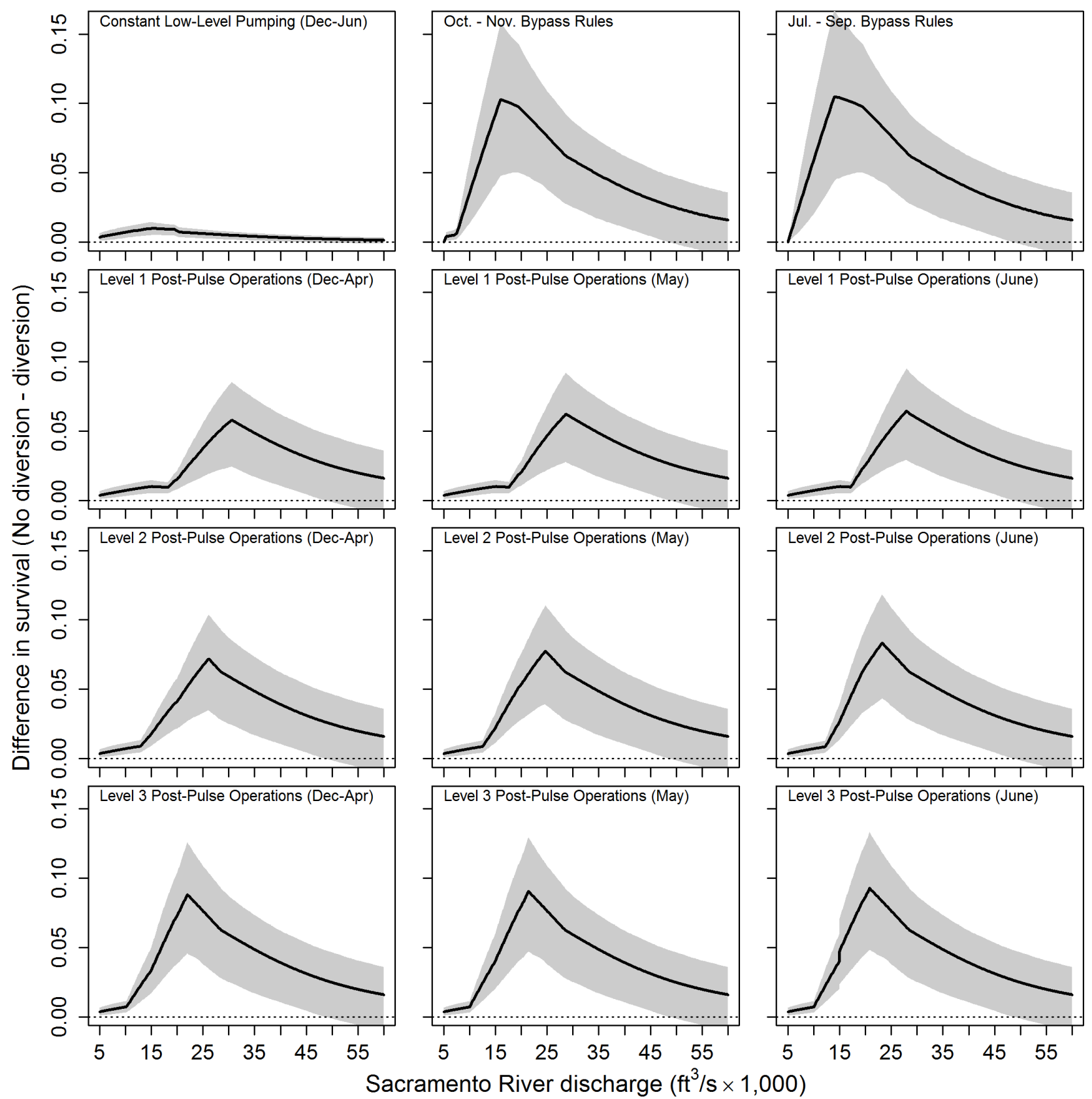

Figure 9. Graphs showing effect of the North Delta Diversion (NDD) bypass rules on the difference in throughSacramento-San Joaquin River Delta survival with and without implementation of the NDD, in northern California. Shaded regions show $90 \%$ credible intervals on the difference in survival with and without diversion. Detail for each graph is shown in figures $10-21$. The dotted line shows where credible intervals overlap zero. -, minus; $\mathrm{ft}^{3} / \mathrm{s}$ $\times 1,000$, thousands of cubic feet per second. 
Constant Low-Level Pumping (Dec-Jun)
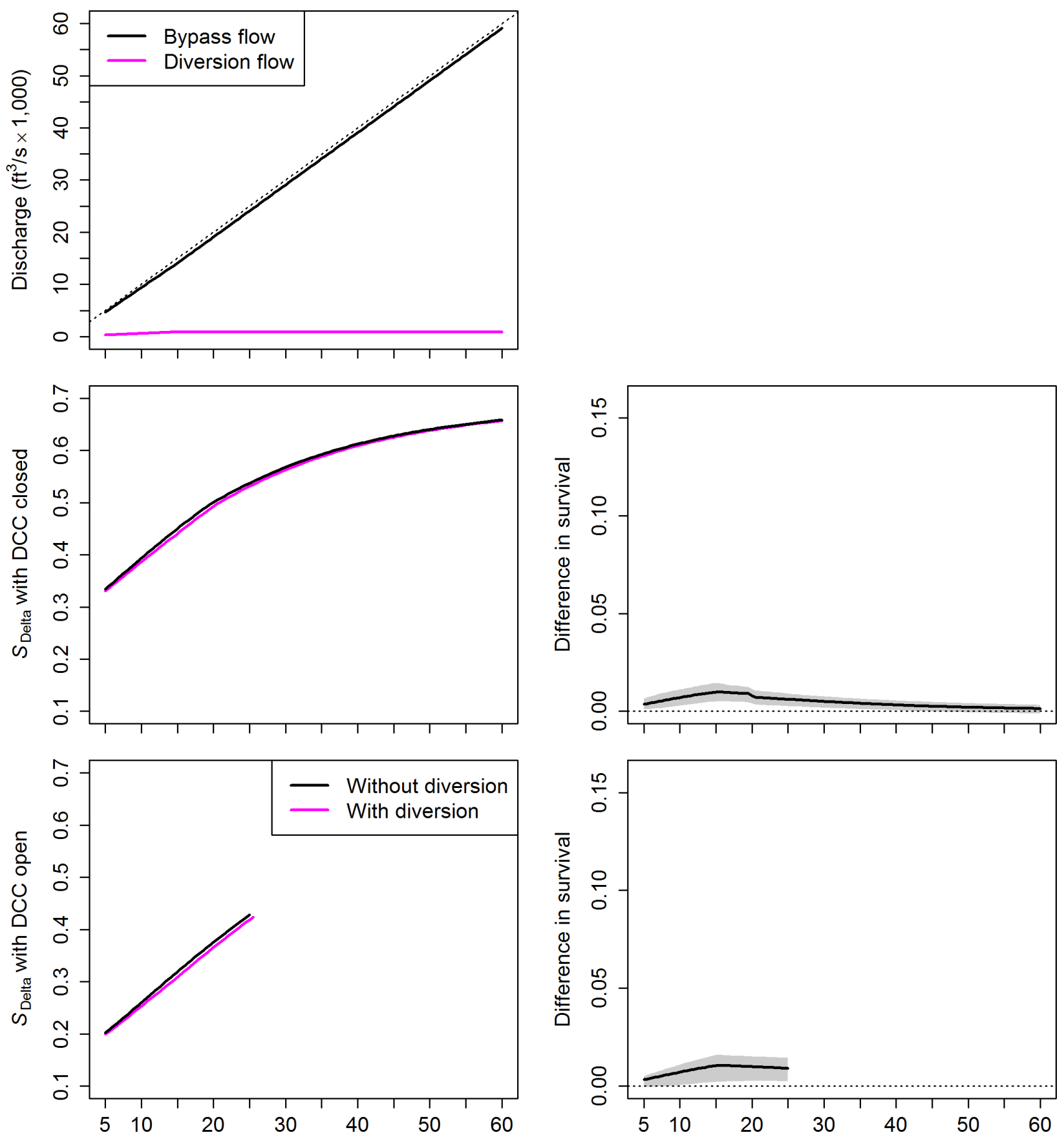

Sacramento River discharge $\left(\mathrm{ft}^{3} / \mathrm{s} \times 1,000\right)$

Figure 10. Graphs showing effect of the North Delta Diversion on bypass discharge (top graph), and survival (S Detta) $_{\text {with }}$ and without the diversion for the Delta Cross Channel (DCC) closed (middle graphs) and open (bottom graphs) for constant low-level pumping as defined in the NDD bypass rules, Sacramento-San Joaquin River Delta, northern California. In the top graph, the dotted line shows bypass discharge when diversion discharge is 0 . In the right-hand graphs, shaded regions show $90 \%$ credible intervals on the difference in survival with and without diversion, and the dotted reference line shows where credible intervals overlap zero. $\mathrm{ft}^{3} / \mathrm{s} \times$ 1,000 , thousands of cubic feet per second. 
Oct. - Nov. Bypass Rules
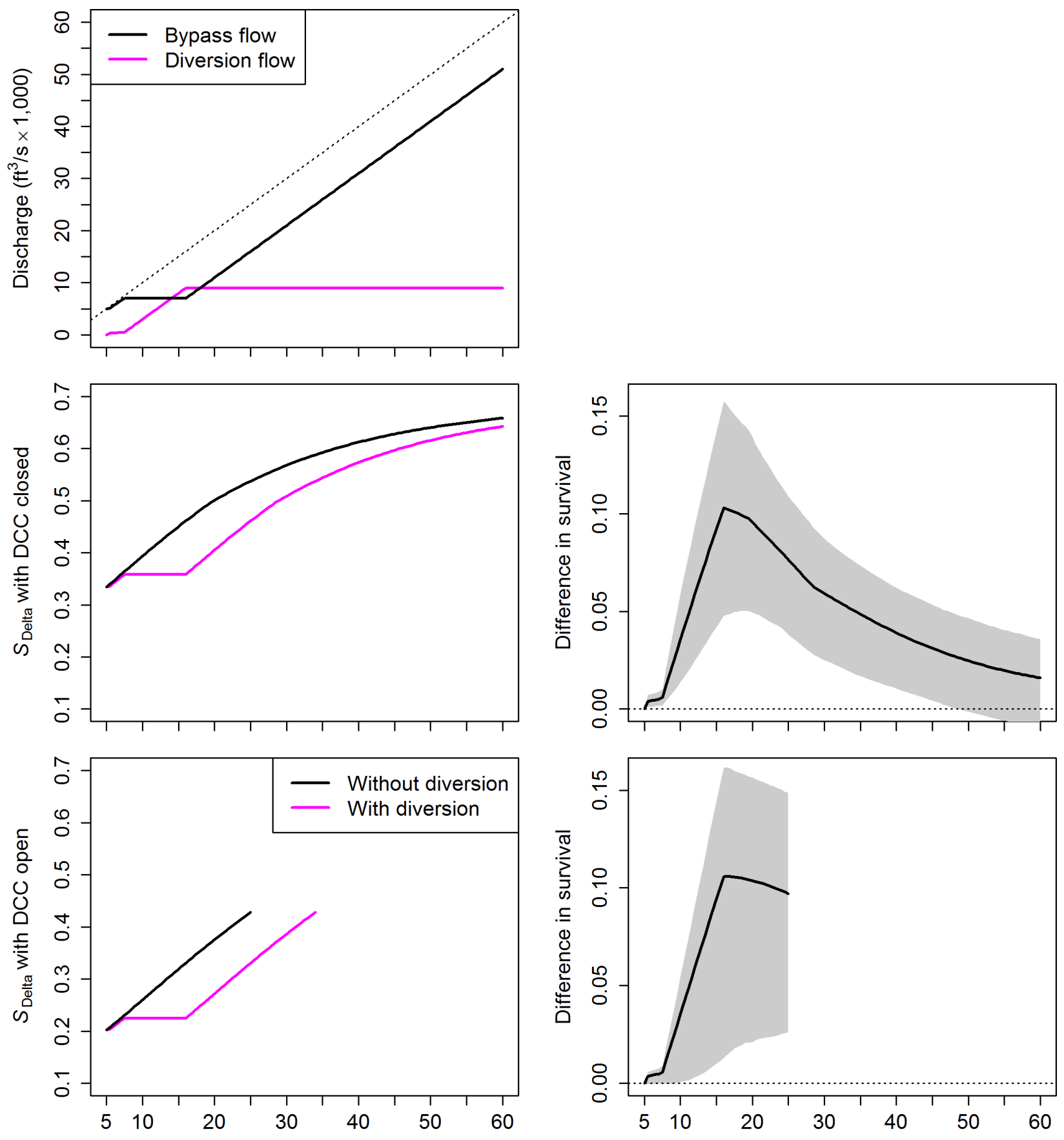

Sacramento River discharge $\left(\mathrm{ft}^{3} / \mathrm{s} \times 1,000\right)$

Figure 11. Graphs showing effect of the North Delta Diversion on bypass discharge (top graph), and survival (S Delta) with and without the diversion for the Delta Cross Channel (DCC) closed (middle graphs) and open (bottom graphs) for October-November bypass rules, Sacramento-San Joaquin River Delta, northern California. In the top graph, the dotted line shows bypass discharge when diversion discharge is 0 . In the right-hand graphs, shaded regions show $90 \%$ credible intervals on the difference in survival with and without diversion, and the dotted reference line shows where credible intervals overlap zero. $\mathrm{ft}^{3} / \mathrm{s} \times 1,000$, thousands of cubic feet per second. 


\section{Level 1 Post-Pulse Operations (Dec-Apr)}
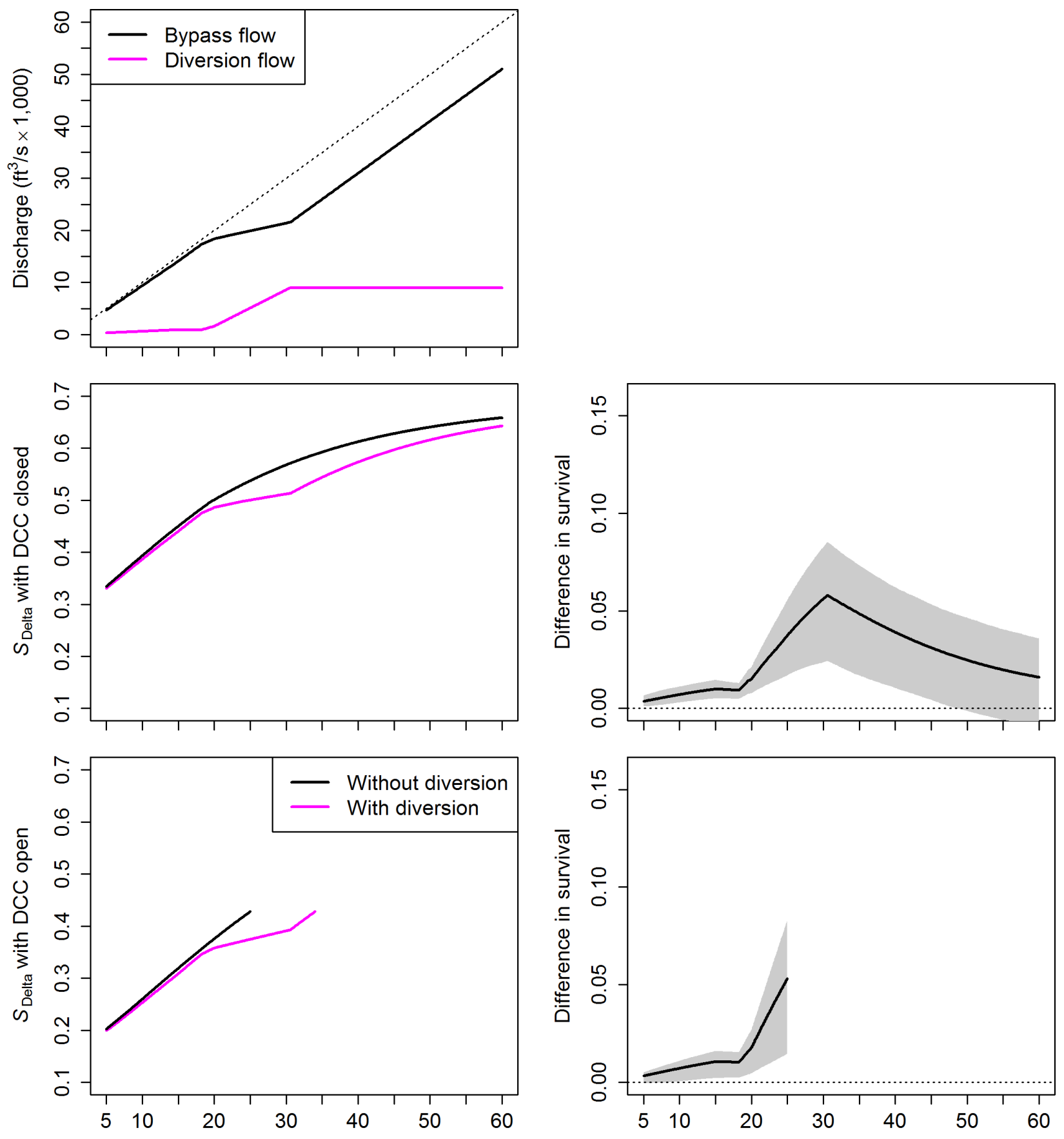

Sacramento River discharge $\left(\mathrm{ft}^{3} / \mathrm{s} \times 1,000\right)$

Figure 12. Graphs showing effect of the North Delta Diversion on bypass discharge (top graph), and survival (S Detta) $_{\text {with }}$ and without the diversion for the Delta Cross Channel (DCC) closed (middle graphs) and open (bottom graphs) for Level 1 post-pulse operations for December-April, Sacramento-San Joaquin River Delta, northern California. In the top graph, the dotted line shows bypass discharge when diversion discharge is 0 . In the right-hand graphs, shaded regions show $90 \%$ credible intervals on the difference in survival with and without diversion, and the dotted reference line shows where credible intervals overlap zero. $\mathrm{ft}^{3} / \mathrm{s} \times 1,000$, thousands of cubic feet per second. 


\section{Level 2 Post-Pulse Operations (Dec-Apr)}
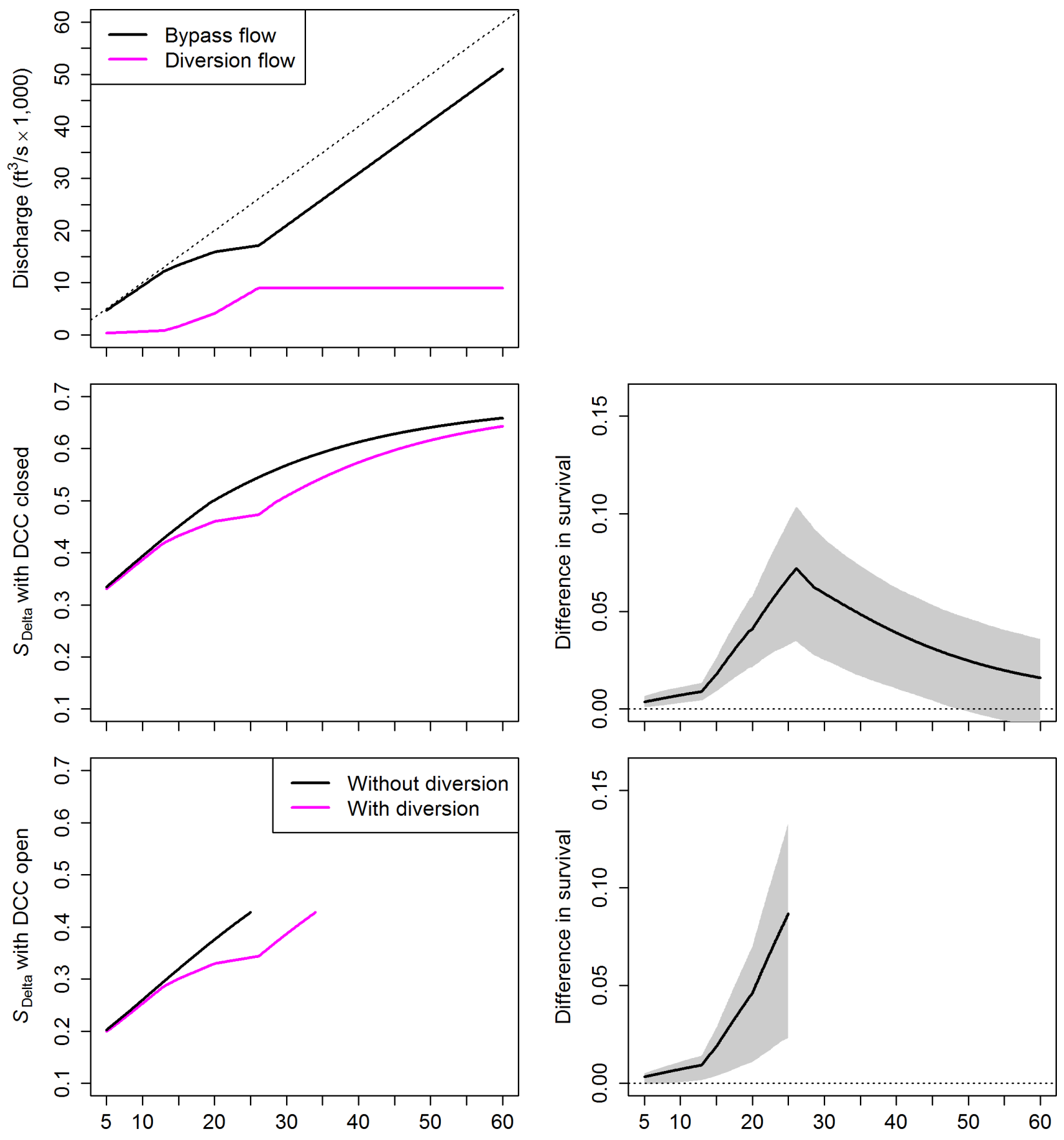

Sacramento River discharge $\left(\mathrm{ft}^{3} / \mathrm{s} \times 1,000\right)$

Figure 13. Graphs showing effect of the North Delta Diversion on bypass discharge (top graph), and survival (S Detta) $_{\text {with }}$ and without the diversion for the Delta Cross Channel (DCC) closed (middle graphs) and open (bottom graphs) for Level 2 post-pulse operations for December-April, Sacramento-San Joaquin River Delta, northern California. In the top graph, the dotted line shows bypass discharge when diversion discharge is 0 . In the right-hand graphs, shaded regions show $90 \%$ credible intervals on the difference in survival with and without diversion, and the dotted reference line shows where credible intervals overlap zero. $\mathrm{ft}^{3} / \mathrm{s} \times 1,000$, thousands of cubic feet per second. 


\section{Level 3 Post-Pulse Operations (Dec-Apr)}
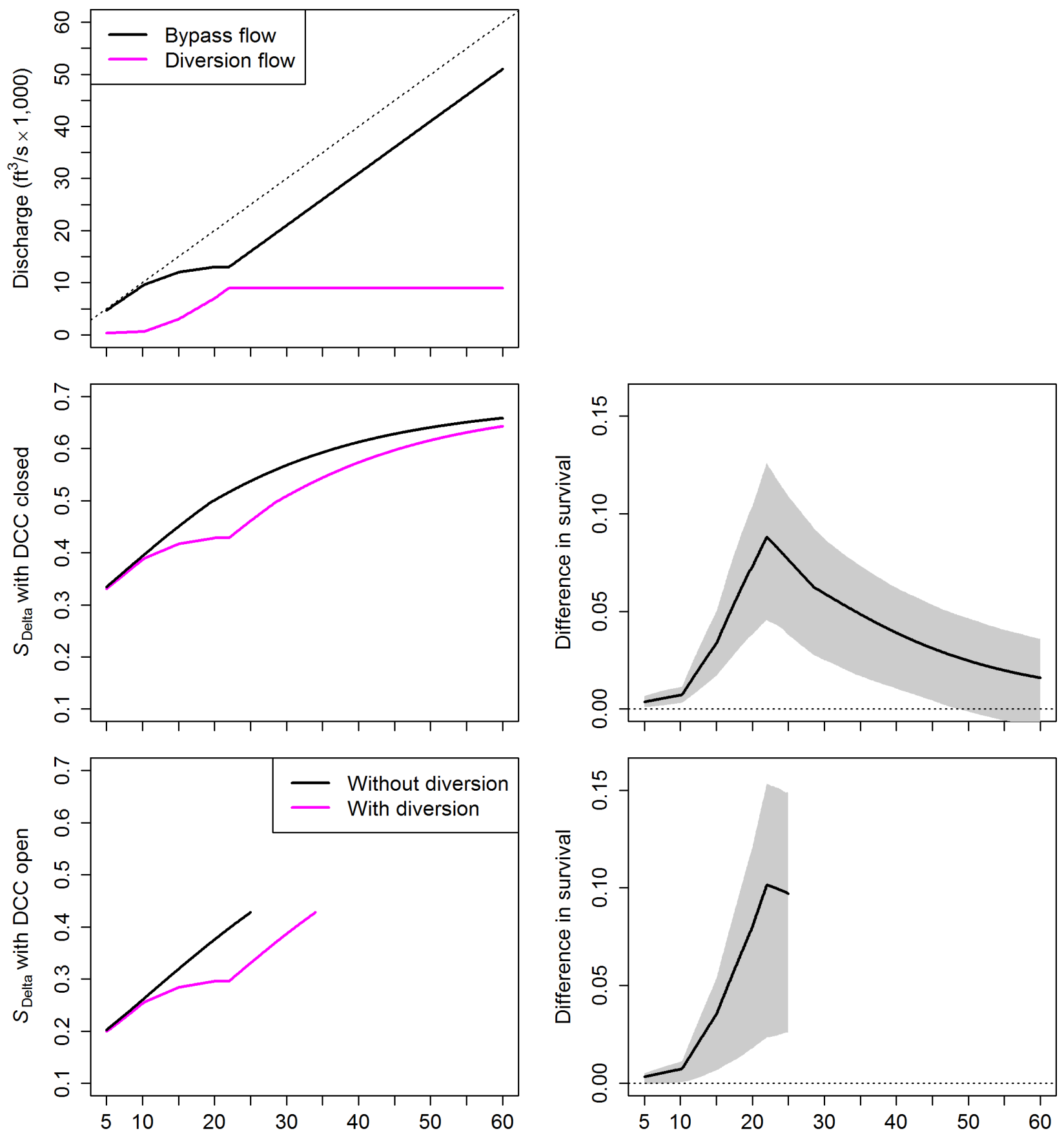

Sacramento River discharge $\left(\mathrm{ft}^{3} / \mathrm{s} \times 1,000\right)$

Figure 14. Graphs showing effect of the North Delta Diversion on bypass discharge (top graph), and survival (S Detta) $_{\text {with }}$ and without the diversion for the Delta Cross Channel (DCC) closed (middle graphs) and open (bottom graphs) for Level 3 post-pulse operations for December-April, Sacramento-San Joaquin River Delta, northern California. In the top graph, the dotted line shows bypass discharge when diversion discharge is 0 . In the right-hand graphs, shaded regions show $90 \%$ credible intervals on the difference in survival with and without diversion, and the dotted reference line shows where credible intervals overlap zero. $\mathrm{ft}^{3} / \mathrm{s} \times 1,000$, thousands of cubic feet per second. 


\section{Level 1 Post-Pulse Operations (May)}
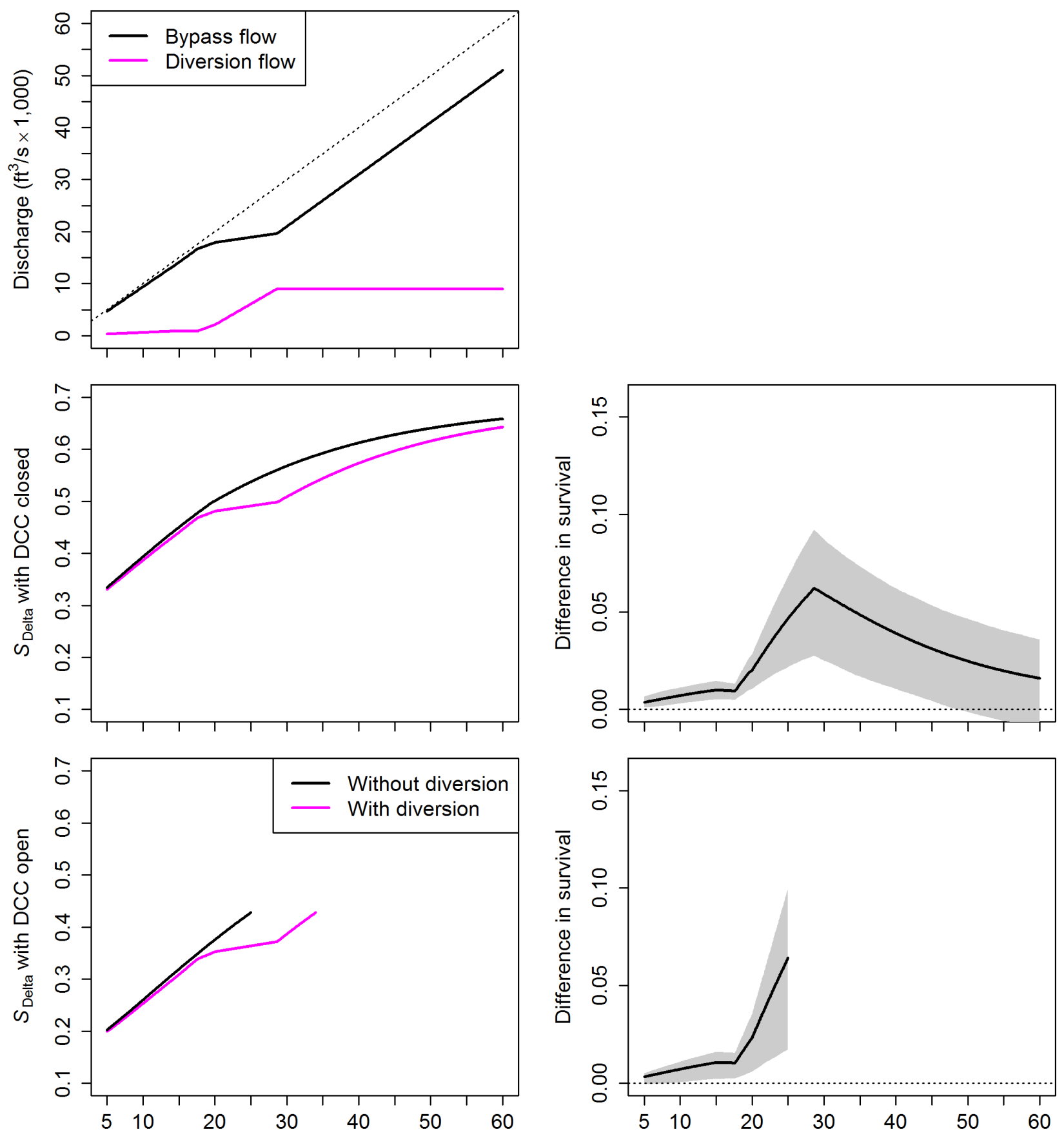

Sacramento River discharge $\left(\mathrm{ft}^{3} / \mathrm{s} \times 1,000\right)$

Figure 15. Graphs showing effect of the North Delta Diversion on bypass discharge (top graph), and survival (S $S_{\text {Delta) }}$ with and without the diversion for the Delta Cross Channel (DCC) closed (middle graphs) and open (bottom graphs) for Level 1 post-pulse operations in May, Sacramento-San Joaquin River Delta, northern California. In the top graph, the dotted line shows bypass discharge when diversion discharge is 0 . In the righthand graphs, shaded regions show $90 \%$ credible intervals on the difference in survival with and without diversion, and the dotted reference line shows where credible intervals overlap zero. $\mathrm{ft}^{3} / \mathrm{s} \times 1,000$, thousands of cubic feet per second. 


\section{Level 2 Post-Pulse Operations (May)}
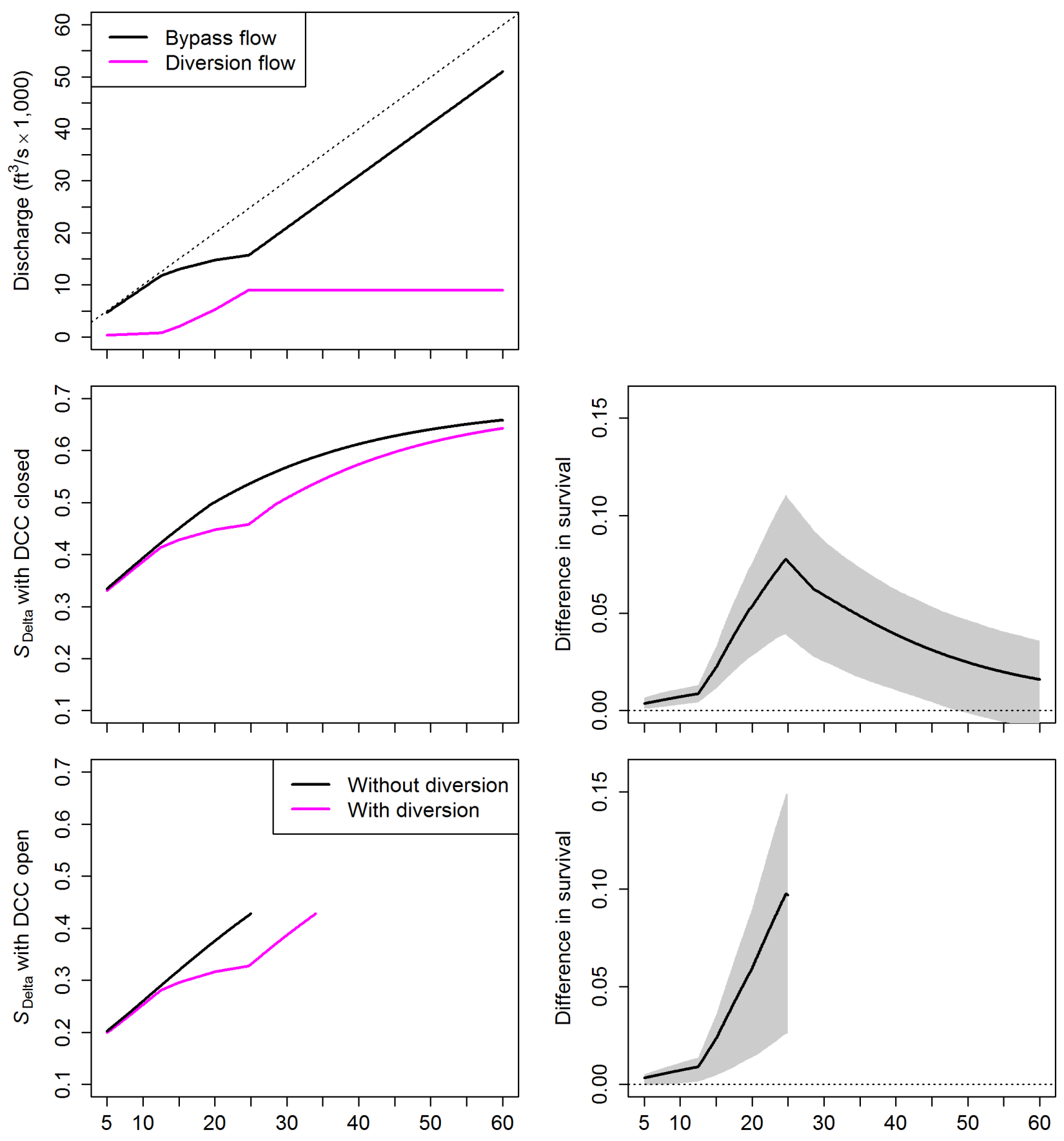

Sacramento River discharge $\left(\mathrm{ft}^{3} / \mathrm{s} \times 1,000\right)$

Figure 16. Graphs showing effect of the North Delta Diversion on bypass discharge (top graph), and survival

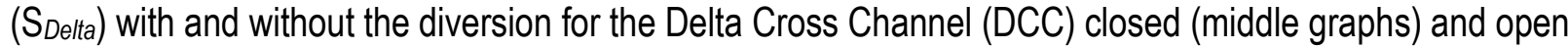
(bottom graphs) for Level 2 post-pulse operations in May, Sacramento-San Joaquin River Delta, northern California. In the top graph, the dotted line shows bypass discharge when diversion discharge is 0 . In the righthand graphs, shaded regions show $90 \%$ credible intervals on the difference in survival with and without diversion, and the dotted reference line shows where credible intervals overlap zero. $\mathrm{ft}^{3} / \mathrm{s} \times 1,000$, thousands of cubic feet per second. 


\section{Level 3 Post-Pulse Operations (May)}
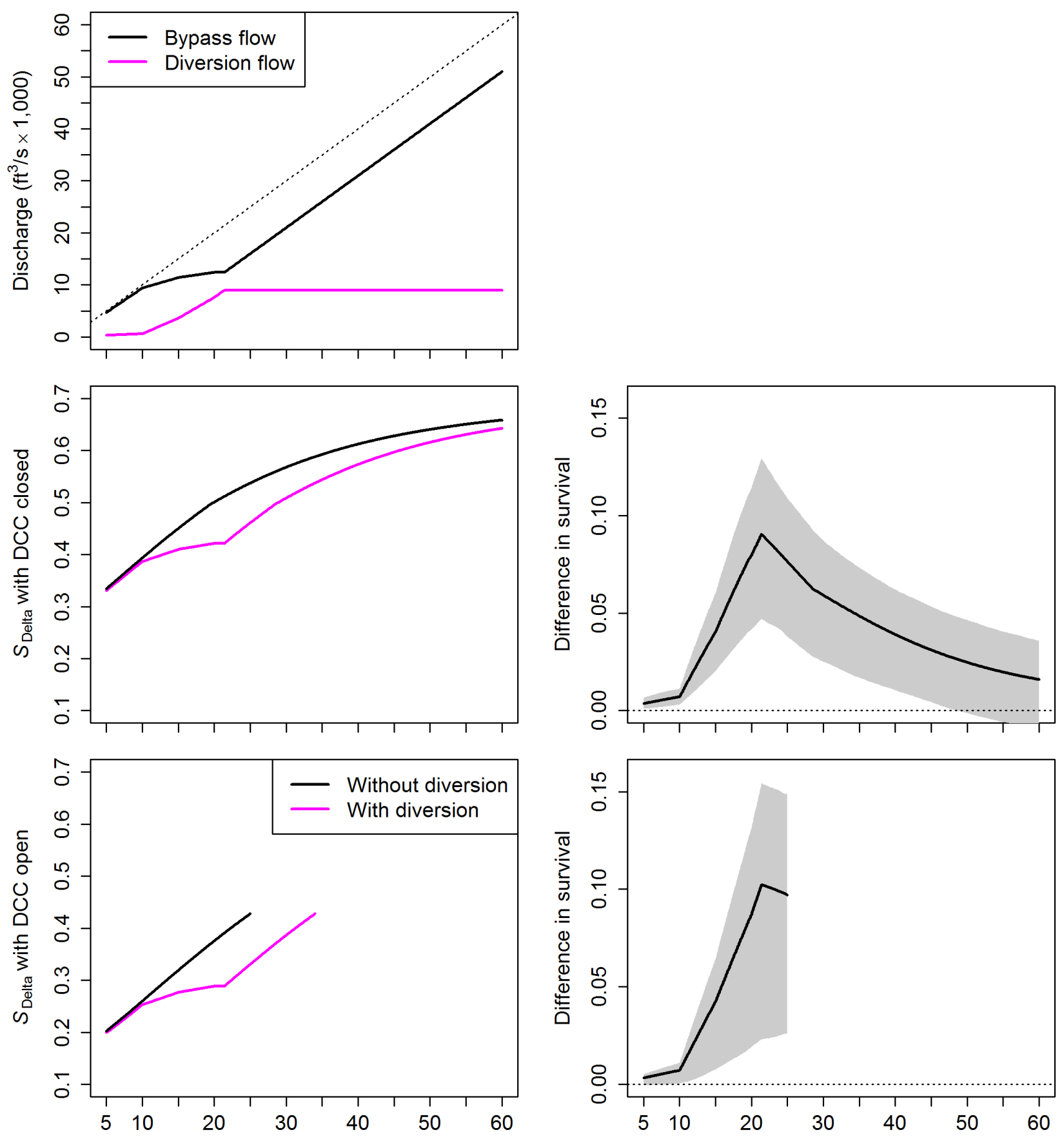

Sacramento River discharge $\left(\mathrm{ft}^{3} / \mathrm{s} \times 1,000\right)$

Figure 17. Graphs showing effect of the North Delta Diversion on bypass discharge (top graph), and survival (S $S_{\text {Delta) }}$ with and without the diversion for the Delta Cross Channel (DCC) closed (middle graphs) and open (bottom graphs) for Level 3 post-pulse operations in May, Sacramento-San Joaquin River Delta, northern California. In the top graph, the dotted line shows bypass discharge when diversion discharge is 0 . In the righthand graphs, shaded regions show $90 \%$ credible intervals on the difference in survival with and without diversion, and the dotted reference line shows where credible intervals overlap zero. $\mathrm{ft}^{3} / \mathrm{s} \times 1,000$, thousands of cubic feet per second. 


\section{Level 1 Post-Pulse Operations (Jun)}
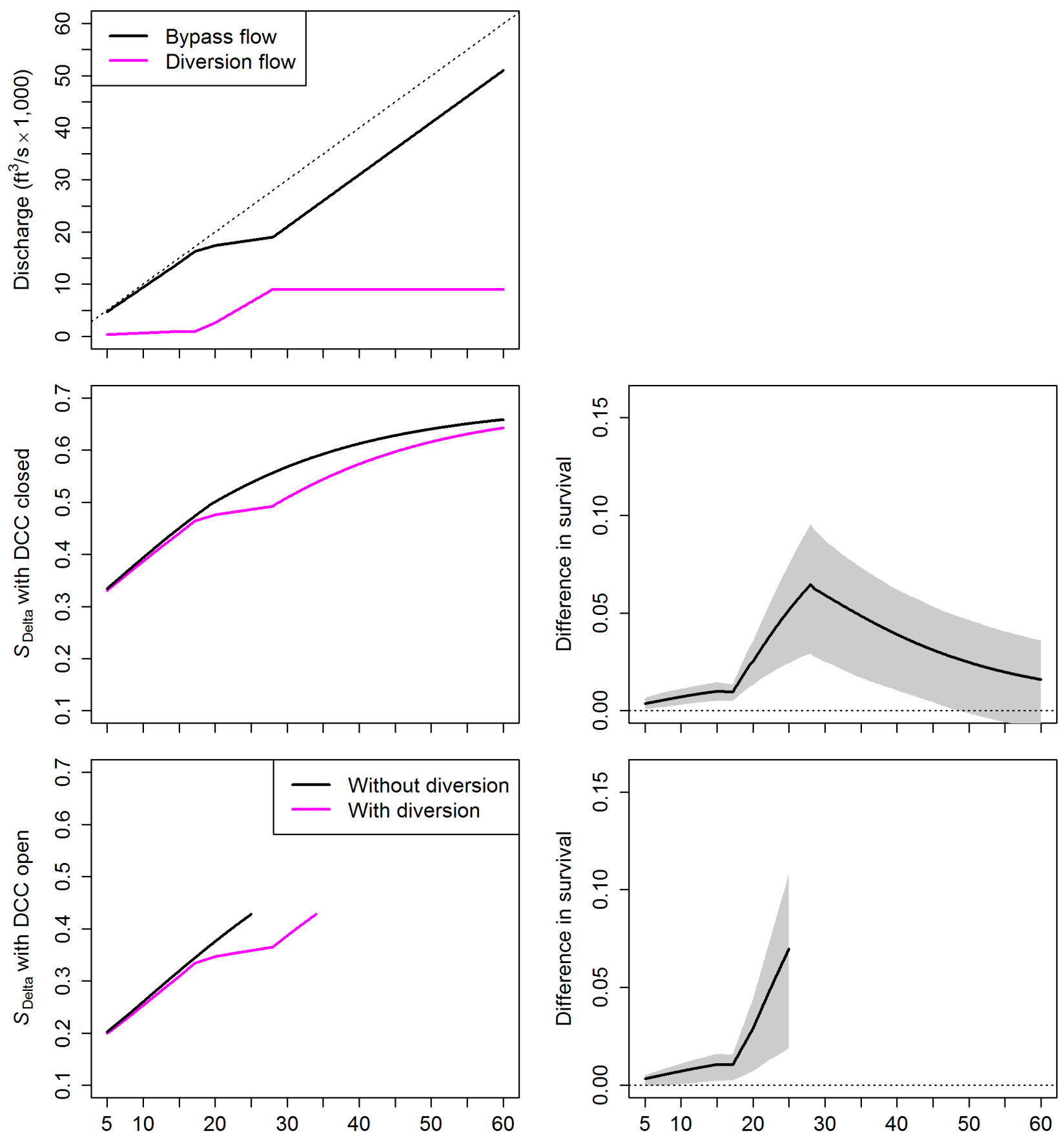

Sacramento River discharge $\left(\mathrm{ft}^{3} / \mathrm{s} \times 1,000\right)$

Figure 18. Graphs showing effect of the North Delta Diversion on bypass discharge (top graph), and survival (S Detta) $_{\text {with }}$ and without the diversion for the Delta Cross Channel (DCC) closed (middle graphs) and open (bottom graphs) for Level 1 post-pulse operations in June, Sacramento-San Joaquin River Delta, northern California. In the top graph, the dotted line shows bypass discharge when diversion discharge is 0 . In the righthand graphs, shaded regions show $90 \%$ credible intervals on the difference in survival with and without diversion, and the dotted reference line shows where credible intervals overlap zero. $\mathrm{ft}^{3} / \mathrm{s} \times 1,000$, thousands of cubic feet per second. 


\section{Level 2 Post-Pulse Operations (Jun)}
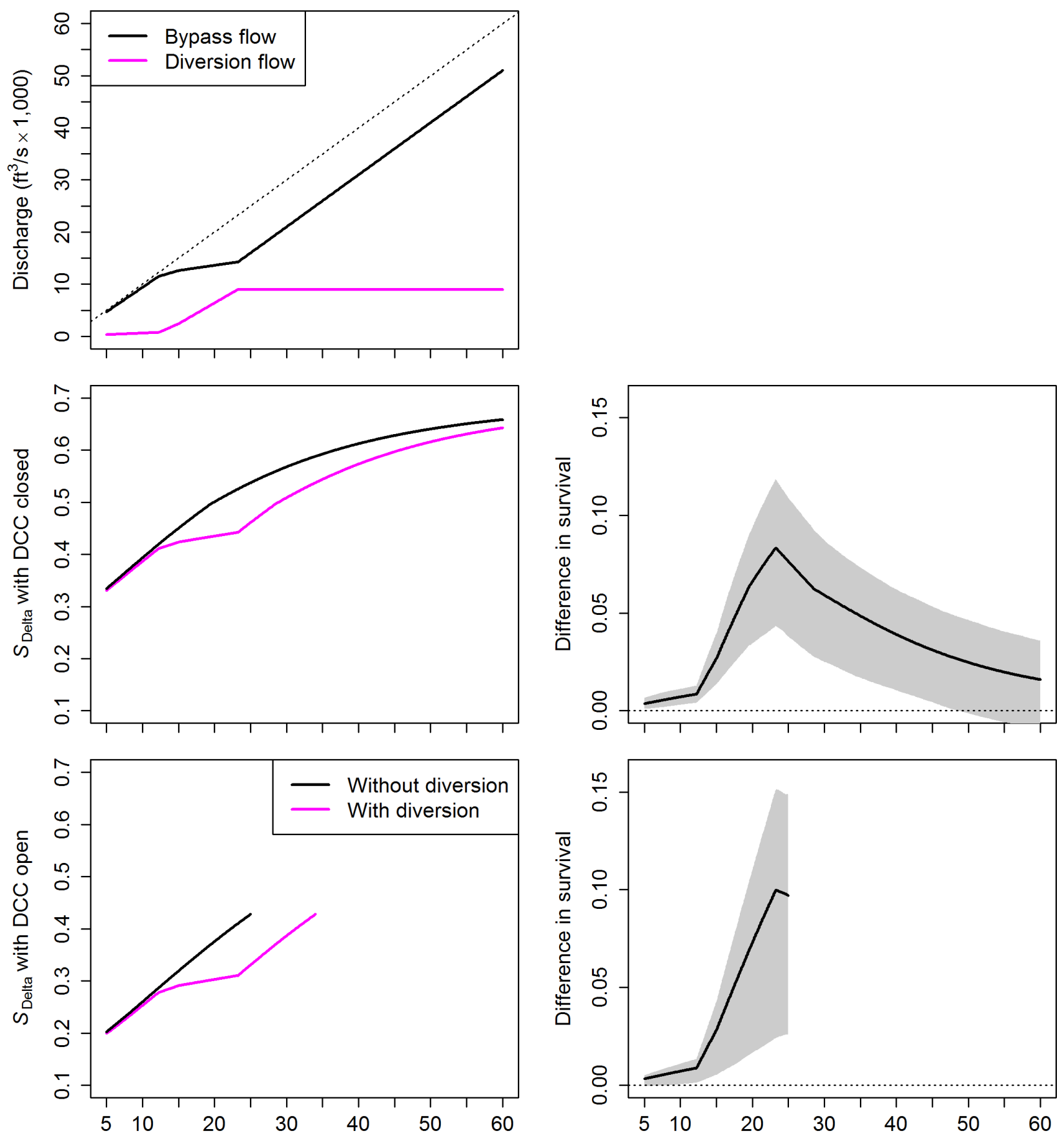

Sacramento River discharge $\left(\mathrm{ft}^{3} / \mathrm{s} \times 1,000\right)$

Figure 19. Graphs showing effect of the North Delta Diversion on bypass discharge (top graph), and survival (S Detta) $_{\text {with }}$ and without the diversion for the Delta Cross Channel (DCC) closed (middle graphs) and open (bottom graphs) for Level 2 post-pulse operations in June, Sacramento-San Joaquin River Delta, northern California. In the top graph, the dotted line shows bypass discharge when diversion discharge is 0 . In the righthand graphs, shaded regions show $90 \%$ credible intervals on the difference in survival with and without diversion, and the dotted reference line shows where credible intervals overlap zero. $\mathrm{ft}^{3} / \mathrm{s} \times 1,000$, thousands of cubic feet per second. 


\section{Level 3 Post-Pulse Operations (Jun)}
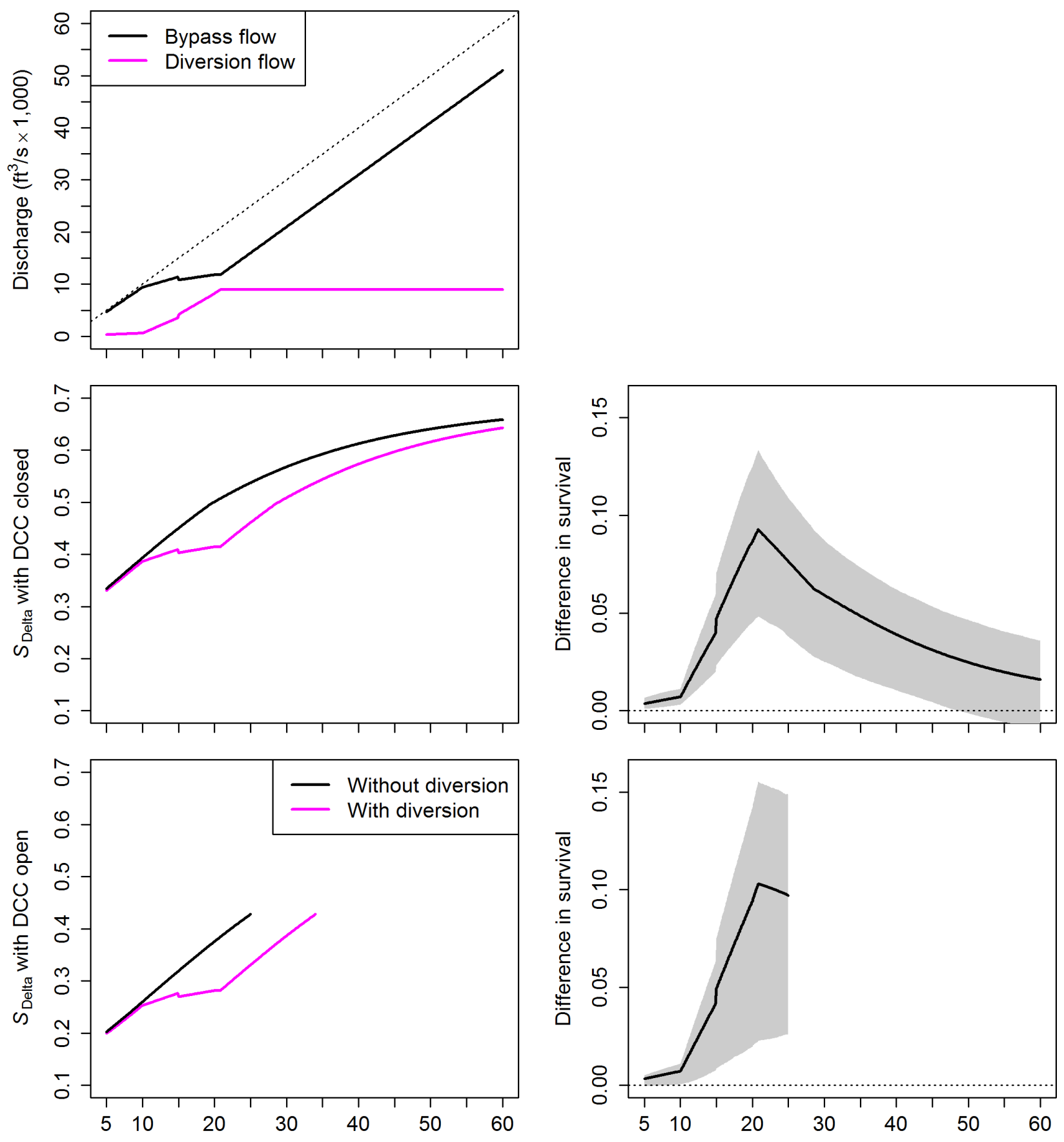

Sacramento River discharge $\left(\mathrm{ft}^{3} / \mathrm{s} \times 1,000\right)$

Figure 20. Graphs showing effect of the North Delta Diversion on bypass discharge (top graph), and survival (S $S_{\text {Delta) }}$ with and without the diversion for the Delta Cross Channel (DCC) closed (middle graphs) and open (bottom graphs) for Level 1 post-pulse operations in June, Sacramento-San Joaquin River Delta, northern California. In the top graph, the dotted line shows bypass discharge when diversion discharge is 0 . In the righthand graphs, shaded regions show $90 \%$ credible intervals on the difference in survival with and without diversion, and the dotted reference line shows where credible intervals overlap zero. $\mathrm{ft}^{3} / \mathrm{s} \times 1,000$, thousands of cubic feet per second. 
Jul. - Sep. Bypass Rules
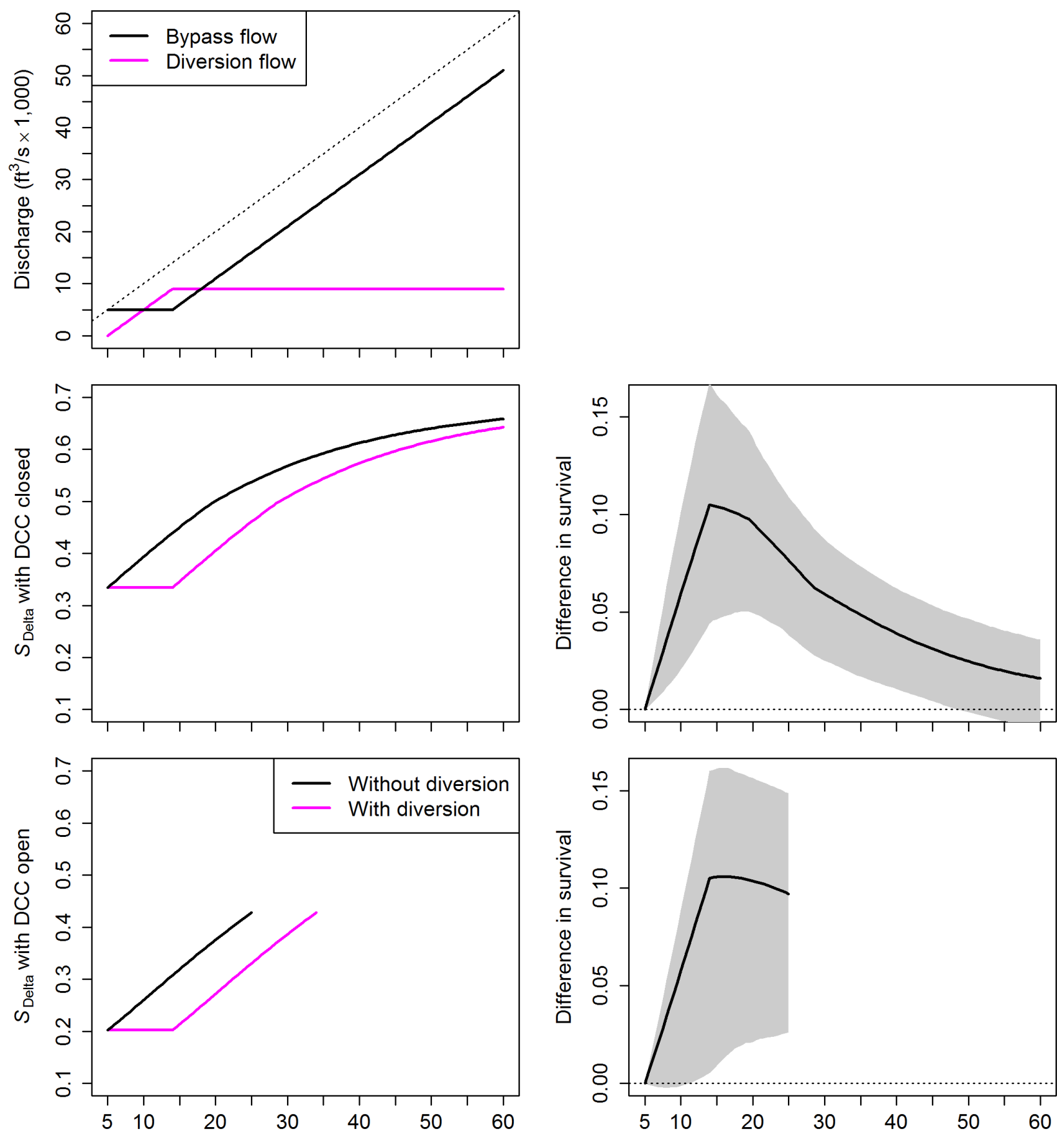

Sacramento River discharge $\left(\mathrm{ft}^{3} / \mathrm{s} \times 1,000\right)$

Figure 21. Graphs showing effect of the North Delta Diversion on bypass discharge (top graph), and survival (S Delta) with and without the diversion for the Delta Cross Channel (DCC) closed (middle graphs) and open (bottom graphs) for July-September bypass rules, Sacramento-San Joaquin River Delta, northern California. In the top graph, the dotted line shows bypass discharge when diversion discharge is 0 . In the right-hand graphs, shaded regions show $90 \%$ credible intervals on the difference in survival with and without diversion, and the dotted reference line shows where credible intervals overlap zero. $\mathrm{ft} / \mathrm{s} \times 1,000$, thousands of cubic feet per second. 


\section{Comparing the Proposed Action and No Action Alternative}

We show detailed survival, travel time, and routing results for two water years-WYs 1979, a below-normal water year, and 1990, a critically dry water year. For WY 1979, through-Delta survival under the PA scenario was considerably lower than the NAA scenario during October-mid-December, owing to differences in bypass discharge and operation of the DCC (fig. 22). During this period, the largest difference in survival (about 20 percentage points) occurred during mid-November, when the DCC was open under PA but closed under the NAA. Median survival differences between scenarios during January-February and mid-April-mid-June were only slightly lower than the NAA scenario, and $90 \%$ credible intervals overlapped 0 (fig. 22). During March, survival between scenarios differed by about 5 percentage points and $90 \%$ credible intervals did not overlap 0 indicating a high probability that the PA scenario would result in lower survival than the NAA scenario in WY 1979. Patterns in travel time through the Delta were the opposite of patterns in survival, with longer median travel times under the PA scenario during October-mid-December and March, and similar median travel times during January-February and mid-April-mid-June (fig. 23). In contrast, for 1990, the critically dry year, bypass discharge and DCC operation were similar except early in the water year, leading to little differences in survival (figs. 24 and 25), travel time (figs. 26 and 27), or routing (fig. 28).

For WY 1979, differences in through-Delta survival between scenarios were caused by (1) the underlying flow survival relation, (2) differences in survival among routes, and (3) differences in routing that shifted fish between high- and low-survival routes. For example, under the PA scenario during October-mid-December, simulations indicated that a high proportion of fish entered the DCC (fig. 29) relative to NAA, which increased the proportion of fish experiencing low survival (fig. 22) and increased travel times (fig. 30). Simulations of route-specific survival showed that survival increased with discharge for all routes (fig. 31), but fish that used Georgiana Slough or the DCC had lower survival than fish that used either the Sacramento River or Sutter and Steamboat Sloughs. Detailed graphs for each water year are available in online appendixes and indicate similar seasonal patterns as for WYs 1979 and 1990 (appendixes 1-10).

Summaries of the 82-year simulation indicated consistent seasonal patterns between scenarios, showing seasonal differences in operation of the NDD as governed by the bypass rules. The simulations indicated a greater than or equal to $(\geq) 0.70$ median probability that survival for the PA scenario was less than the NAA scenario (fig. 32, top graph). Thus, in one-half of the simulation years, there was a high probability that survival for the PA scenario was lower than for the NAA scenario.

Furthermore, the 25 th percentile of this probability was $\geq 0.50$, indicating a greater than $50 \%$ chance of lower survival for the PA scenario in $75 \%$ of simulation years. During October-November, the median probability was near 1 and the 25th percentile ranged from 0.6 to 0.9 , indicating a high likelihood that survival under the PA scenario was lower than under the NAA scenario in most simulation years. During December-April, there was a greater than $70 \%$ probability of a survival difference in $75 \%$ of simulations, whereas during April-June, there was a greater than 50\% probability of a survival difference in $75 \%$ of years (fig. 32, top graph). Distributions of survival differences for the L1 scenario (fig. 32, bottom graph) showed a pattern similar to the pattern for the PA scenario (fig. 32, top graph). 
For median travel time, the probability of a difference between scenarios was of a magnitude similar to that of survival, but had a different seasonal pattern (fig. 33, top graph). The simulations indicated a greater than 0.5 probability that median travel time under PA was greater than NAA for $75 \%$ of simulation years. However, during October-November and February-March, there was near a $100 \%$ chance of a difference in median travel times in one-half of the simulation years. During other times of year, the median probability of a difference in travel time ranged from about 0.7 to 0.9 .

Boxplots of the median difference between scenarios indicated seasonal difference in the magnitude of the difference in survival and travel time. During October-November, the median survival differences between the PA and NAA scenarios ranged from -0.03 to -0.05 . Furthermore, the 25 th percentile ranged from about -0.07 to -0.10 , indicating that survival differences were -0.07 to 0.10 or larger in $25 \%$ of years (fig. 34, top graph). During December-April, the period of strictest bypass rules, the median survival difference was about 2 percentage points and the 25 th percentile ranged from 3 to 5 percentage points, indicating that survival differences exceeded these values in $25 \%$ of years (fig. 34). Survival differences between the L1 and NAA scenarios showed a seasonal pattern to that of the PA scenario (fig. 34, middle graph). Differences between L1 and PA scenarios showed that the median difference was about 0 , but positive differences exceeded negative differences (fig. 34, bottom graph). This finding indicates that survival was similar between scenarios in most years, but in some years the L1 scenario provided higher survival than the PA scenario. Seasonal patterns in travel time differences between scenarios were the opposite of parallel seasonal patterns in survival (fig. 35).

Differences between the below-normal WY 1979 and the critically dry WY 1990 (figs. 22-31) emerged as a consistent pattern among water year types (figs. 36 and 37). Survival differences between PA and NAA were highest in wet and above-normal water years, lower in below-normal and dry years, and lowest in critically dry years (fig. 36). In critically dry years, the median difference was 0 , although the 25 th percentile ranged from about -0.02 to -0.10 in October-November. Travel time differences had a pattern that was the opposite of survival differences (fig. 37). 

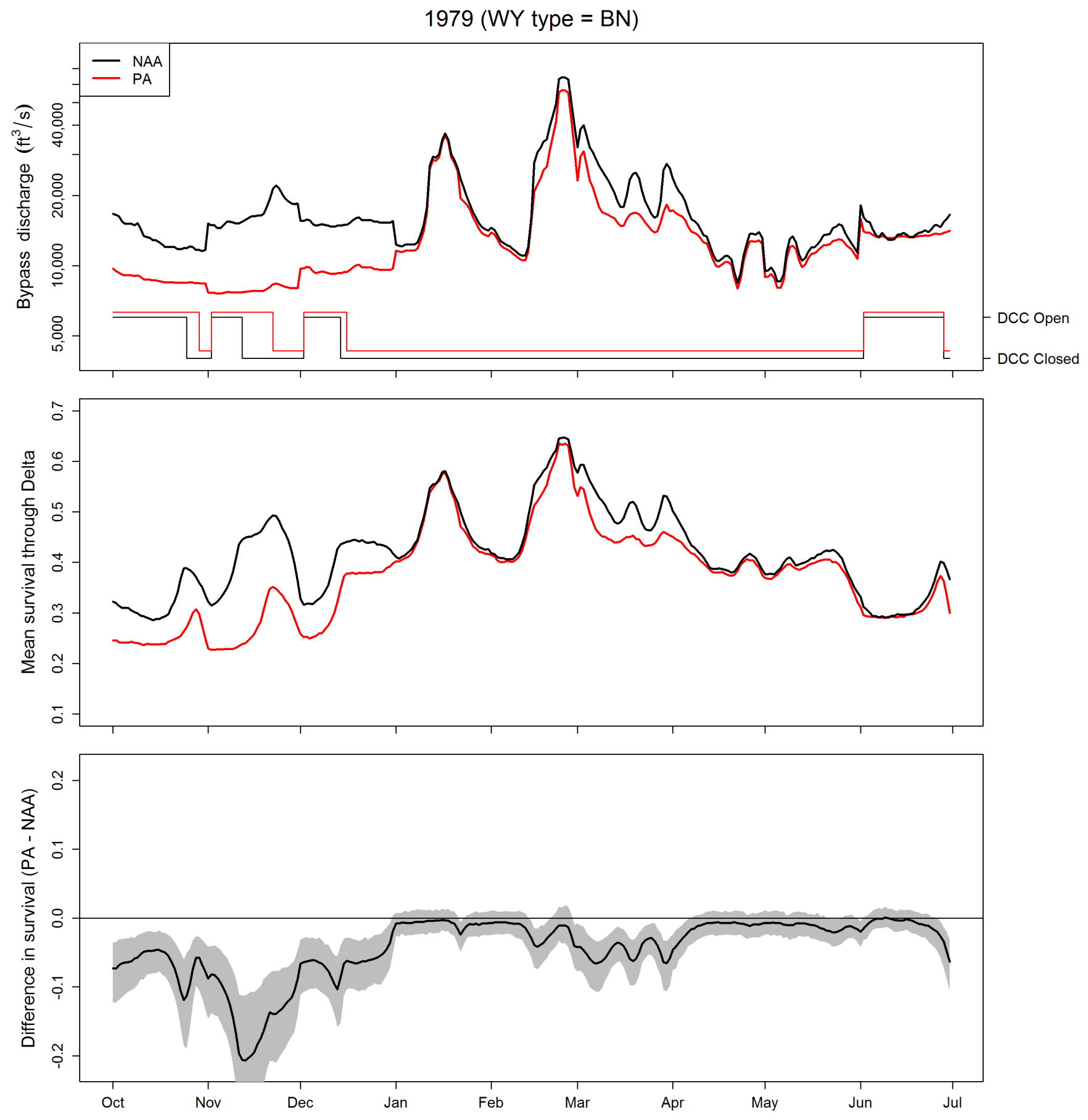

Figure 22. Graphs showing simulated daily bypass flows and Delta Cross Channel (DCC) gate operations for water year 1979 (top graph), median of simulated mean daily survival through the Sacramento-San Joaquin River Delta, northern California (middle graph), and the difference in survival between the Proposed Action (PA) and No Action Alternative (NAA) scenarios (bottom graph). Heavy lines in the top graph show bypass discharge on the primary $y$-axis, and thin lines show DCC operation of open or closed on the second y-axis. In the bottom graph, the gray shaded region shows the $90 \%$ credible interval on the difference in survival between scenarios.

Discharge in the top graph is shown on a logarithmic scale to highlight variation in discharge when discharge is low. BN, Below Normal; WY, water year; $\mathrm{ft}^{3} / \mathrm{s}$, cubic foot per second; -, minus. 
$1979($ WY type $=$ BN)
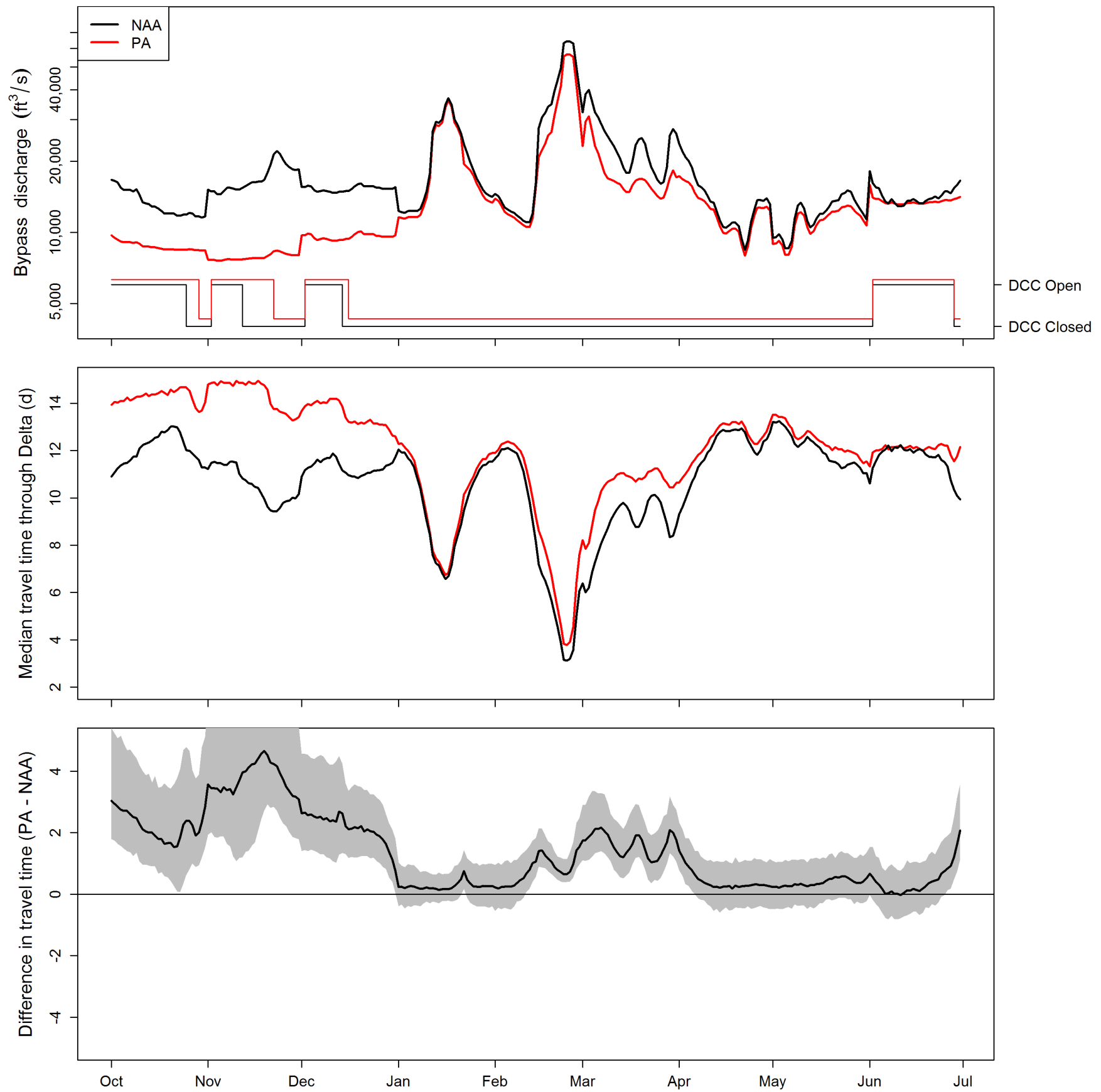

Figure 23. Graphs showing simulated daily bypass flows and Delta Cross Channel (DCC) gate operations for water year 1979 (top graph), simulated median daily travel time of juvenile Chinook salmon through the Sacramento-San Joaquin River Delta, northern California (middle graph), and the difference in travel time between the Proposed Action (PA) and No Action Alternative (NAA) scenarios (bottom graph). Heavy lines in the top graph show bypass discharge on the primary y-axis, and thin lines show DCC operation of open or closed on the second y-axis. In the bottom graph, the gray shaded region shows the $90 \%$ credible interval on the difference in median travel time between scenarios. Discharge in the top graph is shown on a logarithmic scale to highlight variation in discharge when discharge is low. BN, Below Normal; d, days; WY, water year; $\mathrm{ft}^{3} / \mathrm{s}$, cubic foot per second; -, minus. 

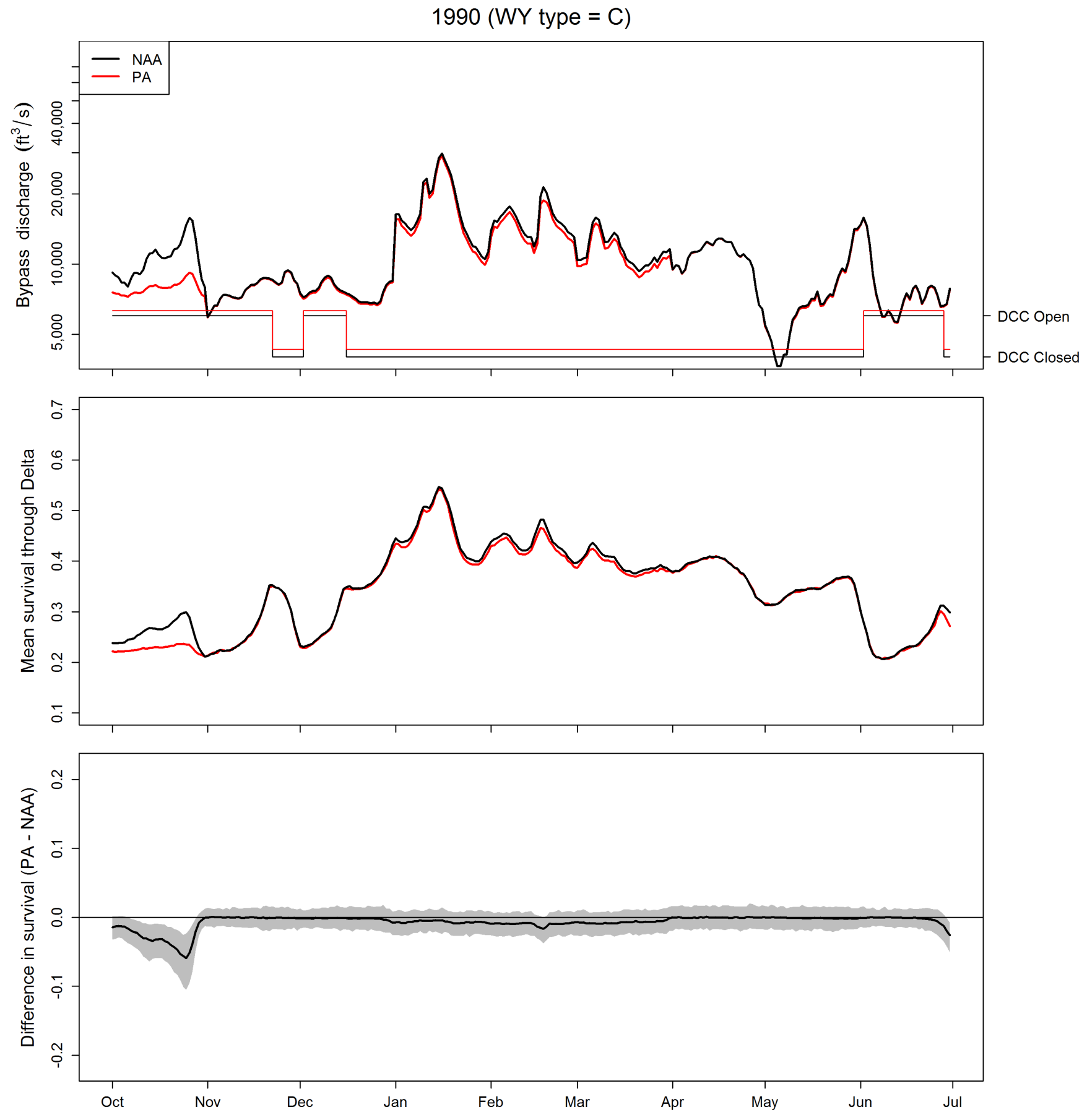

Figure 24. Graphs showing simulated daily bypass flows and Delta Cross Channel (DCC) gate operations for water year 1990 (top graph), median of simulated mean daily survival through the Sacramento-San Joaquin River Delta, northern California (middle graph), and the difference in survival between the Proposed Action (PA) and No Action Alternative (NAA) scenarios (bottom graph). Heavy lines in the top graph show bypass discharge on the primary y-axis, and thin lines show DCC operation of open or closed on the second y-axis. In the bottom graph, the gray shaded region shows the $90 \%$ credible interval on the difference in survival between scenarios.

Discharge in the top graph is shown on a logarithmic scale to highlight variation in discharge when discharge is low. C, Critical; WY, water year; $\mathrm{ft}^{\mathrm{t}} / \mathrm{s}$, cubic foot per second; -, minus. 

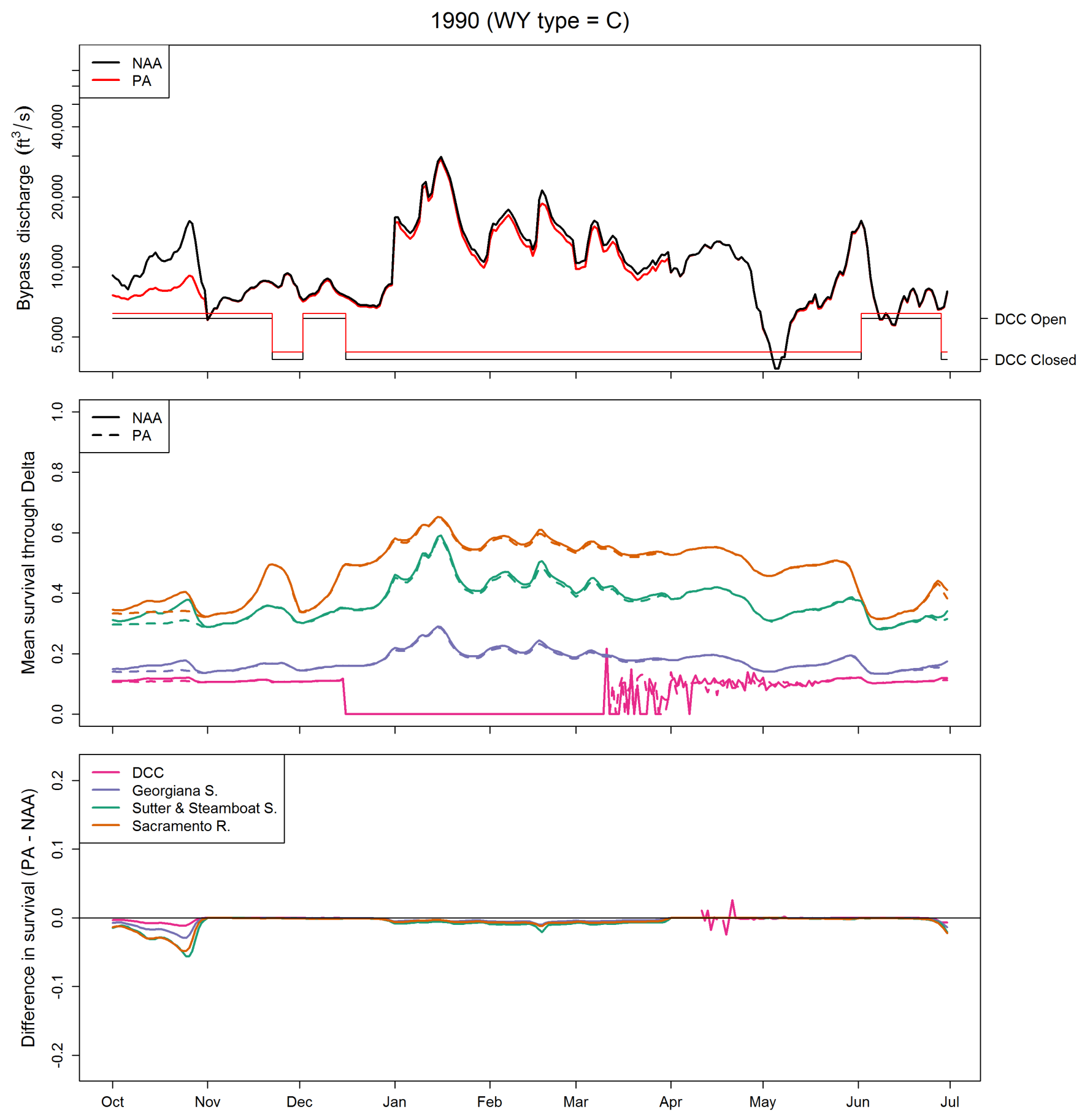

Figure 25. Graphs showing simulated daily bypass flows and Delta Cross Channel (DCC) gate operations for water year 1990 (top graph), median of simulated mean route-specific survival through the Sacramento-San Joaquin River Delta, northern California (middle graph), and the difference in route-specific survival between the Proposed Action (PA) and No Action Alternative (NAA) scenarios (bottom graph). Heavy lines in the top graph show bypass discharge on the primary y-axis, and thin lines show DCC operation of open or closed on the second $y$-axis. Discharge in the top panel is shown on a logarithmic scale to highlight variation in discharge when discharge is low. C, Critical; WY, water year; $\mathrm{ft} / \mathrm{s}$, cubic foot per second; -, minus. 


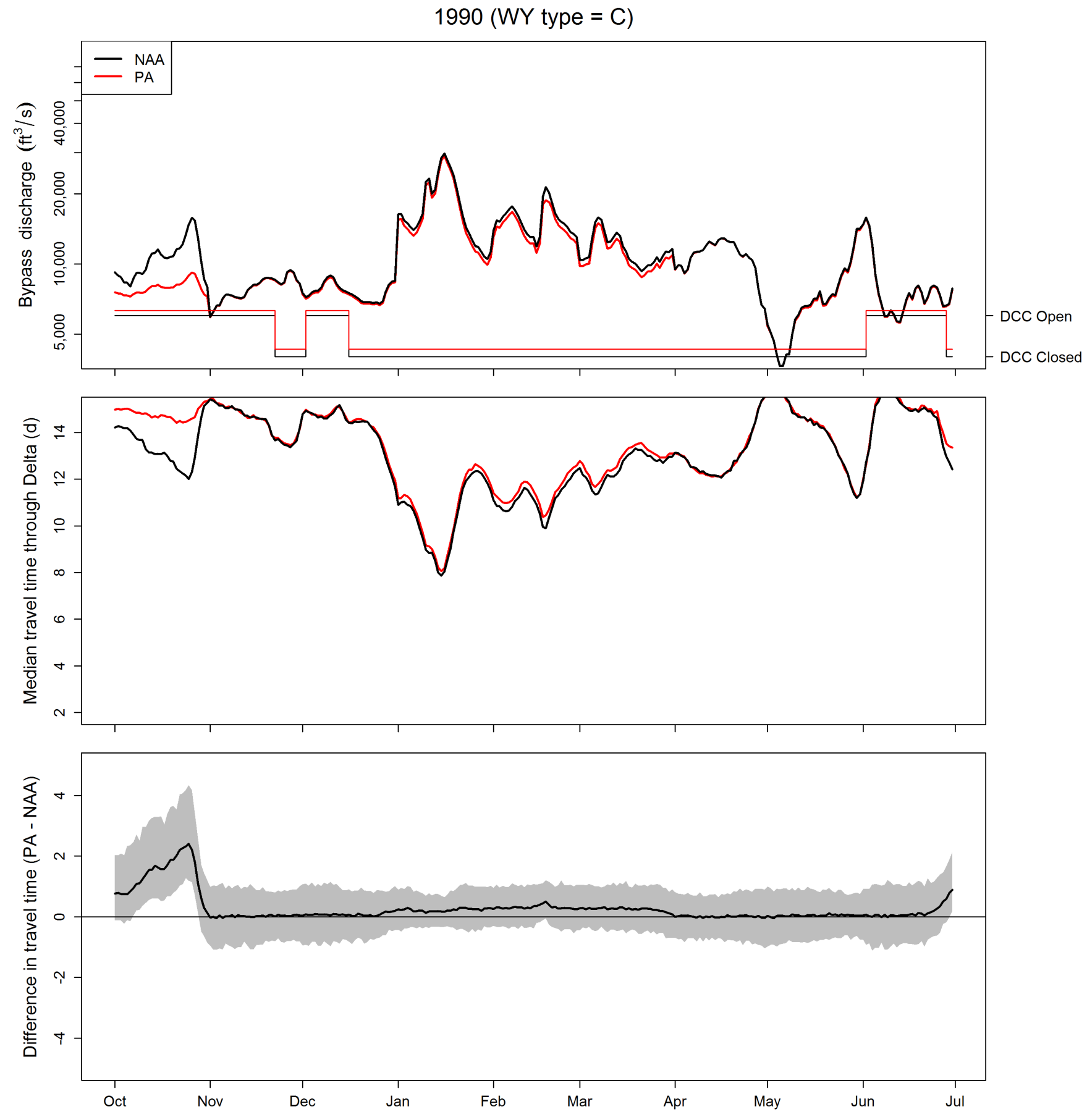

Figure 26. Graphs showing simulated daily bypass flows and Delta Cross Channel (DCC) gate operations for water year 1990 (top graph), simulated median daily travel time through the Sacramento-San Joaquin River Delta, northern California (middle graph), and the difference in travel time of juvenile Chinook salmon between the Proposed Action (PA) and No Action Alternative (NAA) scenarios (bottom graph). Heavy lines in the top graph show bypass discharge on the primary y-axis, and thin lines show DCC operation of open or closed on the second y-axis. In the bottom graph, the gray shaded region shows the $90 \%$ credible interval on the difference in median travel time between scenarios. Discharge in the top graph is shown on a logarithmic scale to highlight variation in discharge when discharge is low. C, Critical; d, days; WY, water year; $\mathrm{ft}^{3} / \mathrm{s}$, cubic foot per second; -, minus. 

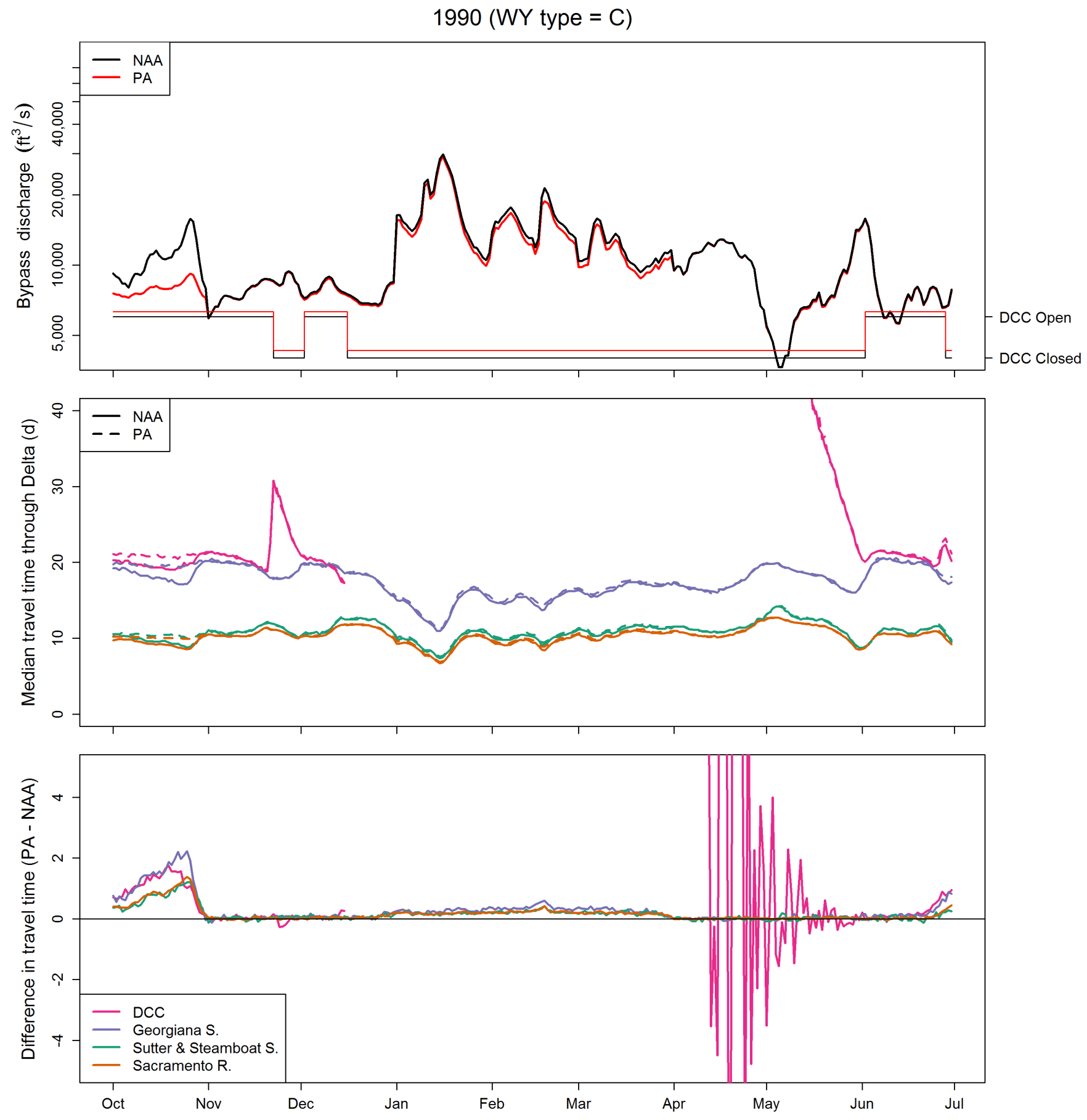

Figure 27. Graphs showing simulated daily bypass flows and Delta Cross Channel (DCC) gate operations for water year 1990 (top graph), simulated median route-specific travel time of juvenile Chinook salmon through the Sacramento-San Joaquin River Delta, northern California (middle graph), and the difference in route-specific travel time between the Proposed Action (PA) and No Action Alternative (NAA) scenarios (bottom graph). Heavy lines in the top graph show bypass discharge on the primary y-axis, and thin lines show DCC operation of open or closed on the second $y$-axis. Discharge in the top panel is shown on a logarithmic scale to highlight variation in discharge when discharge is low. C, Critical; WY, water year; $\mathrm{ft}^{3} / \mathrm{s}$, cubic foot per second; -, minus. 

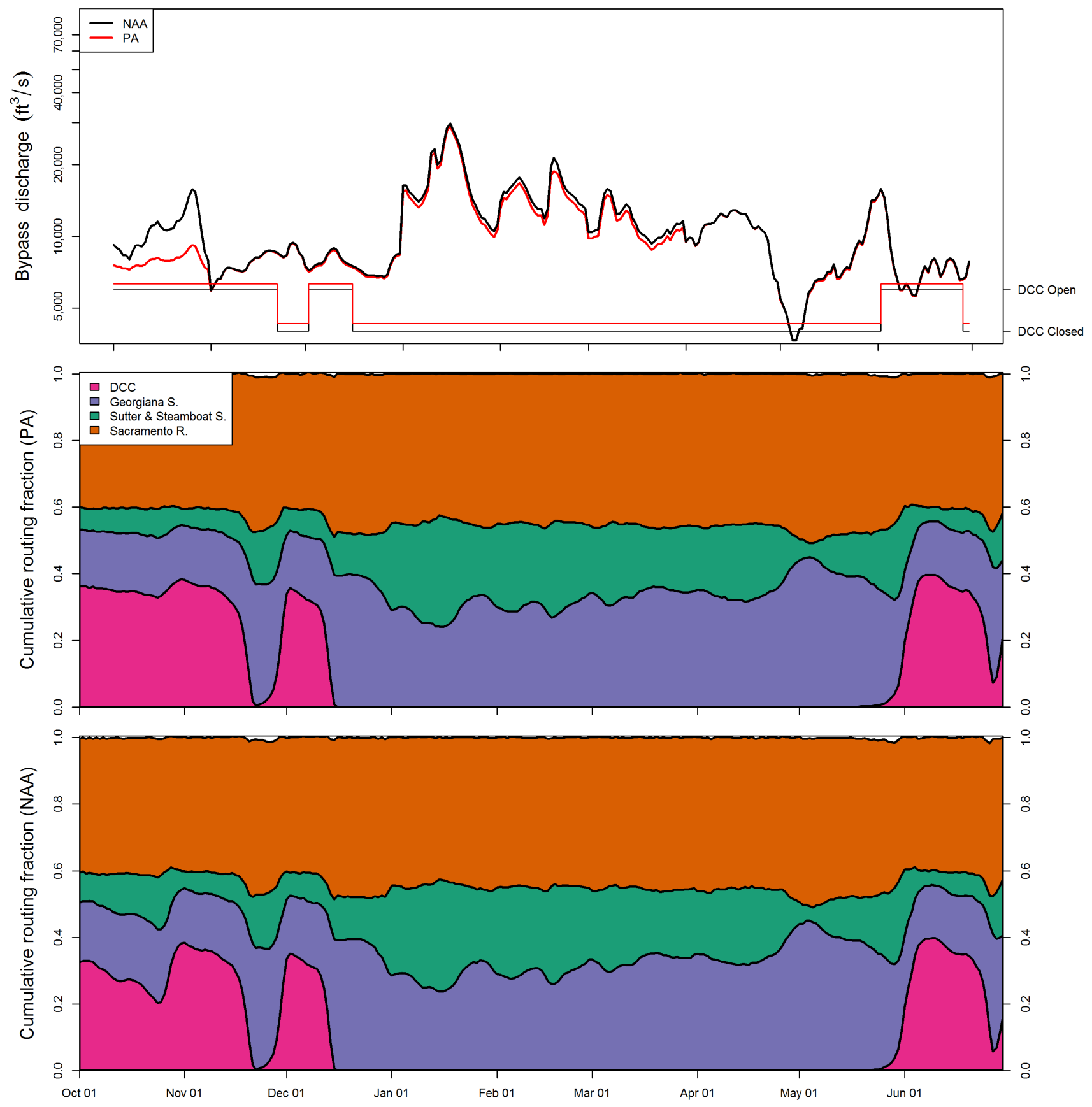

Figure 28. Graphs showing simulated daily bypass flows and Delta Cross Channel (DCC) gate operations for water year 1990 (top graph), and stacked line plots showing the daily cumulative migration route probabilities for the Proposed Action (PA, middle graph) and No Action Alternative (NAA, bottom graph) scenarios, SacramentoSan Joaquin River Delta, northern California. Heavy lines in the top graph show bypass discharge on the primary $y$-axis, and thin lines show DCC operation of open or closed on the second y-axis. Discharge in the top graph is shown on a logarithmic scale to highlight variation in discharge when discharge is low. C, Critical; WY, water year; $\mathrm{ft} 3 / \mathrm{s}$, cubic foot per second. 
$1979(\mathrm{WY}$ type $=\mathrm{BN})$
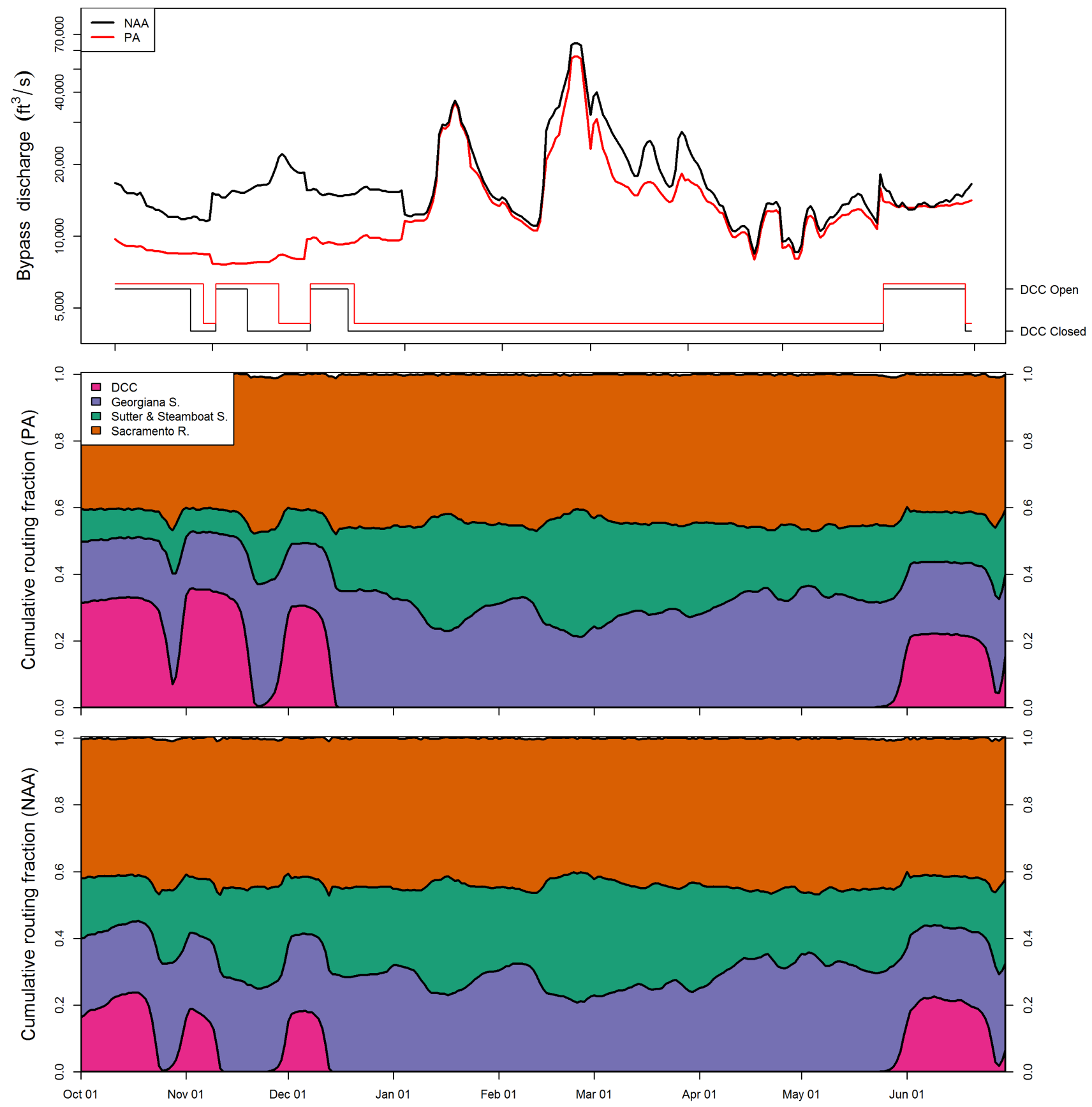

Figure 29. Graphs showing simulated daily bypass flows and Delta Cross Channel (DCC) gate operations for water year 1979 (top graph), and stacked line plots showing the daily cumulative migration route probabilities for the Proposed Action (PA, middle graph) and No Action Alternative (NAA, bottom graph) scenarios, SacramentoSan Joaquin River Delta, northern California. Heavy lines in the top graph show bypass discharge on the primary $y$-axis, and thin lines show DCC operation of open or closed on the second y-axis. Discharge in the top graph is shown on a logarithmic scale to highlight variation in discharge when discharge is low. BN, Below Normal; WY, water year; $\mathrm{ft} 3 / \mathrm{s}$, cubic foot per second. 

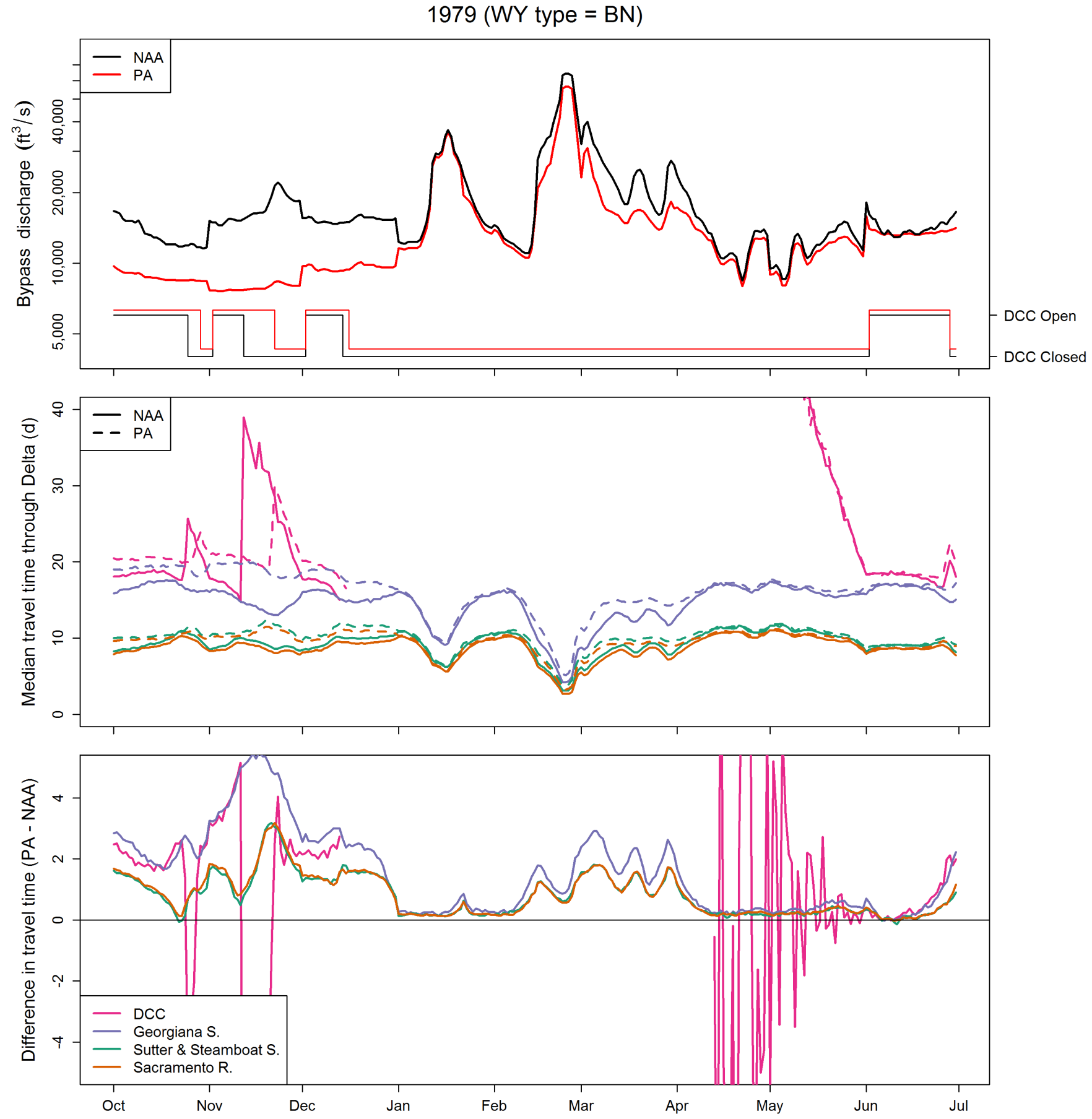

Figure 30. Graphs showing simulated daily bypass flows and Delta Cross Channel (DCC) gate operations for water year 1979 (top graph), simulated median route-specific travel time of juvenile Chinook salmon through the Sacramento-San Joaquin River Delta, northern California (middle graph), and the difference in route-specific travel time between the Proposed Action (PA) and No Action Alternative (NAA) scenarios (bottom graph). Heavy lines in the top graph show bypass discharge on the primary $y$-axis, and thin lines show DCC operation of open or closed on the second $y$-axis. Discharge in the top graph is shown on a logarithmic scale to highlight variation in discharge when discharge is low. BN, Below Normal; WY, water year; ft3/s, cubic foot per second; -, minus. 

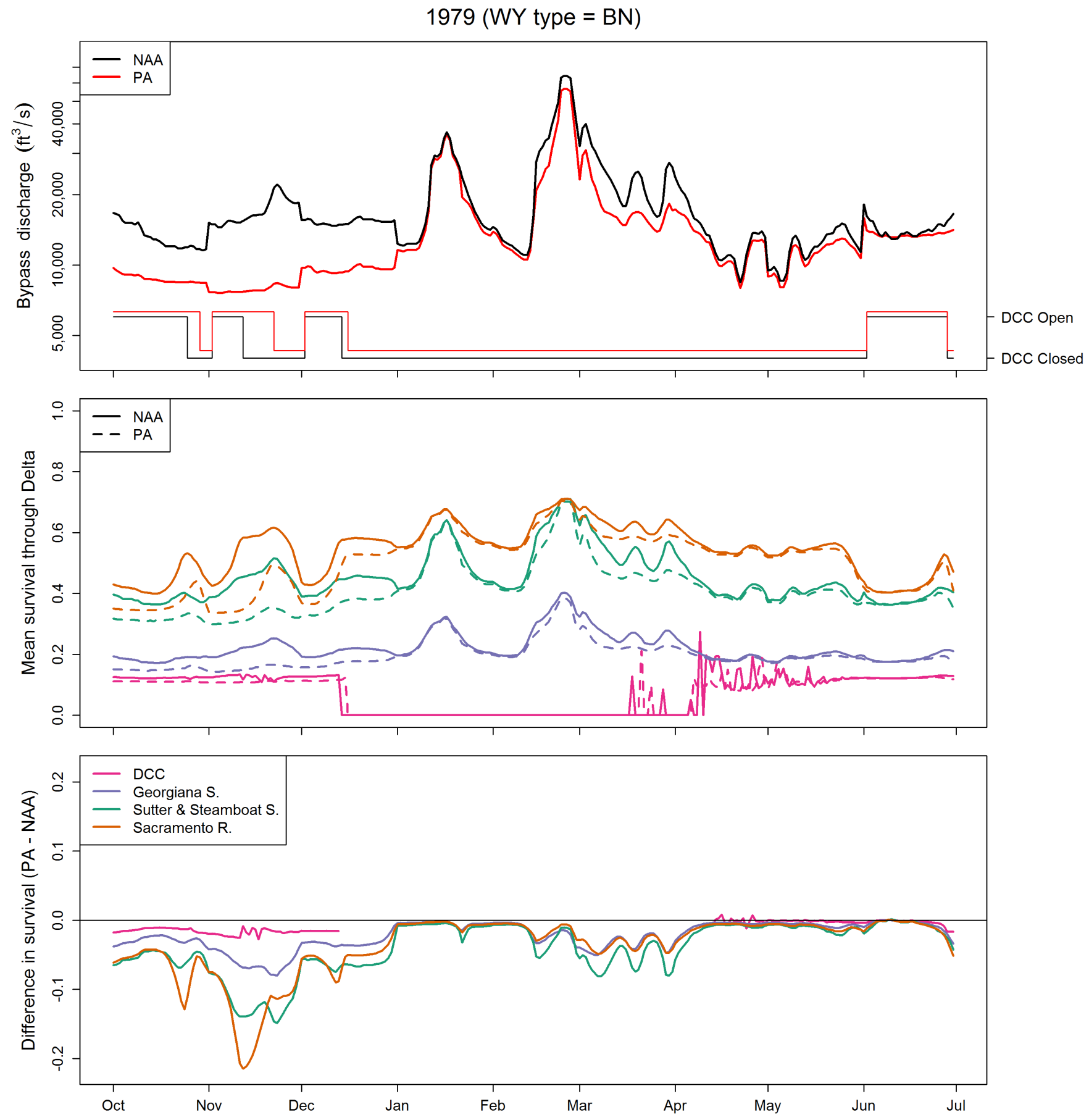

Figure 31. Graphs showing simulated daily bypass flows and Delta Cross Channel (DCC) gate operations for water year 1979 (top graph), median of simulated mean route-specific survival through the Sacramento-San Joaquin River Delta, northern California (middle graph), and the difference in route-specific survival between the Proposed Action (PA) and No Action Alternative (NAA) scenarios (bottom graph). Heavy lines in the top graph show bypass discharge on the primary y-axis, and thin lines show DCC operation of open or closed on the second $y$-axis. Discharge in the top graph is shown on a logarithmic scale to highlight variation in discharge when discharge is low. BN, Below Normal; WY, water year; $\mathrm{ft}^{3} / \mathrm{s}$, cubic foot per second; -, minus. 

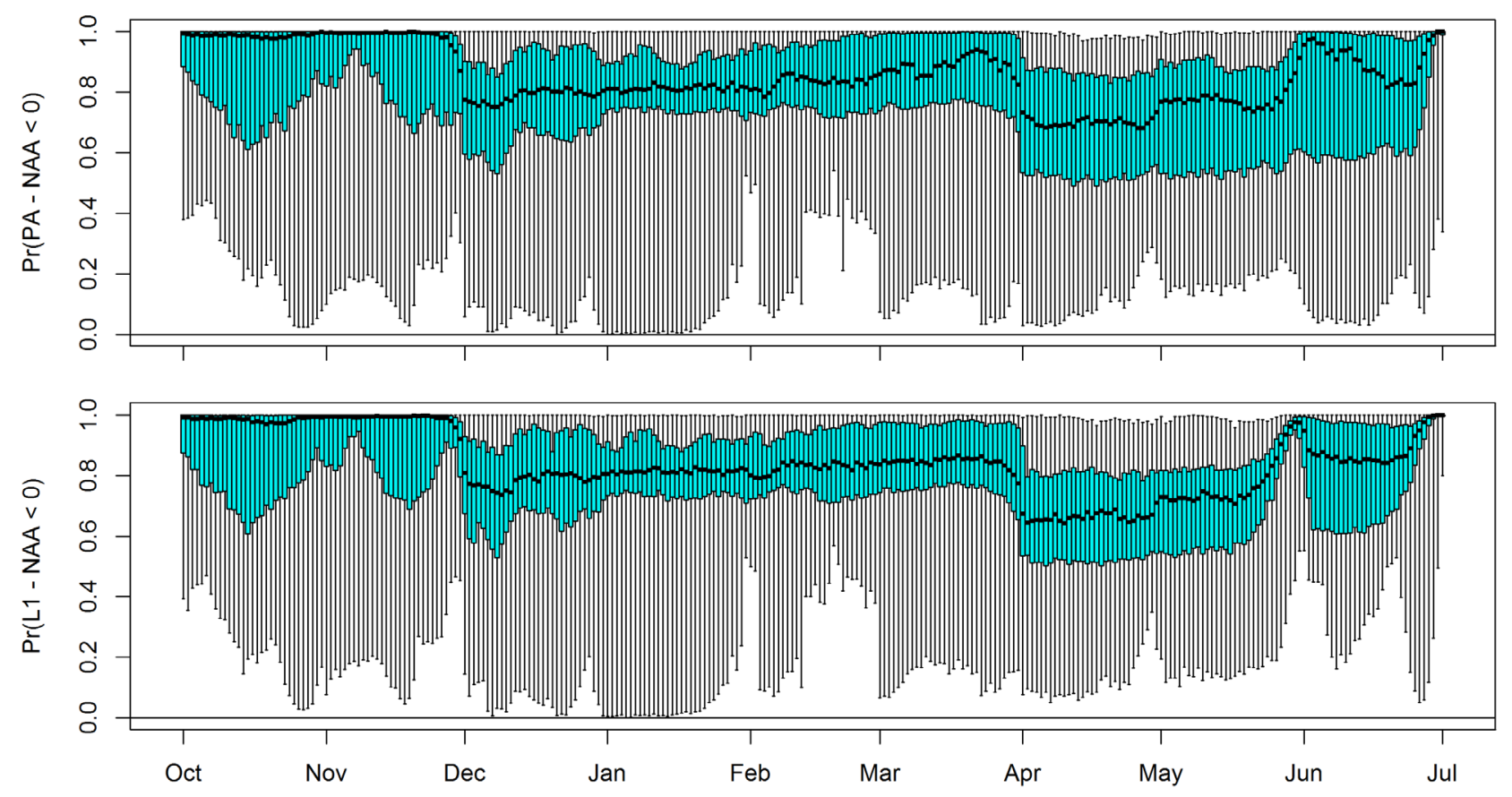

Figure 32. Daily boxplots showing the distribution of the probability that through-Sacramento-San Joaquin River Delta survival for either the Level 1 (L1) or Proposed Action (PA) scenarios is less than survival for the No Action Alternative (NAA) scenario, in northern California. Each boxplot represents the distribution of median survival differences among years for a given date. The point in each box represents the median, the box hinges represent the 25th and 75th percentiles, and the whiskers indicate the minimum and maximum. Pr, probability; <, less than; - , minus. 

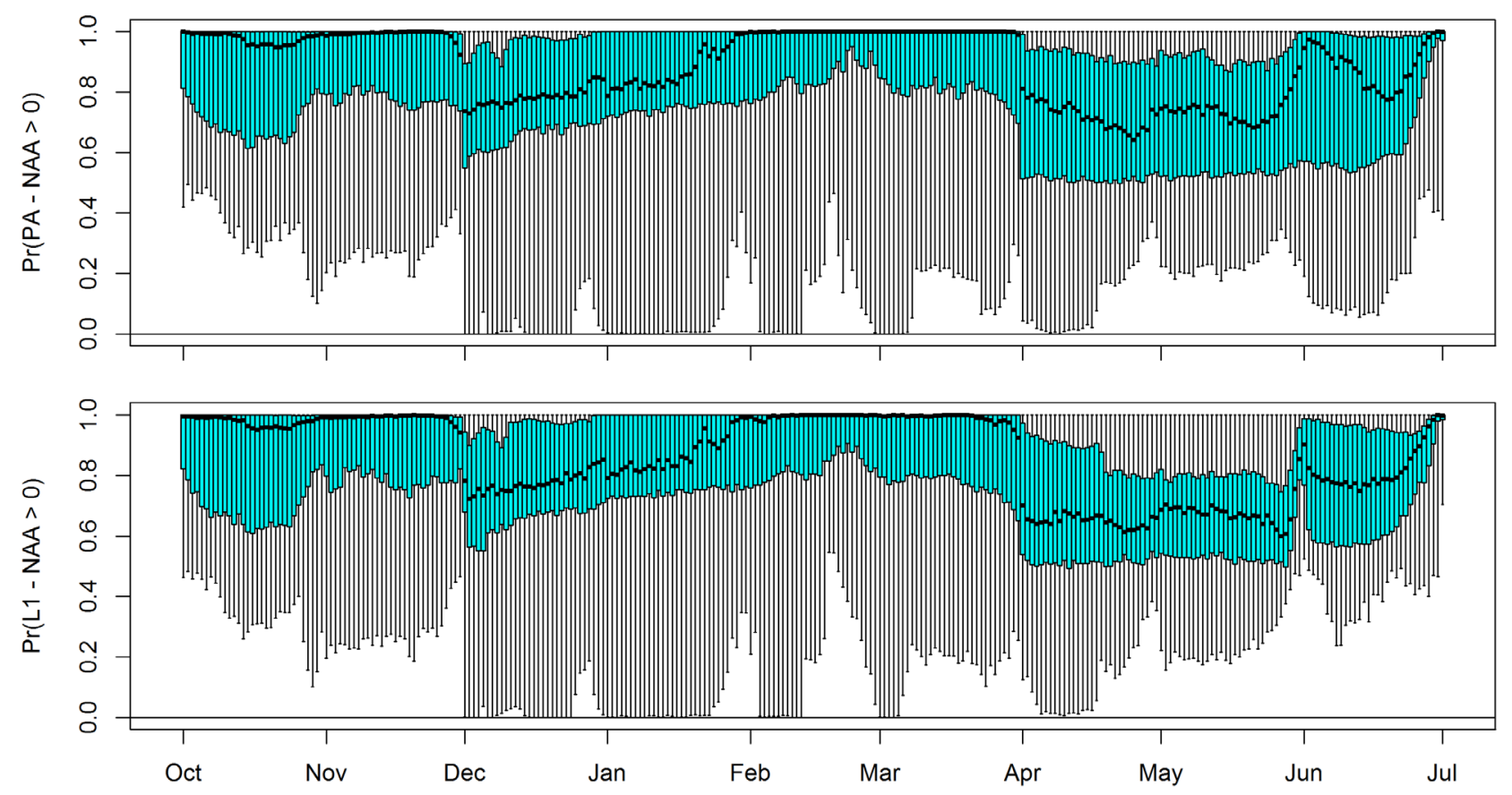

Figure 33. Daily boxplots showing the distribution of the probability that the difference in median travel time of juvenile Chinook salmon through the Sacramento-San Joaquin River Delta between the No Action Alternative (NAA) and either the Level 1 (L1) or Proposed Action (PA) scenarios is greater than 0 , in northern California. Each boxplot represents the distribution of median survival differences among years for a given date. The point in each box represents the median, the box hinges represent the 25th and 75th percentiles, and the whiskers indicate the minimum and maximum. Pr, probability; >, greater than; -, minus. 

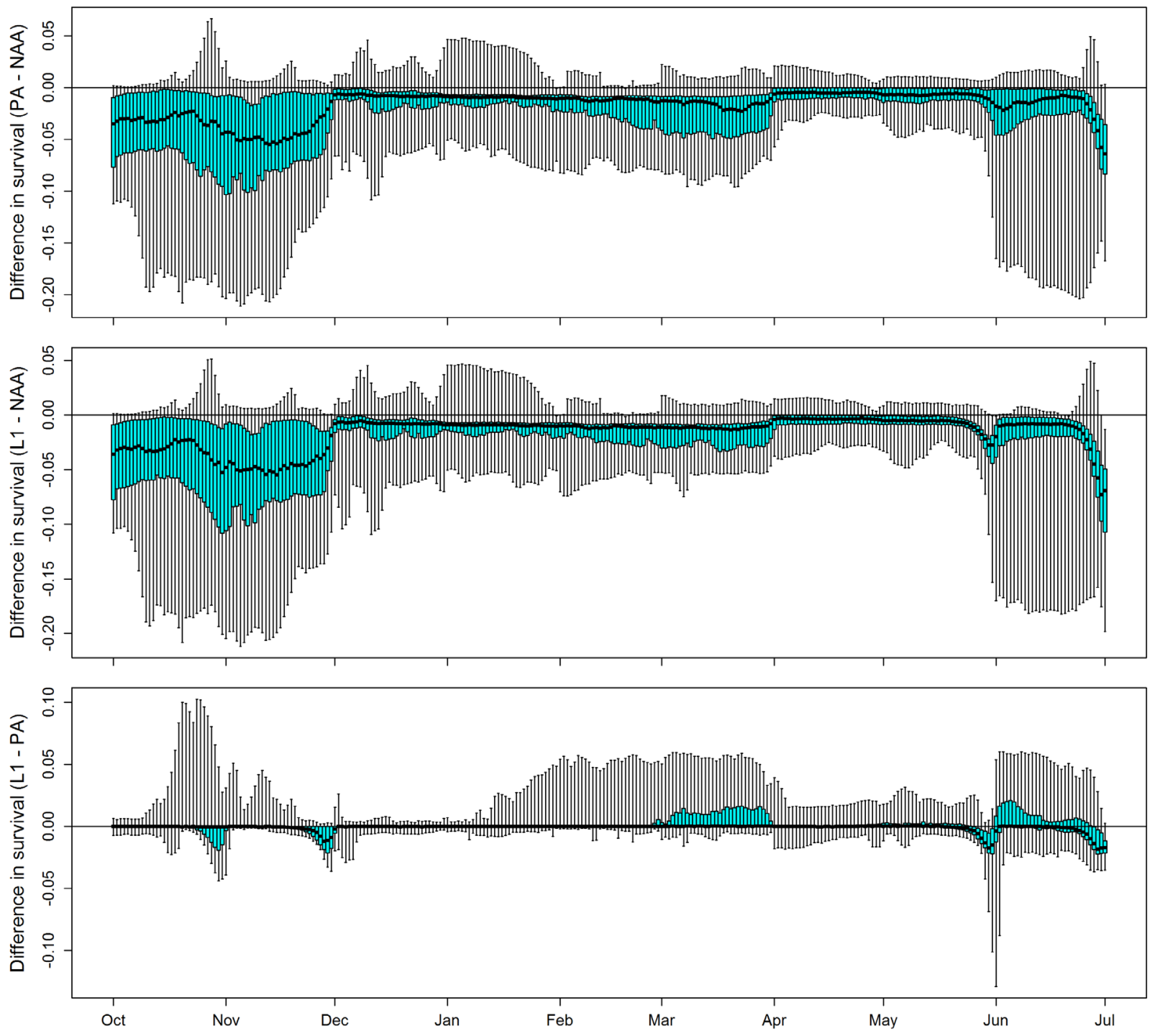

Figure 34. Daily boxplots showing daily median differences in through-Sacramento-San Joaquin River Delta survival between the No Action Alternative (NAA), Proposed Action (PA), and Level 1 (L1) scenarios, in northern California. Each boxplot represents the distribution of median survival differences among years for a given date. The point in each box represents the median, the box hinges represent the 25th and 75th percentiles, and the whiskers indicate the minimum and maximum. -, minus. 

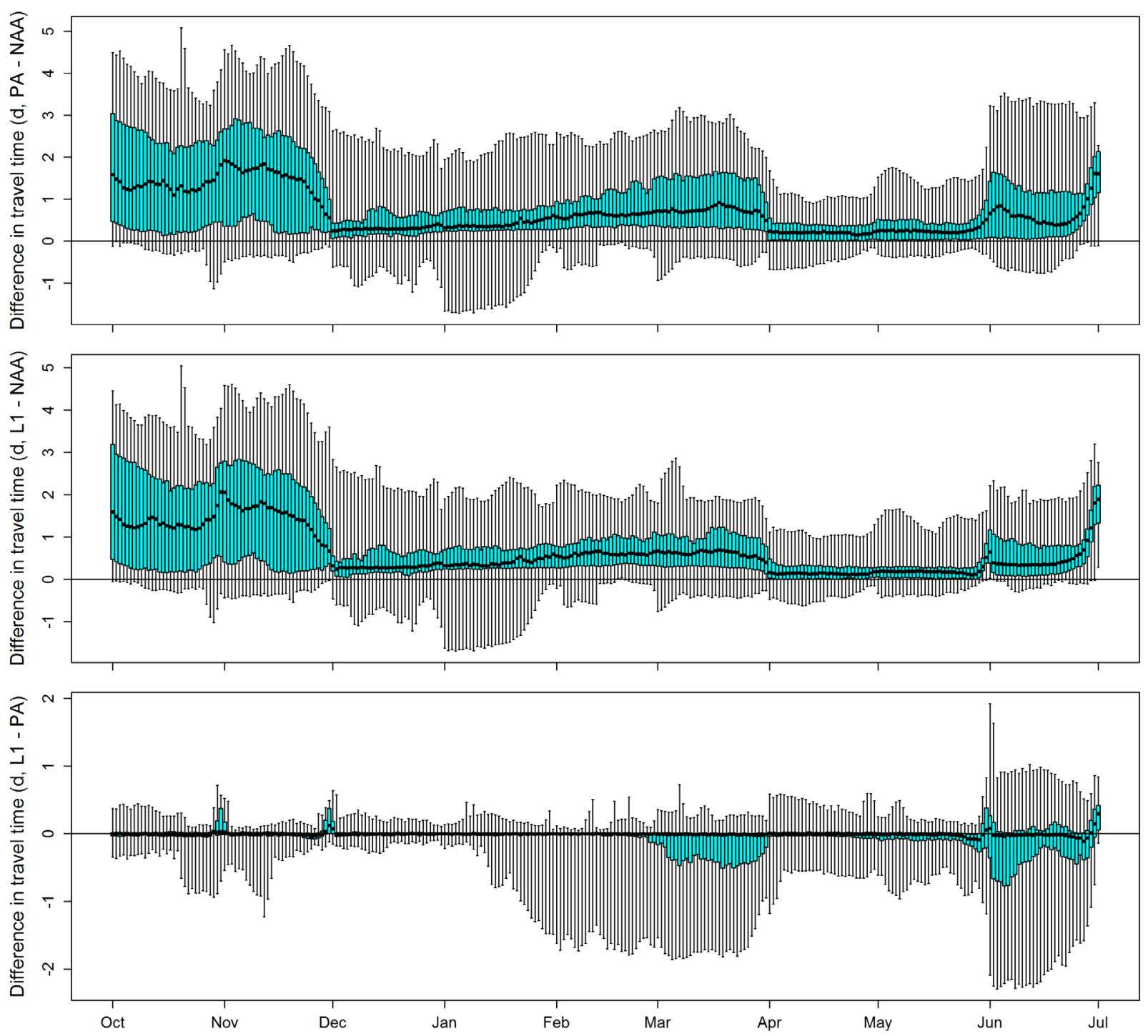

Figure 35. Daily boxplots showing median differences in median travel time of juvenile Chinook salmon between the No Action Alternative (NAA), Proposed Action (PA), and Level 1 (L1) scenarios, in the Sacramento-San Joaquin River Delta, northern California. Each boxplot represents the distribution of median travel time differences among years for a given date. The point in each box represents the median, the box hinges represent the 25th and 75 th percentile, and the whiskers indicate the minimum and maximum. $d$, days; -, minus. 

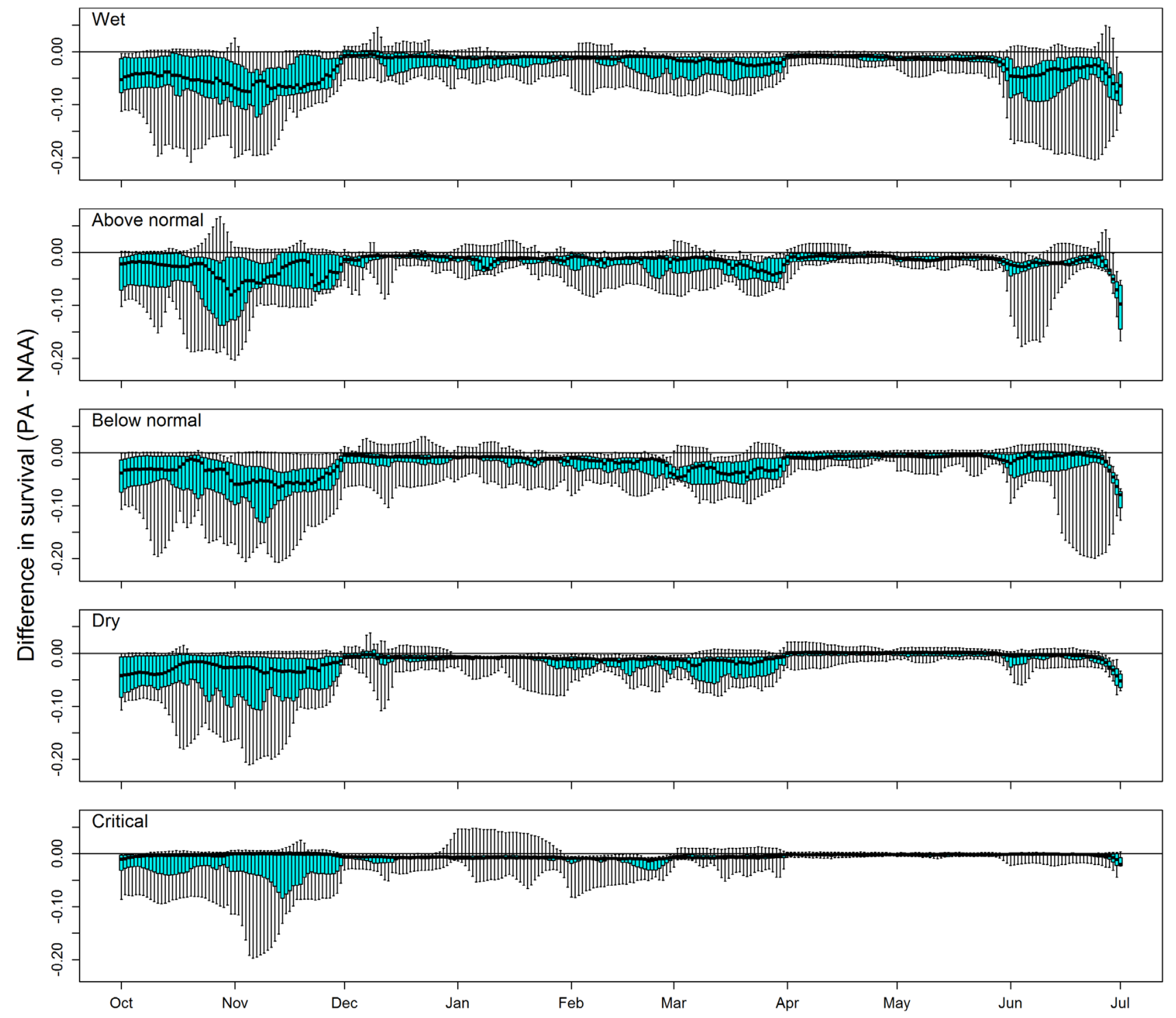

Figure 36. Daily boxplots showing median differences in median through-Sacramento-San Joaquin River Delta survival between the Proposed Action (PA) and No Action Alternative (NAA) scenarios by water year type, in northern California. Each boxplot represents the distribution of median survival differences among years for a given date. The point in each box represents the median, the box hinges represent the 25th and 75th percentile, and the whiskers indicate the minimum and maximum. -, minus. 

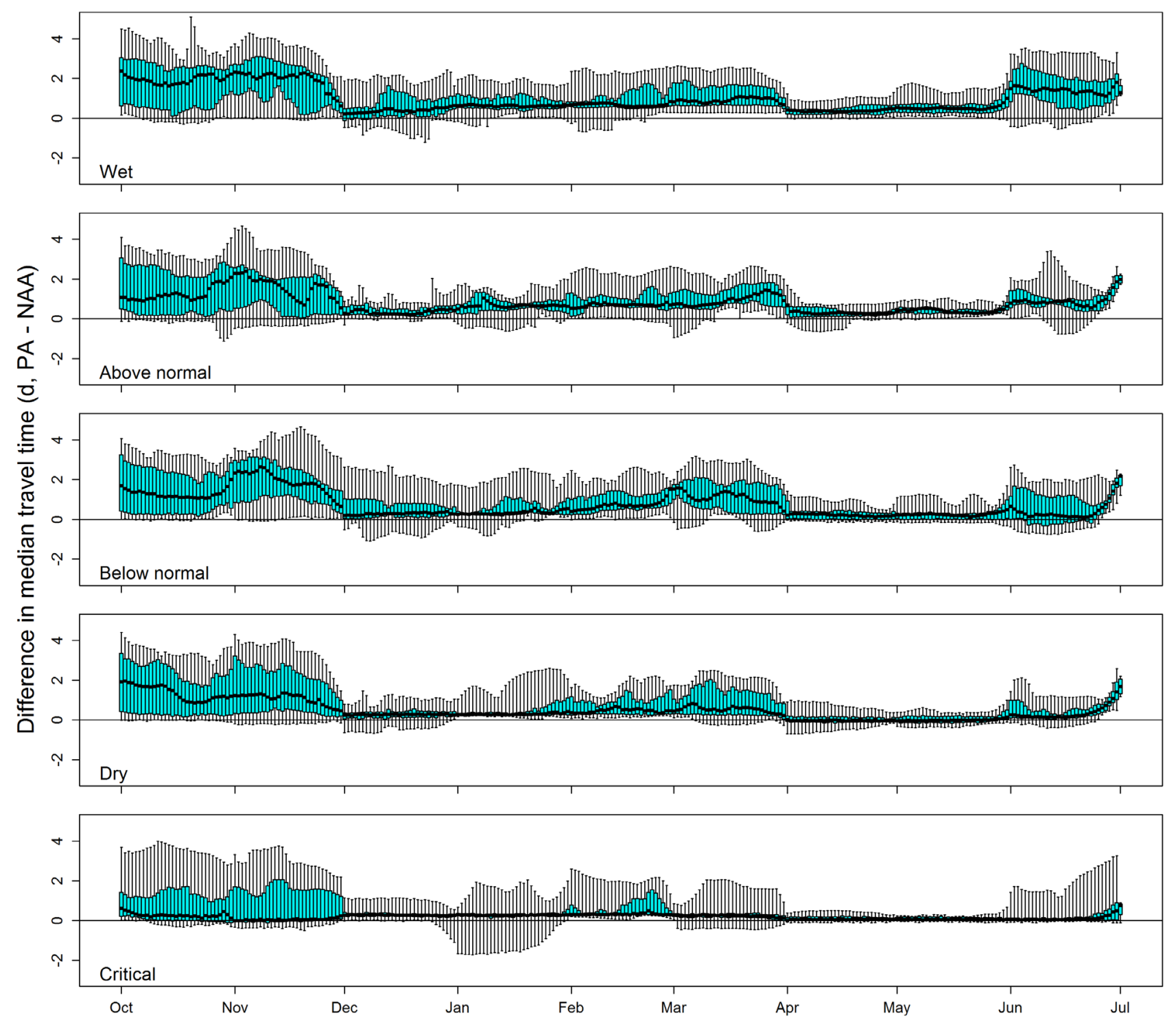

Figure 37. Daily boxplots showing median differences in median travel time of juvenile Chinook salmon between the Proposed Action (PA) and No Action Alternative (NAA) scenarios by water year type, in the Sacramento-San Joaquin River Delta, northern California. Each box plot represents the distribution of median travel time differences among years for a given date. The point in each box represents the median, the box hinges represent the 25th and 75th percentile, and the whiskers indicate the minimum and maximum. $d$, days; -, minus. 


\section{Using Survival Criteria for Shaping Rule Curves}

For all scenarios, the rule curves based on survival criterion generally result in NDD flows that (1) increase more slowly with Freeport discharge relative to the L1 curve, (2) are higher than the L1 curve at low flows (less than about $20,000 \mathrm{ft}^{3} / \mathrm{s}$ ), and (3) are lower than the $\mathrm{L} 1$ curve at Freeport flows greater than about $20,000 \mathrm{ft}^{3} / \mathrm{s}$ (figs. 38-43). Additionally, NDD flows based on rule curves generated using a relative difference (figs. 38-40) increase more steeply than those based on an absolute difference (figs. 41-43). Furthermore, increases in near-field mortality associated with the NDD considerably decrease NDD flows required to maintain a given survival criterion. For example, with near-field mortality of 0.05 , it is impossible to achieve a relative difference of less than $(<) 0.05$ (fig. 40). For a given scenario, our analysis shows how lower NDD flows are required as the allowable survival difference decreases. For example, at river flows of $20,000 \mathrm{ft}^{3} / \mathrm{s}$, diversion of a little more than $4,000 \mathrm{ft}^{3} / \mathrm{s}$ results in a $9 \%$ relative decrease in survival, whereas diversion of a little more than 1,000 $\mathrm{ft}^{3} / \mathrm{s}$ yields a $4 \%$ relative decrease in survival (fig. 40 ).

The posterior distribution of survival differences provides insights into how a particular rule curve affects the expected distribution survival differences (absolute and relative). For example, under the L1, December-April bypass rule curve, median absolute survival differences increase to about 0.05 at $30,000 \mathrm{ft}^{3} / \mathrm{s}$, corresponding to a relative difference of 0.09 (fig. 44). However, the 90th percentile of the posterior distribution indicates that there is a $10 \%$ chance of observing absolute survival differences as large 0.08 , corresponding to a relative difference of about 0.14 (fig. 44 ). In contrast, by using probabilistic criteria to determine diversion rates, survival differences are maintained at less than the given specified value across the range of flows. For example, a criterion that achieves a $90 \%$ probability of a relative difference $<0.06$ maintains survival differences at less than this value, resulting in a lower median relative survival decrease that ranges between 0.03 and 0.04 over a wide range of flows (fig. 45). Similarly, an absolute criterion of $<0.03$ maintains a median difference between 0.01 and 0.02 (fig. 46). The posterior distributions show how selection of an absolute (or relative) criterion results in a variable relative (or fixed) survival difference. For example, given an absolute criterion of $<0.03$, the relative difference in survival decreases as discharge increases (fig. 46). Posterior distributions for each rule curve in figs. 38-43 are provided in online appendixes (appendix 11). 


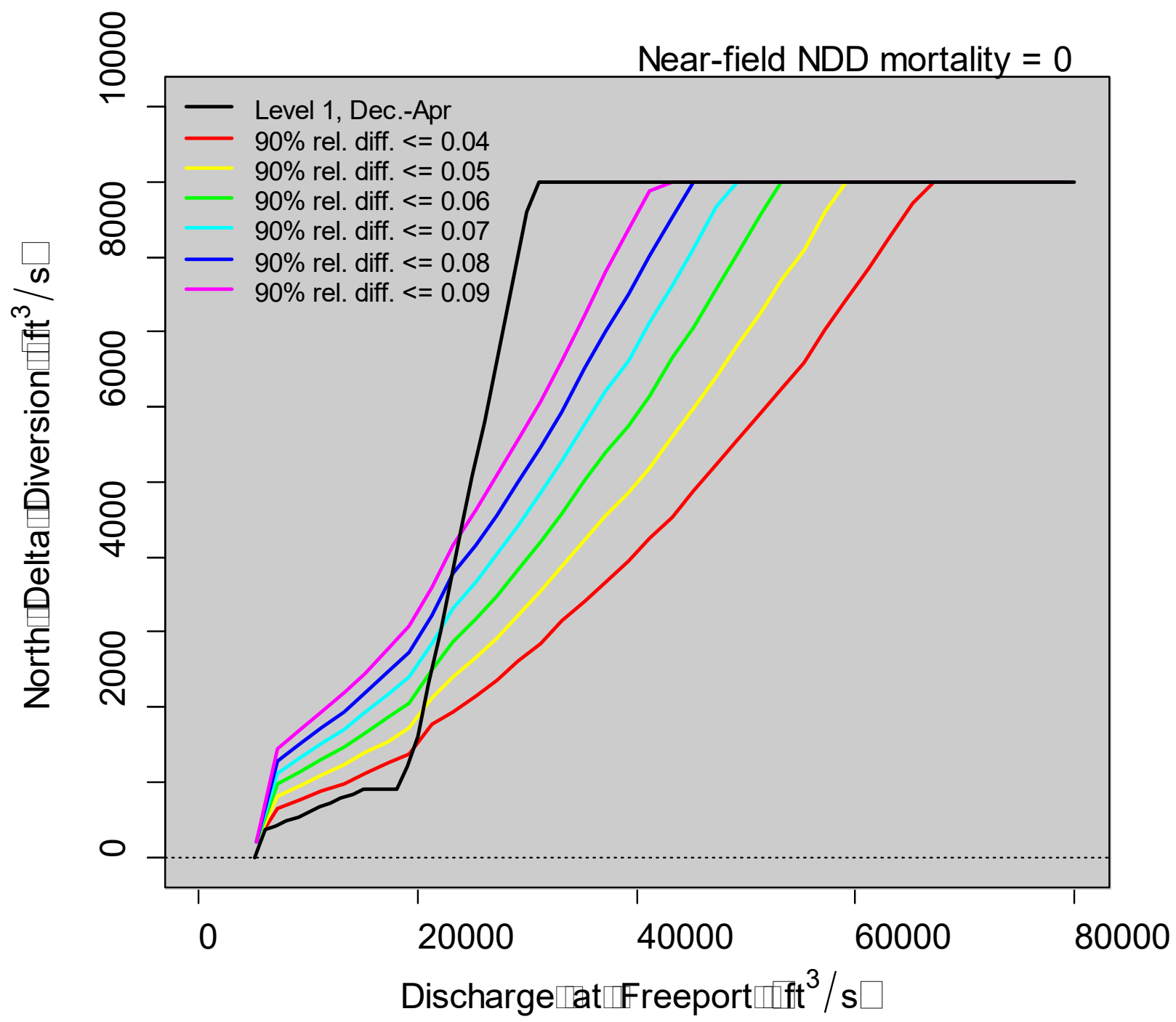

Figure 38. Graph showing North Delta Diversion (NDD) flow rates as a functions of Sacramento River discharge required to achieve a $90 \%$ probability of a given relative decrease in survival assuming 0 near-field mortality, in the Sacramento-San Joaquin River Delta, northern California. $\mathrm{ft}^{3} / \mathrm{s}$, cubic foot per second; =, equals; \% abs. diff $<=$, percent absolute difference less than or equal to. 


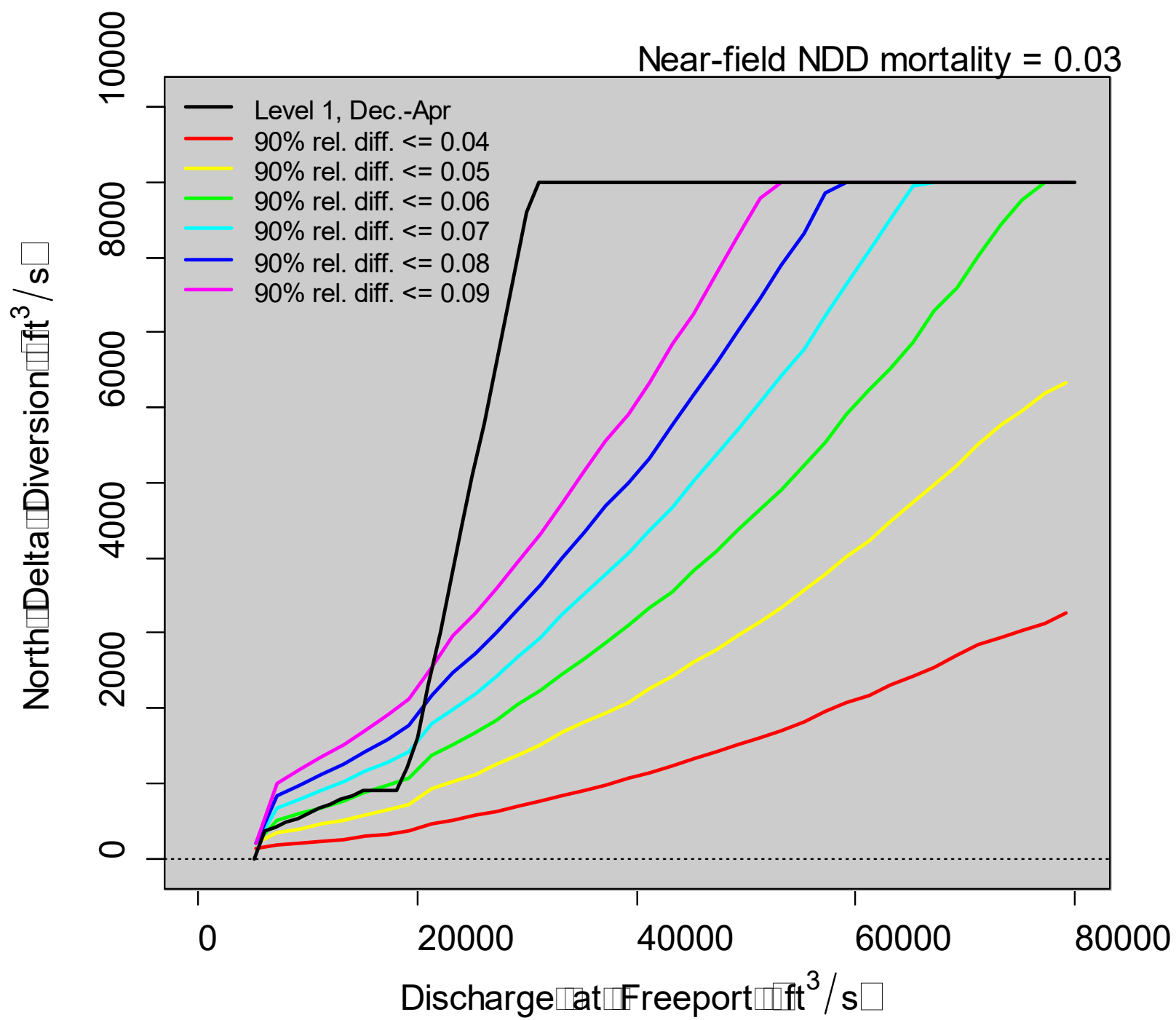

Figure 39. Graph showing North Delta Diversion (NDD) rates as a functions of Sacramento River discharge required to achieve a $90 \%$ probability of a given relative decrease in survival assuming near-field mortality of 0.03 , in the Sacramento-San Joaquin River Delta, northern California. $\mathrm{ft}^{3} / \mathrm{s}$, cubic foot per second; =, equals; \% abs. diff $<=$, percent absolute difference less than or equal to. 


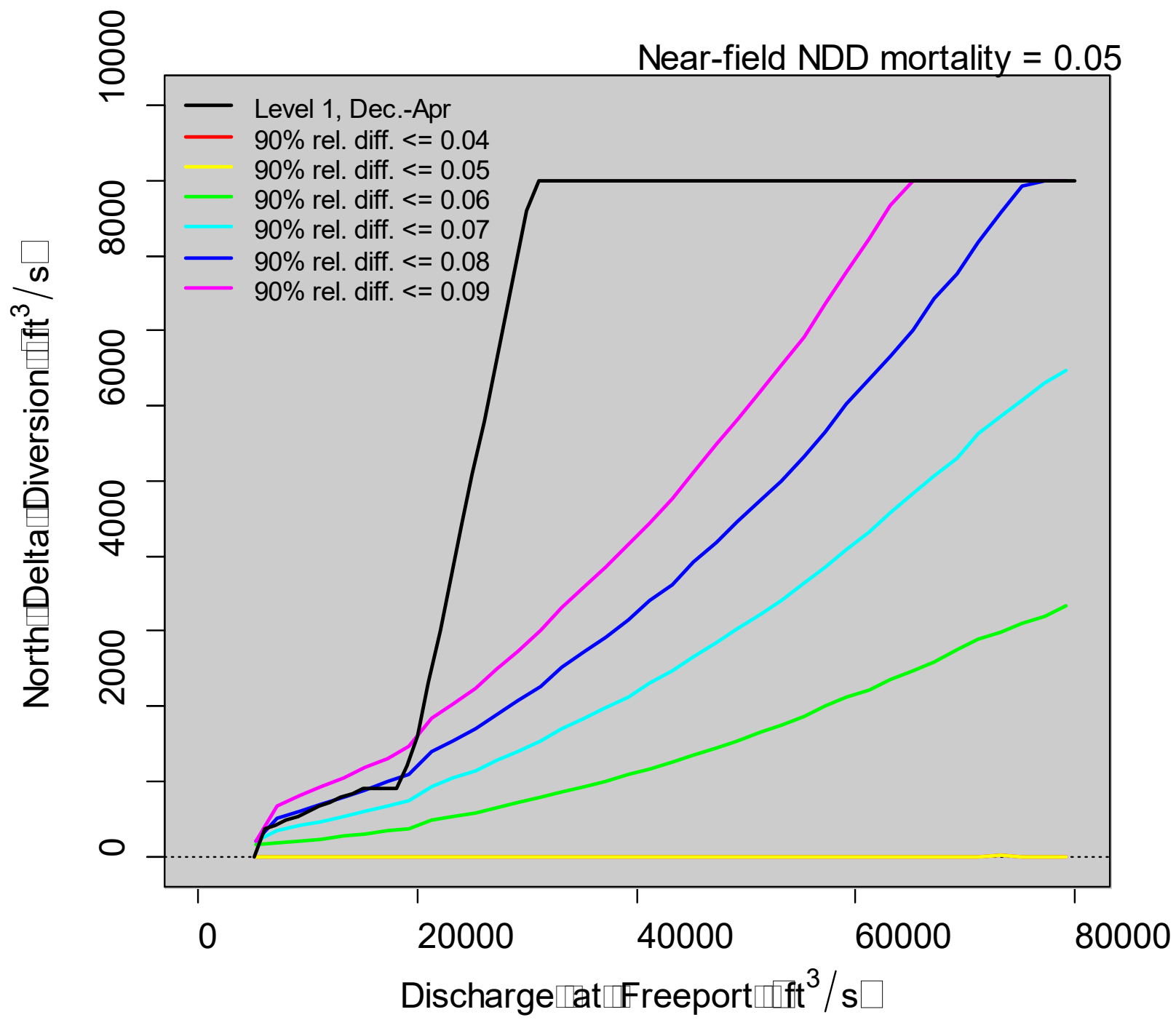

Figure 40. Graph showing North Delta Diversion (NDD) rates as a functions of Sacramento River discharge required to achieve a $90 \%$ probability of a given relative decrease in survival assuming near-field mortality of 0.05 , in the Sacramento-San Joaquin River Delta, northern California. $\mathrm{ft}^{3} / \mathrm{s}$, cubic foot per second; =, equals; \% abs. diff $<=$, percent absolute difference less than or equal to. 


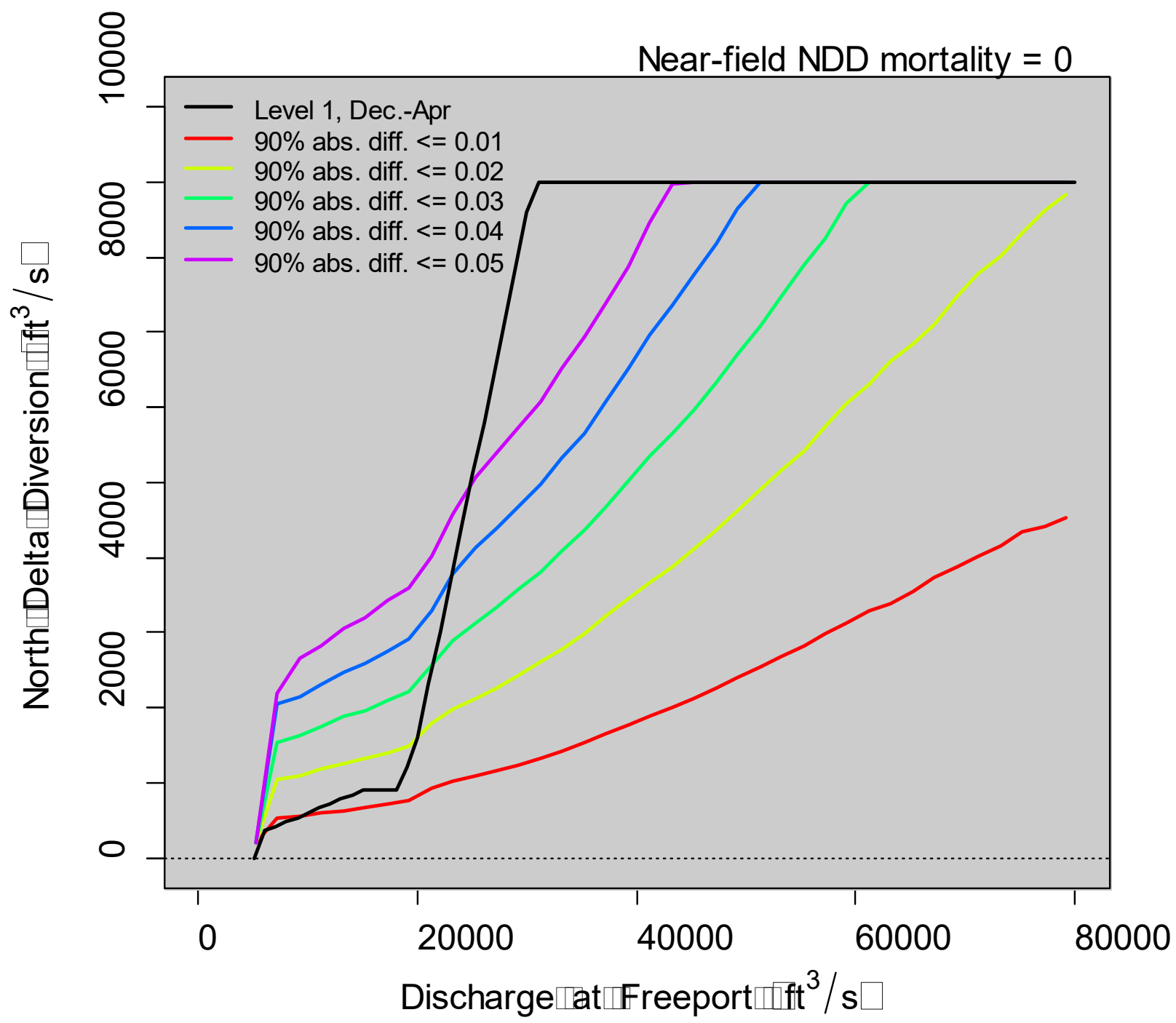

Figure 41. Graph showing North Delta Diversion (NDD) rates as a functions of Sacramento River discharge required to achieve a $90 \%$ probability of a given absolute decrease in survival assuming 0 near-field mortality, in the Sacramento-San Joaquin River Delta, northern California. $\mathrm{ft}^{3} / \mathrm{s}$, cubic foot per second; =, equals; \% abs. diff $<=$, percent absolute difference less than or equal to. 


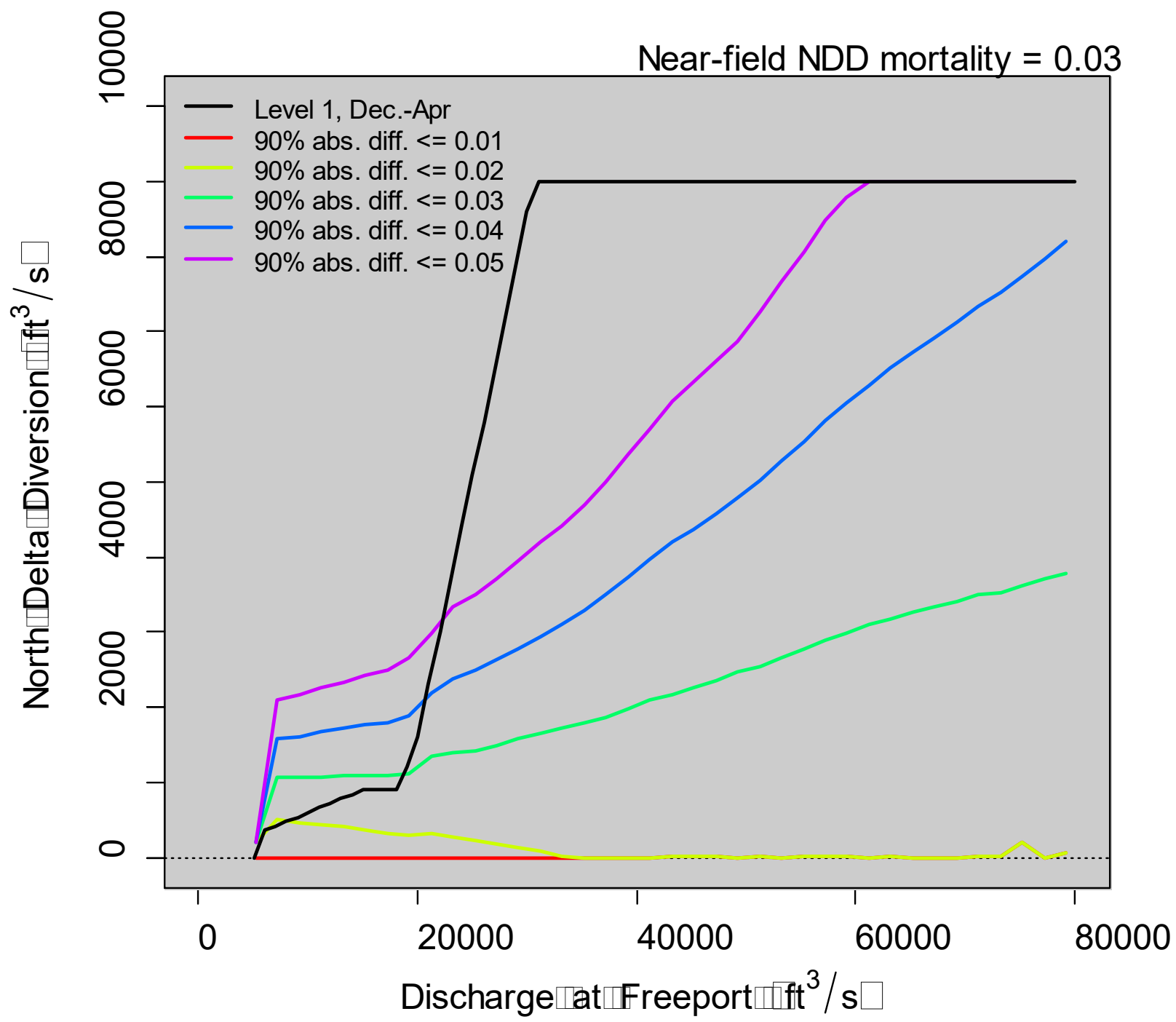

Figure 42. Graph showing North Delta Diversion (NDD) rates as a functions of Sacramento River discharge required to achieve a $90 \%$ probability of a given absolute decrease in survival assuming near-field mortality of 0.03 , in the Sacramento-San Joaquin River Delta, northern California. $\mathrm{ft}^{\mathrm{t}} / \mathrm{s}$, cubic foot per second; =, equals; \% abs. diff $<=$, percent absolute difference less than or equal to. 


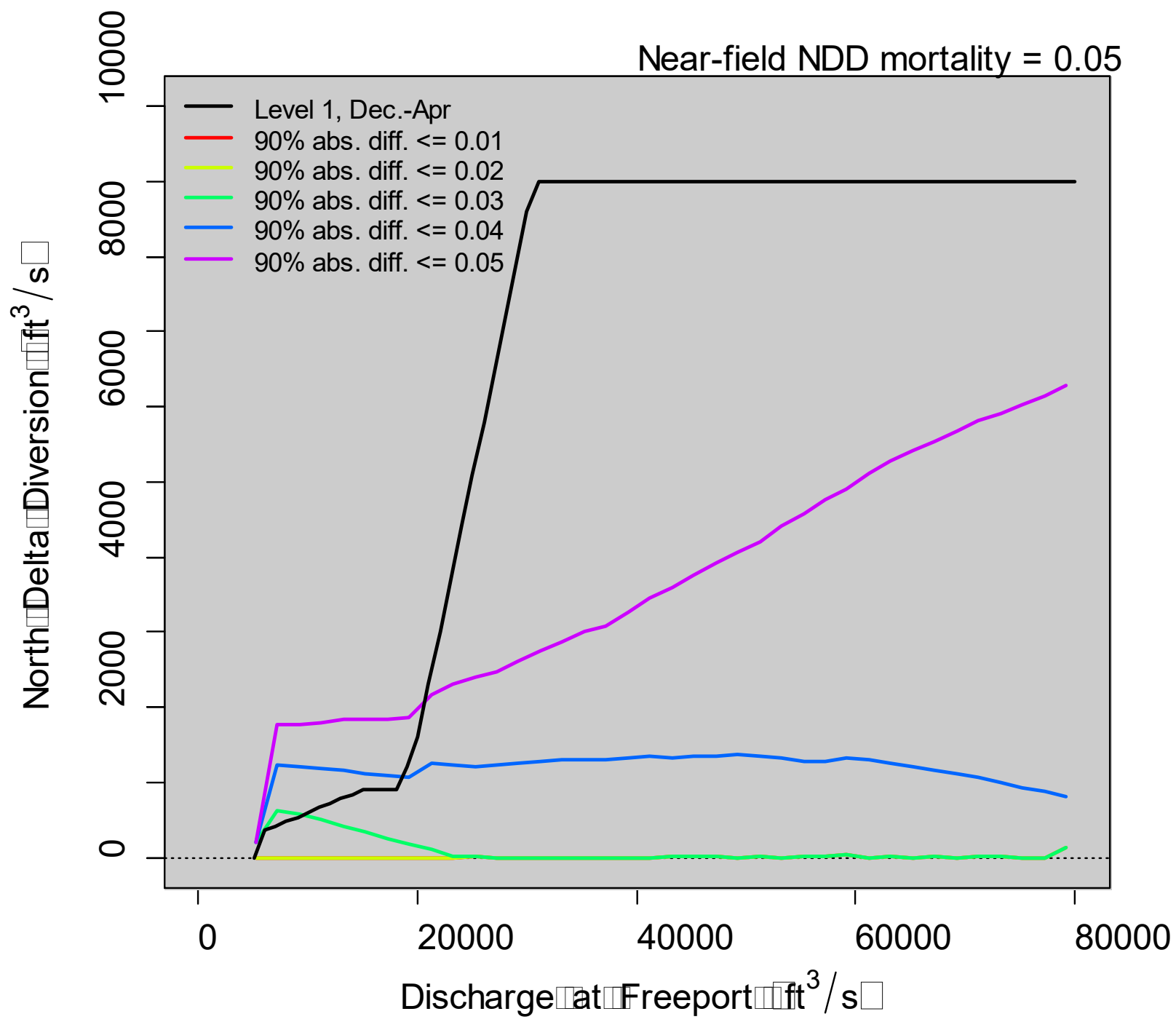

Figure 43. Graph showing North Delta Diversion (NDD) rates as a functions of Sacramento River discharge required to achieve a $90 \%$ probability of a given absolute decrease in survival assuming near-field mortality of 0.05 , in the Sacramento-San Joaquin River Delta, northern California. $\mathrm{ft}^{\mathrm{t}} / \mathrm{s}$, cubic foot per second; =, equals; \% abs. diff $<=$, percent absolute difference less than or equal to. 


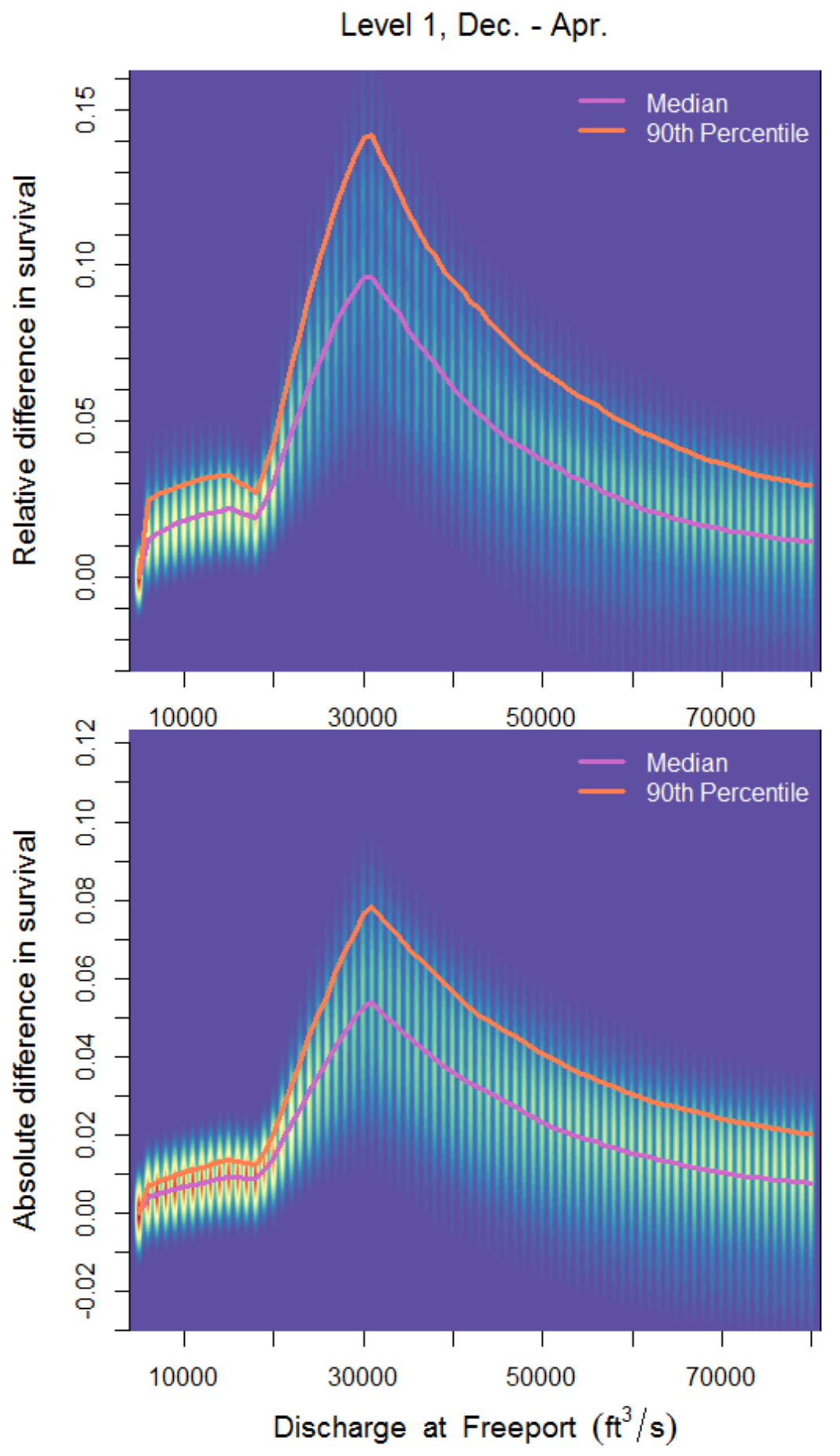

Figure 44. Graphs showing posterior distributions for the relative (top graph) and absolute (bottom graph) difference in survival between no diversion and diversion at rates based on the Level 1, December-April bypass rule. Each vertical color band is the posterior distribution of the survival differences that were calculated in increments of 1,000 cubic feet per second (ft $3 / \mathrm{s})$ for the Sacramento River at Freeport, California. Darker colors indicate regions of higher probability and lighter colors indicate regions of lower probability. Pink line marks the median difference in survival where there is a $50 \%$ probability of the survival difference being higher or lower. Orange line is the 90 th percentile where $10 \%$ of survival differences are higher and $90 \%$ are lower. 


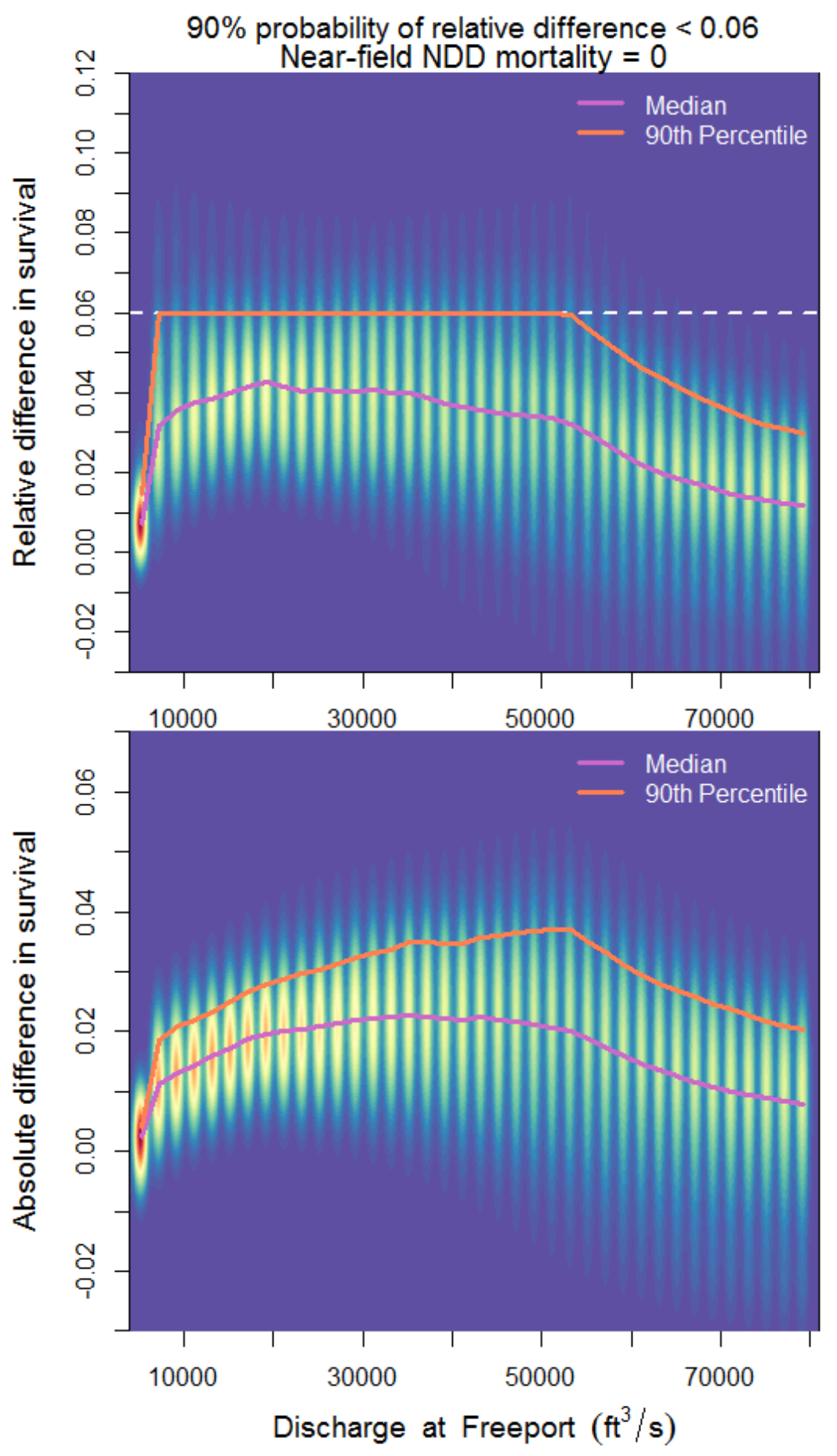

Figure 45. Graphs showing posterior distributions for the relative (top graph) and absolute (bottom graph) difference in survival between no diversion and diversion at rates based on a criterion of a $90 \%$ probability of a relative difference in survival of $<0.06$ with 0 near-field mortality. Each vertical color band is the posterior distribution of the survival differences that were calculated in increments of 2,000 cubic feet per second ( $\mathrm{ft} 3 / \mathrm{s})$ for the Sacramento River at Freeport, California. Darker colors indicate regions of higher probability and lighter colors indicate regions of lower probability. Pink line marks the median difference in survival where there is a $50 \%$ probability of the survival difference being higher or lower. Orange line is the 90th percentile where $10 \%$ of survival differences are higher and $90 \%$ are lower. NDD, North Delta Diversion; =, equals. 


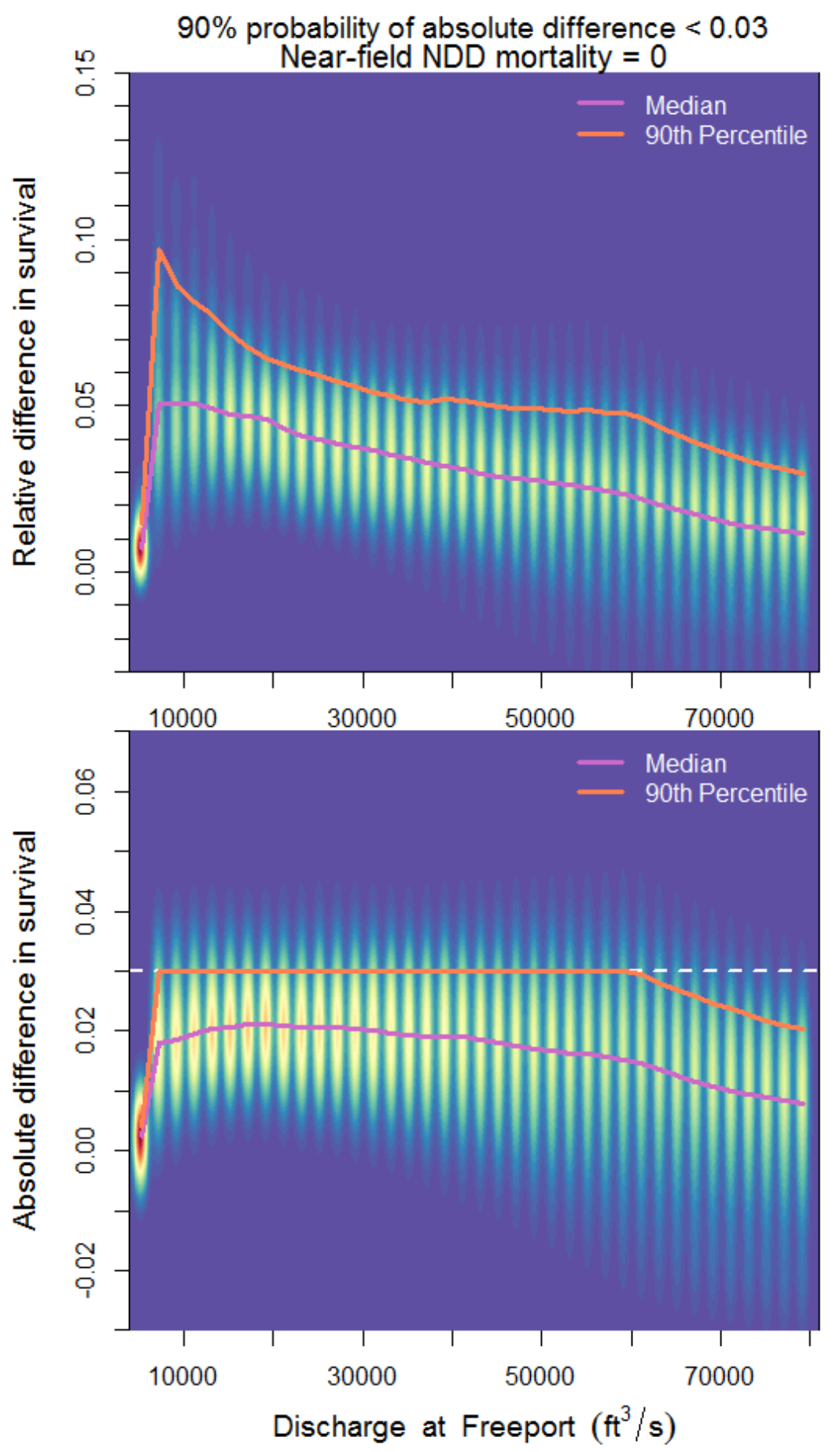

Figure 46. Graphs showing posterior distributions for the relative (top graph) and absolute (bottom graph) difference in survival between no diversion and diversion at rates based on a criterion of a $90 \%$ probability of an absolute difference in survival of $<0.03$ with 0 near-field mortality. Each vertical color band is the posterior distribution of the survival differences that were calculated in increments of 2,000 $\mathrm{ft} 3 / \mathrm{s}$ for the Sacramento River at Freeport, California. Darker colors indicate regions of higher probability and lighter colors indicate lower probability. Pink line marks the median difference in survival where there is a $50 \%$ probability of the survival difference being higher or lower. range line is the $90^{\text {th }}$ percentile where $10 \%$ of survival differences are higher and $90 \%$ are lower. NDD, North Delta Diversion; =, equals. 


\section{Evaluating Real-Time Operations}

Daily simulated operations, median daily survival, daily differences in survival are shown in all odd figures numbers of figures 47-68; mean annual survival and mean annual survival differences are shown in all even figure numbers of figures 48-68. Mean annual survival had large credible intervals in all years, ranging from about 0.35 to 0.70 , but the median of mean annual survival was high in all years, ranging from about 0.45 to 0.60 . Annual survival was high because increases in the Knights Landing Catch Index coincided with periods of increased flow when survival was high. For example, in WY 2003, the highest catches occurred in late December, coincident with a large freshet when discharge of the Sacramento River at Freeport approached $50,000 \mathrm{ft}^{3} / \mathrm{s}$, which increased daily survival to about 0.6 . Because most of the catch occurred during high flows when survival was high, the median of mean annual survival was weighted more towards periods of high survival.

In contrast to wide credible intervals on mean annual survival, the credible intervals on the difference in survival were narrow because the difference in survival relative to no diversion was paired by each draw of the posterior parameter distribution. Median differences in annual survival of each scenario relative to no diversion were negative in all years, but the difference was relatively small, ranging from -0.01 to -0.04. Comparing the L1 scenario to the UPP scenario, survival differences were similar between scenarios in 5 years $(2004,2006,2007,2008$, and 2011), and the magnitude of survival differences for UPP was less than for L1 in 4 years $(2005,2010,2012$, and 2014) and greater in 2 years (2003 and 2009).

Although annual survival was similar between scenarios, the daily survival probabilities showed that the UPP scenario had higher daily survival probabilities more frequently than the L1 scenario. For example, in WY 2005, constant low-level pumping was implemented for eight pulses of fish for the UPP scenario, but only for one pulse of fish for the L1 scenario (fig. 51, top two graphs). During periods when different operations were implemented between scenarios, survival decreased by less under the UPP scenario for much of the migration season relative to the L1 scenario (fig. 51, bottom graph). For many of these pulses, survival under the L1 scenario was 4-5 percentage points less than under the UPP scenario (fig. 51, bottom graph). This difference in daily survival between scenarios occurred in most years, owing to the protection of an unlimited number of pulses under the UPP scenario. 


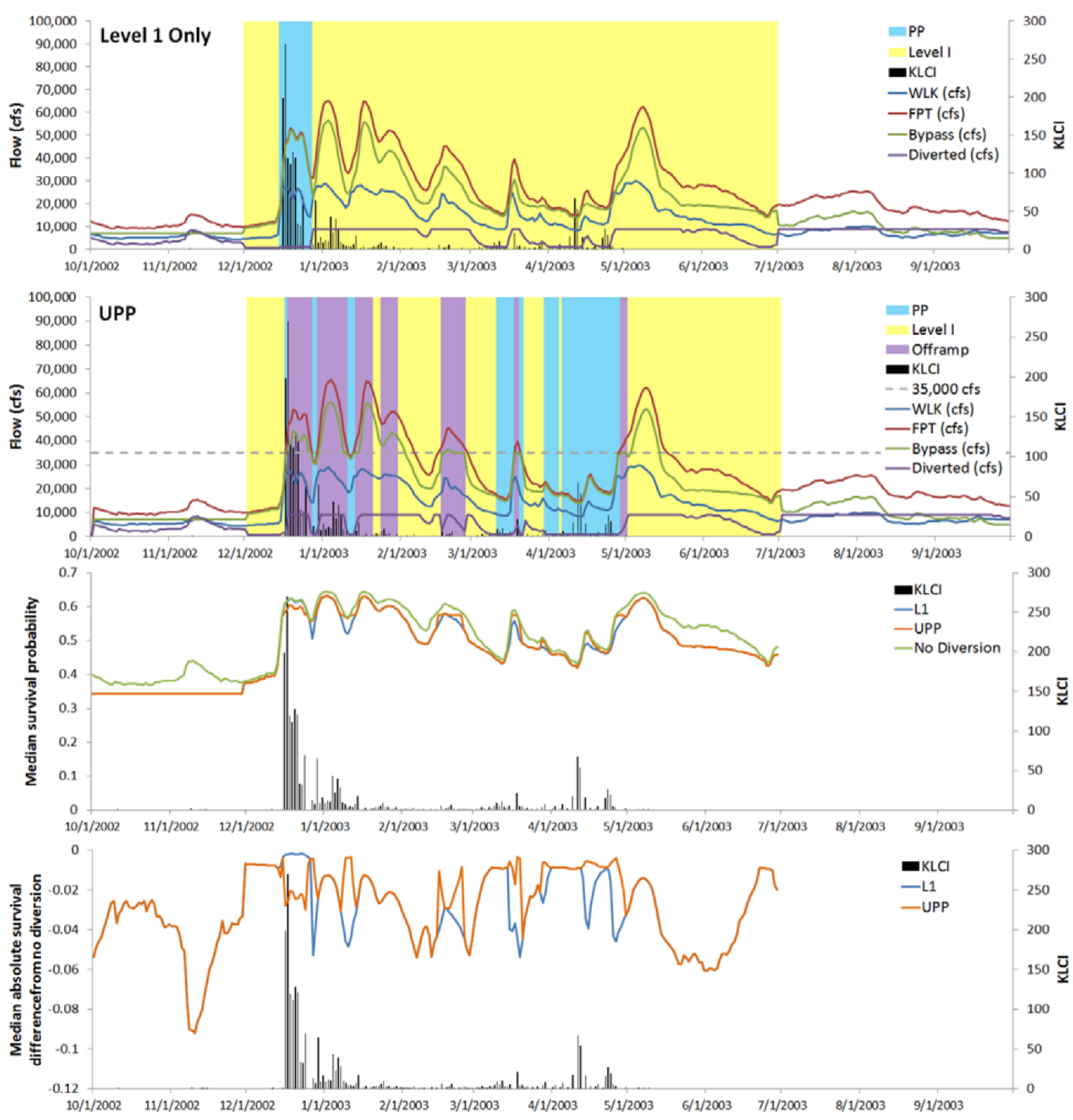

Figure 47. Graphs showing Level 1 (L1) real-time operations (top graph), revised Unlimited Pulse Protection (UPP) real-time operations (second graph from top), median daily through-Sacramento-San Joaquin River Delta survival probability (third graph from top), and median daily difference in survival of each real-time scenario relative to the no diversion scenario (bottom graph), for water year 2003. Knights Landing Catch Index (KLCl) is plotted along the right vertical axis. Yellow shading ("Level 1" in graph explanations) indicates periods of Level 1 pumping, blue shading ("PP" in graph explanations) indicates periods of pulse protection based on the $\mathrm{KLCl}$, and purple shading ("Offramp" in graph explanation) indicates pulse protection offramp periods. FPT, Sacramento River discharge at Freeport; WLK, Sacramento River discharge at Wilkins Slough; cfs, cubic foot per second. 
Water year: 2003
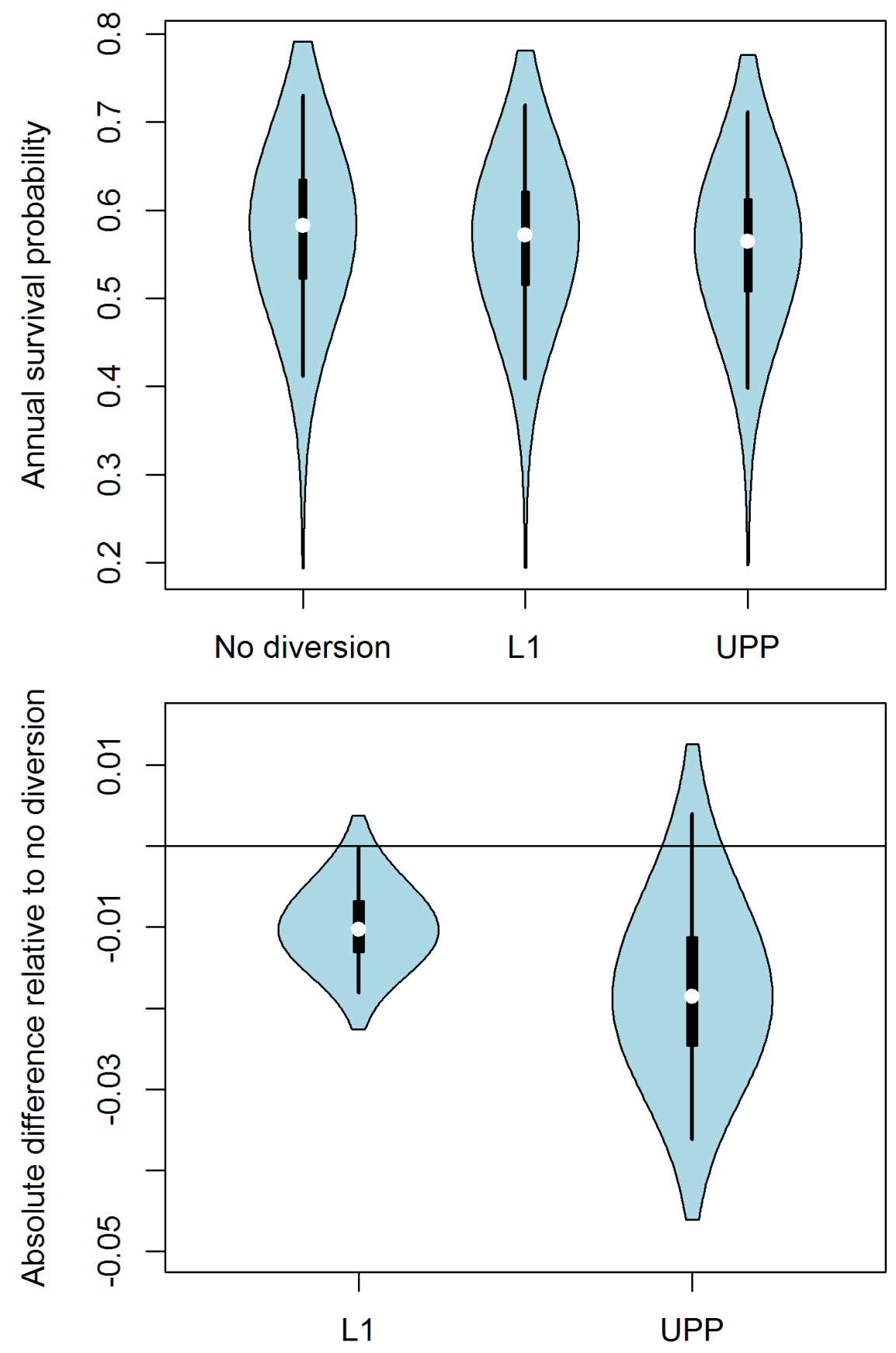

Figure 48. Violin plots showing posterior distributions of annual survival probability for Level 1 (L1) real-time operations and revised Unlimited Pulse Protection (UPP) real-time operations (top graph), and the difference in annual survival of each real-time scenario relative to the no diversion scenario (bottom graph), for water year 2003. Violins represent non-parametric kernel density estimates of the full posterior distributions, thin vertical lines represent the $95 \%$ credible intervals, thick vertical lines represent the 25 th-75th percentiles, and white dots represent the medians. 


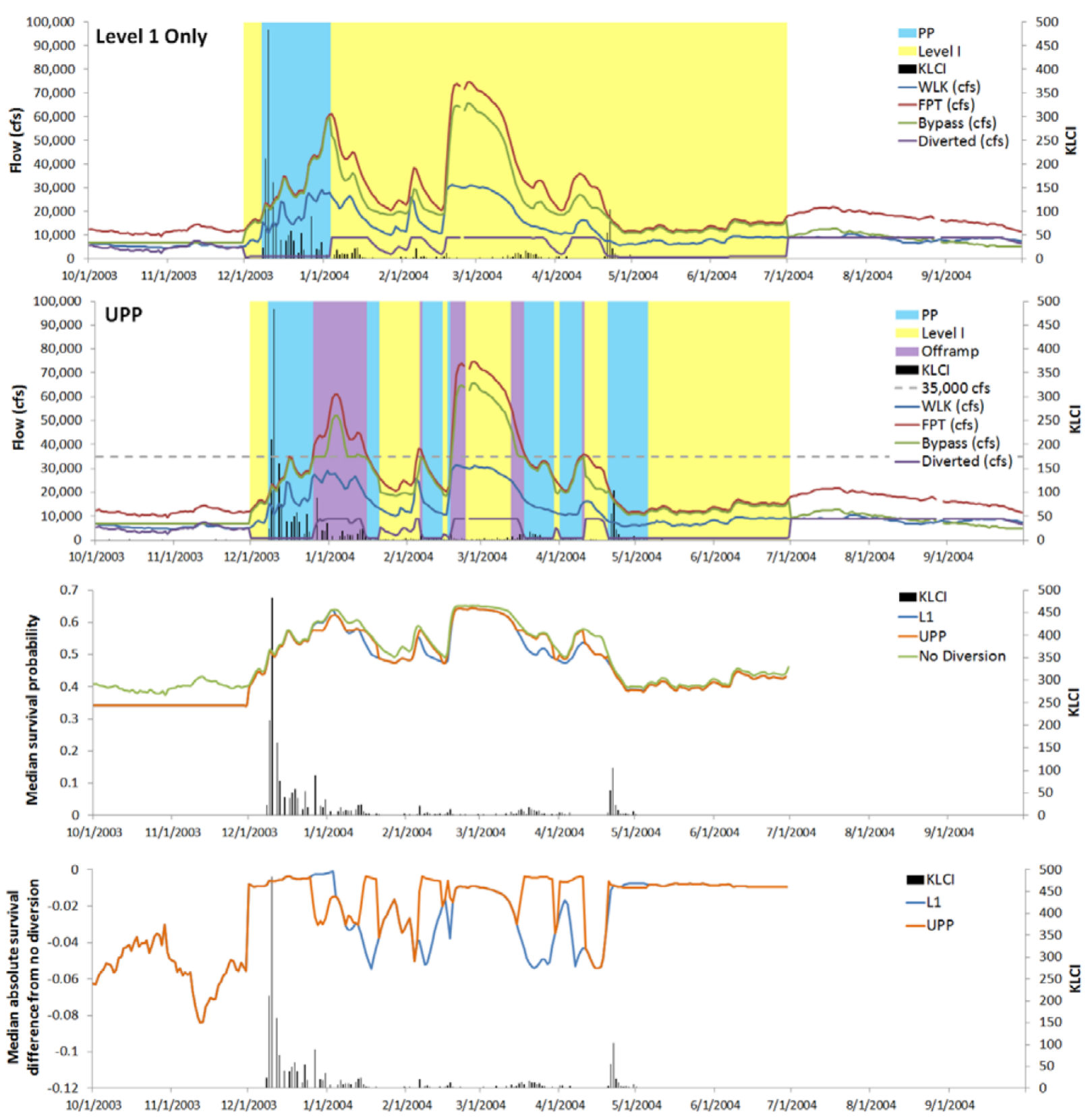

Figure 49. Graphs showing Level 1 (L1) real-time operations (top graph), revised Unlimited Pulse Protection (UPP) real-time operations (second graph from top), median daily through-Sacramento-San Joaquin River Delta survival probability (third graph from top), and median daily difference in survival of each real-time scenario relative to the no diversion scenario (bottom graph), for water year 2004. The Knights Landing Catch Index (KLCl) is plotted along the right vertical axis. Yellow shading ("Level 1" in graph explanations) indicates periods of Level 1 pumping, blue shading ("PP" in graph explanations) indicates periods of pulse protection based on the $\mathrm{KLCl}$, and purple shading ("Offramp" in graph explanation) indicates pulse protection offramp periods. FPT, Sacramento River discharge at Freeport; WLK, Sacramento River discharge at Wilkins Slough; cfs, cubic foot per second. 
Water year: 2004
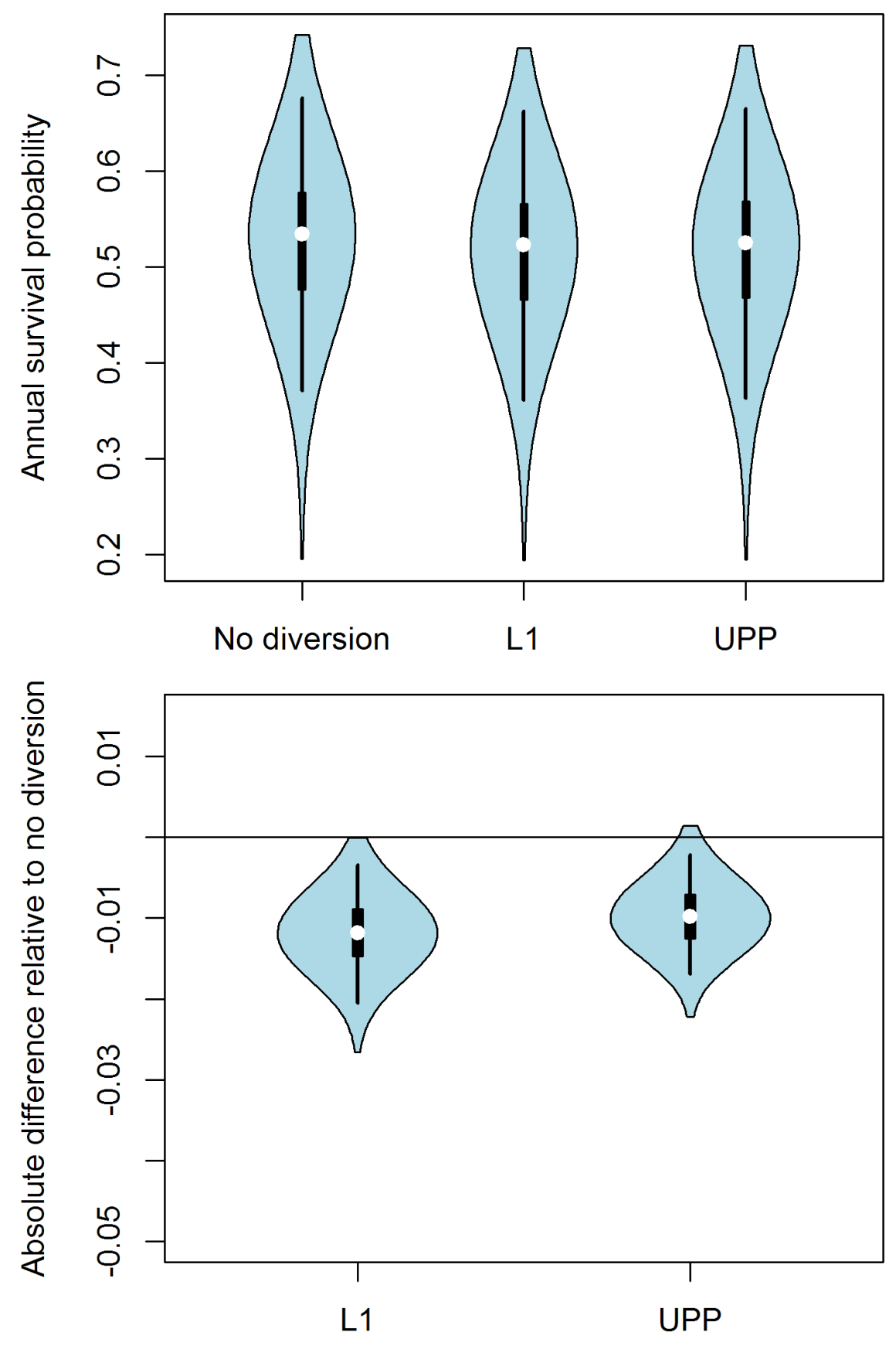

Figure 50. Violin plots showing posterior distributions of annual survival probability for Level 1 (L1) real-time operations and revised Unlimited Pulse Protection (UPP) real-time operations (top graph), and the difference in annual survival of each real-time scenario relative to the no diversion scenario (bottom graph), for water year 2004. Violins represent non-parametric kernel density estimates of the full posterior distributions, thin vertical lines represent the $95 \%$ credible intervals, thick vertical lines represent 25th-75th percentiles, and white dots represent the medians. 


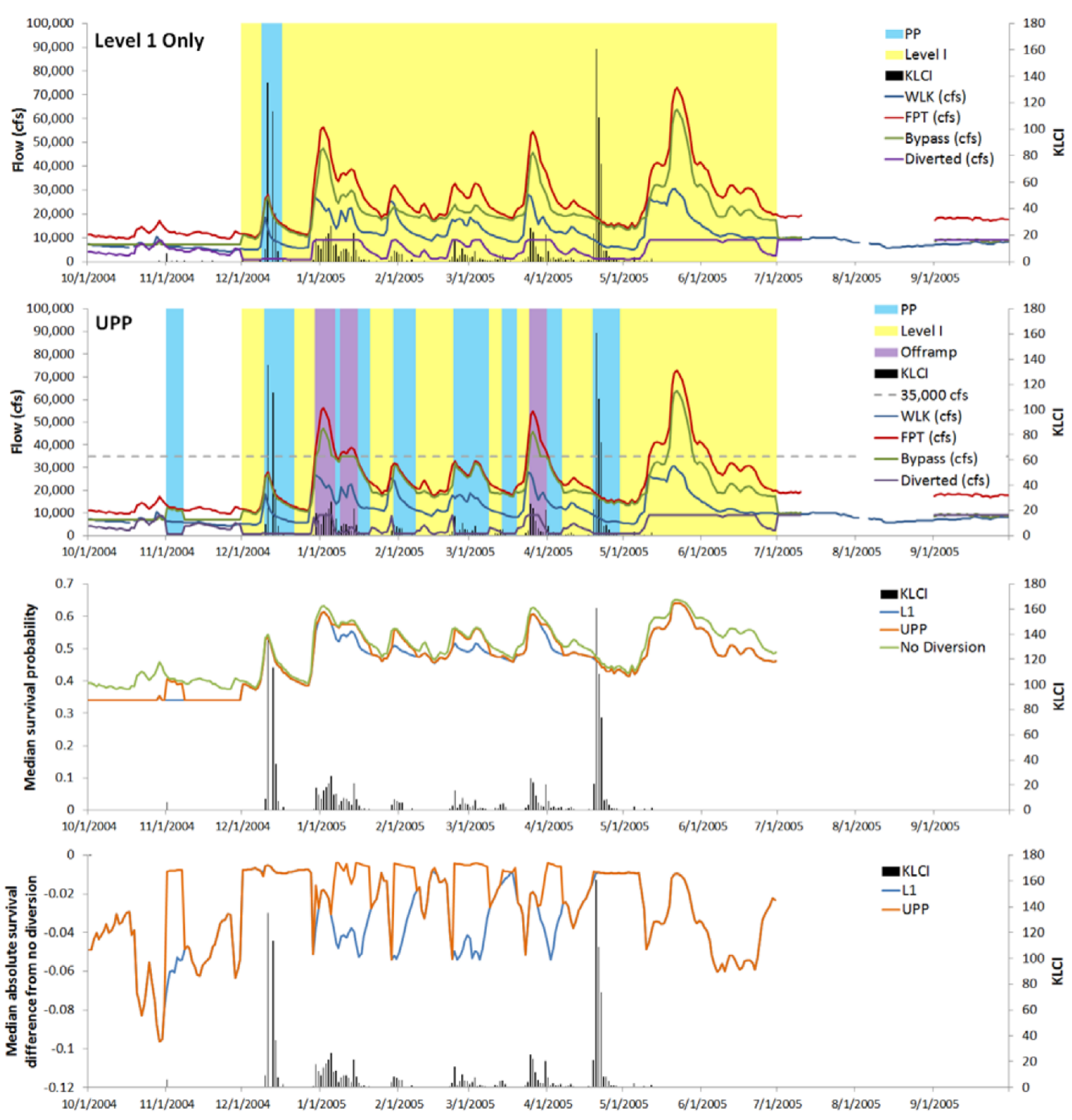

Figure 51. Graphs showing Level 1 (L1) real-time operations (top graph), revised Unlimited Pulse Protection (UPP) real-time-operations (second graph from top), median daily through-Sacramento-San Joaquin River Delta survival probability (third graph from top), and median daily difference in survival of each real-time scenario relative to the no diversion scenario (bottom graph), for water year 2005. The Knights Landing Catch Index (KLCl) is plotted along the right vertical axis. Yellow shading ("Level 1" in graph explanations) indicates periods of Level 1 pumping, blue shading ("PP" in graph explanations) indicates periods of pulse protection based on the $\mathrm{KLCl}$, and purple shading ("Offramp" in graph explanation) indicates pulse protection offramp periods. FPT, Sacramento River discharge at Freeport; WLK, Sacramento River discharge at Wilkins Slough; cfs, cubic foot per second. 


\section{Water year: 2005}
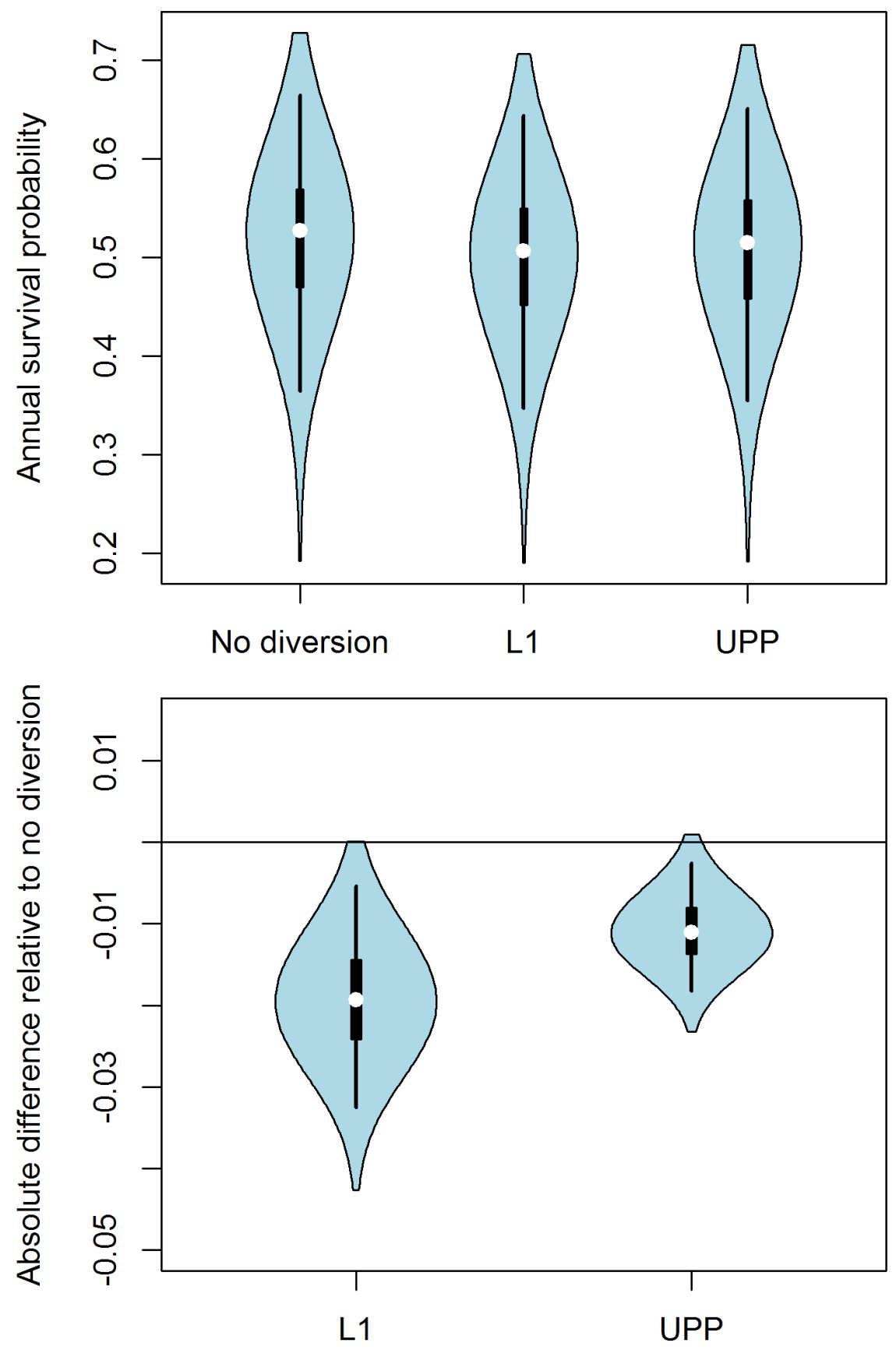

Figure 52. Violin plots showing posterior distributions of annual survival probability for Level 1 (L1) real-time operations and revised Unlimited Pulse Protection (UPP) real-time operations (top graph), and the difference in annual survival of each real-time scenario relative to the no diversion scenario (bottom graph), for water year 2005. Violins represent non-parametric kernel density estimates of the full posterior distributions, thin vertical lines represent the $95 \%$ credible intervals, thick vertical lines represent the 25 th-75th percentiles, and white dots represent the medians. 


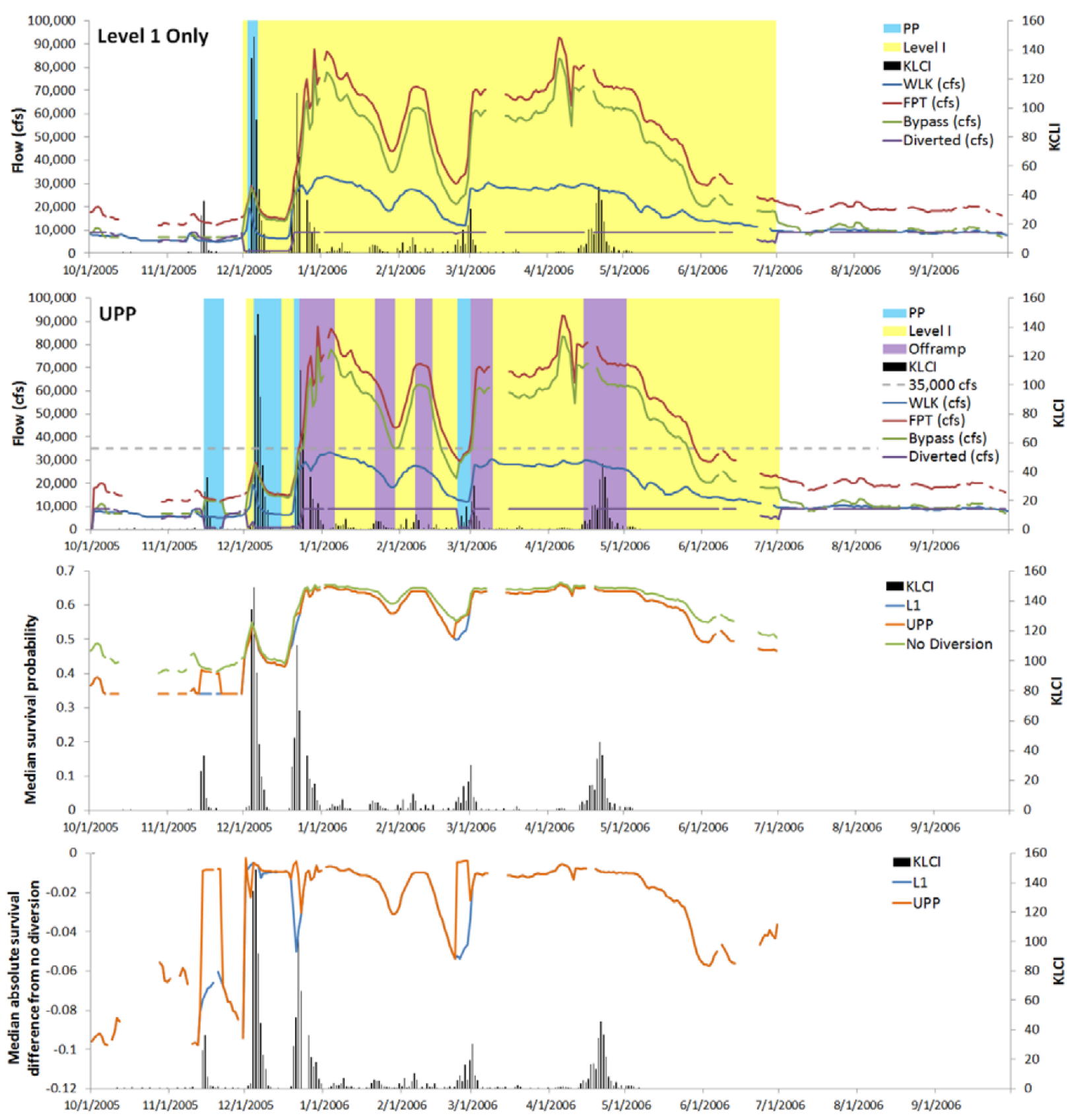

Figure 53. Graphs showing Level 1 (L1) real-time operations (top graph), revised Unlimited Pulse Protection (UPP) real-time operations (second graph from top), median daily through-Sacramento-San Joaquin River Delta survival probability (third graph from top), and median daily difference in survival of each real- time scenario relative to the no diversion scenario (bottom graph), for water year 2006. The Knights Landing Catch Index (KLCl) is plotted along the right vertical axis. Yellow shading ("Level 1" in graph explanations) indicates periods of Level 1 pumping, blue shading ("PP" in graph explanations) indicates periods of pulse protection based on the KLC, and purple shading ("Offramp" in graph explanation) indicates pulse protection offramp periods. FPT, Sacramento River discharge at Freeport; WLK, Sacramento River discharge at Wilkins Slough; cfs, cubic foot per second. 
Water year: 2006
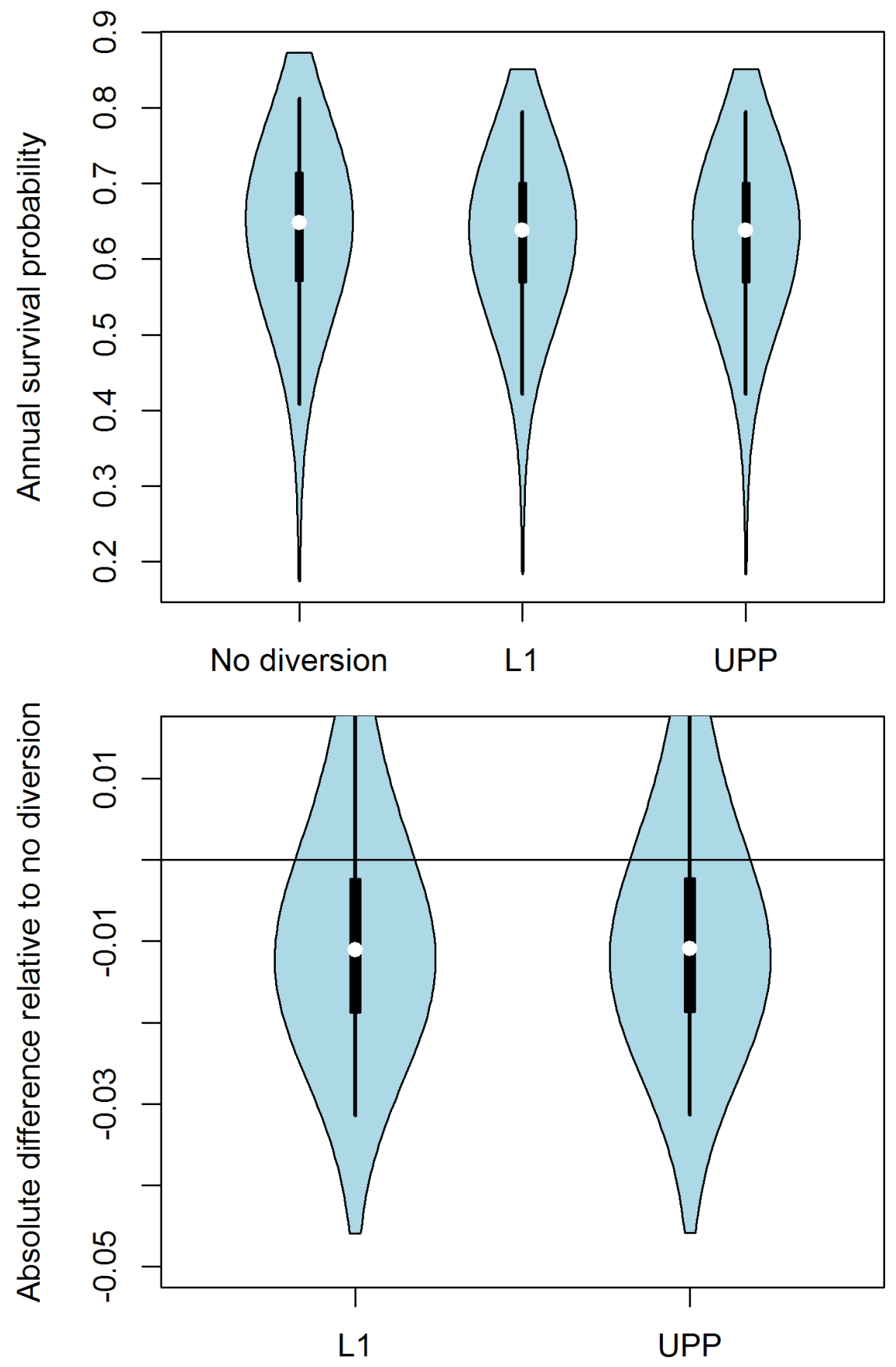

Figure 54. Violin plots showing posterior distributions of annual survival probability for Level 1 (L1) real-time operations and revised Unlimited Pulse Protection (UPP) real-time operations (top graph), and the difference in annual survival of each real-time scenario relative to the no diversion scenario (bottom graph), for water year 2006. Violins represent non-parametric kernel density estimates of the full posterior distributions, thin vertical lines represent the $95 \%$ credible intervals, thick vertical lines represent the 25 th-75th percentiles, and white dots represent the medians. 

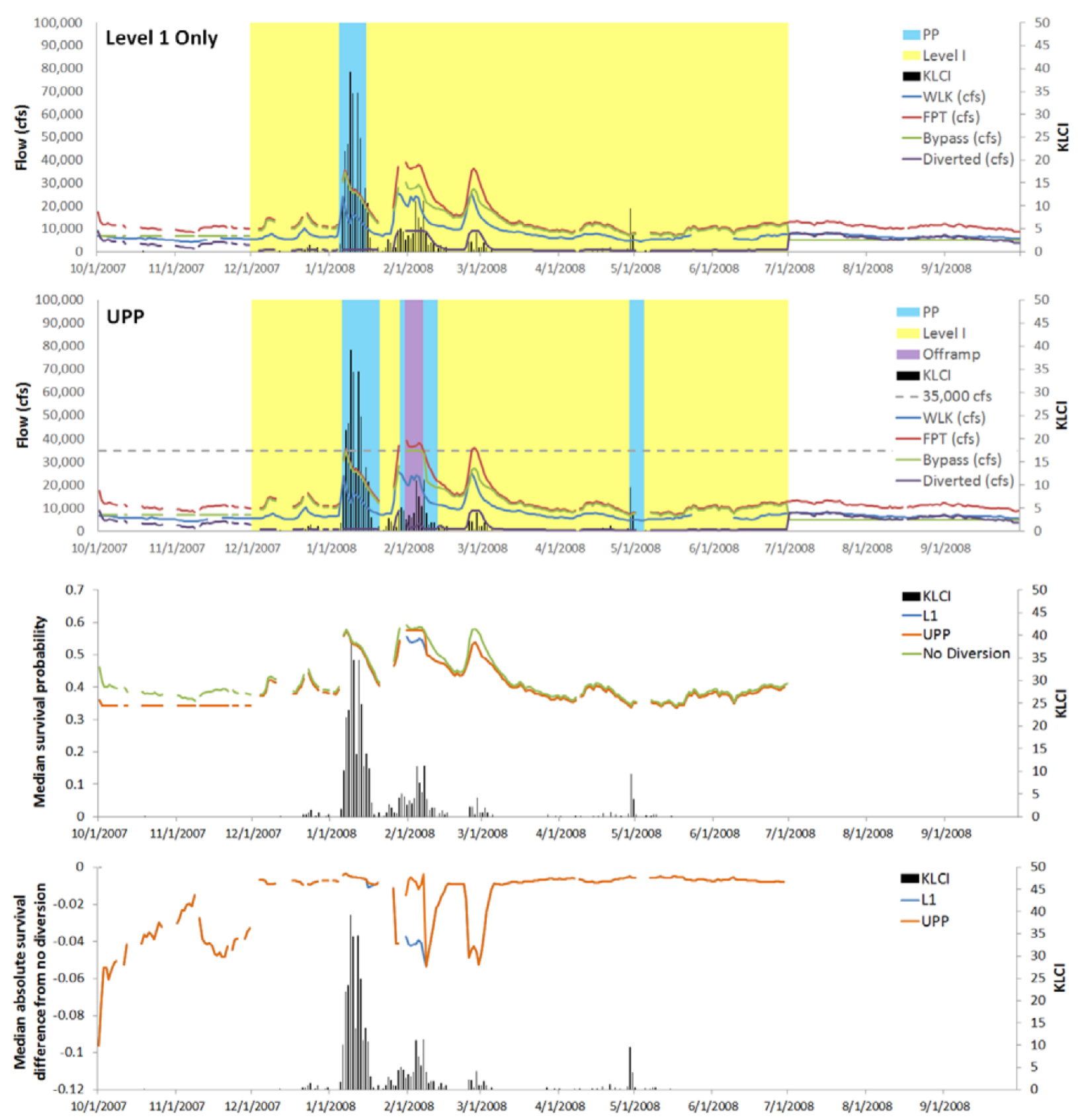

Figure 55. Graphs showing Level 1 (L1) real-time operations (top graph), revised Unlimited Pulse Protection (UPP) real-time operations (second graph from top), median daily through-Sacramento-San Joaquin River Delta survival probability (third graph from top), and median daily difference in survival of each real-time scenario relative to the no diversion scenario (bottom graph), for water year 2007. The Knights Landing Catch Index (KLCl) is plotted along the right vertical axis. Yellow shading ("Level 1" in graph explanations) indicates periods of Level 1 pumping, blue shading ("PP" in graph explanations) indicates periods of pulse protection based on the $\mathrm{KLCl}$, and purple shading ("Offramp" in graph explanation) indicates pulse protection offramp periods. FPT, Sacramento River discharge at Freeport; WLK, Sacramento River discharge at Wilkins Slough; cfs, cubic foot per second. 
Water year: 2007
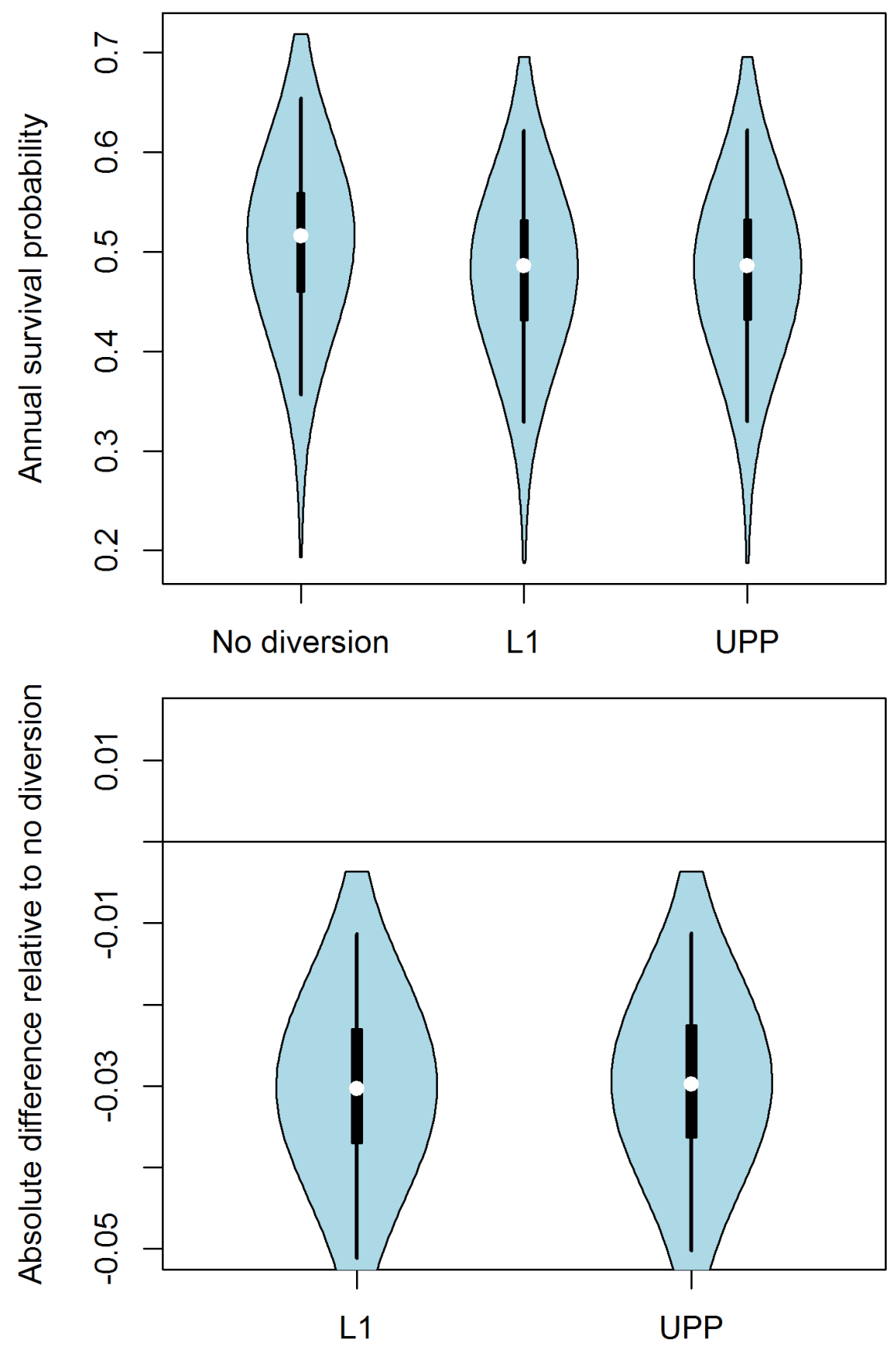

Figure 56. Violin plots showing posterior distributions of annual survival probability for Level 1 (L1) real-time operations and revised Unlimited Pulse Protection (UPP) real-time operations (top graph), and the difference in annual survival of each real-time scenario relative to the no diversion scenario (bottom graph), for water year 2007. Violins represent non-parametric kernel density estimates of the full posterior distributions, thin vertical lines represent the $95 \%$ credible intervals, thick vertical lines represent the 25 th-75th percentiles, and white dots represent the medians. 

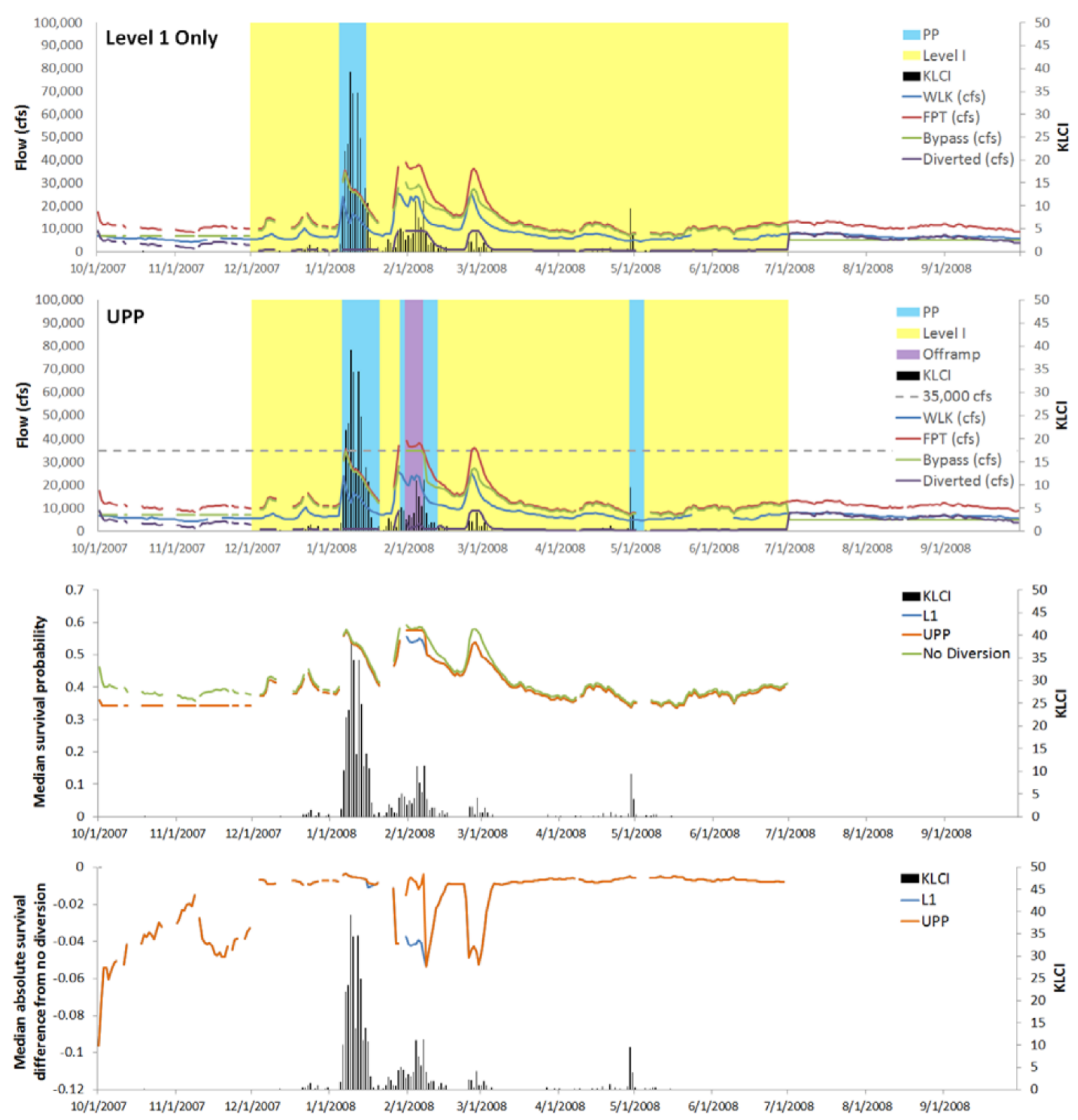

Figure 57. Graphs showing Level 1 (L1) real-time operations (top graph), revised Unlimited Pulse Protection (UPP) real-time operations (second graph from top), median daily through-Sacramento-San Joaquin River Delta survival probability (third graph from top), and median daily difference in survival of each real-time scenario relative to the no diversion scenario (bottom graph) for water year 2008. The Knights Landing Catch Index (KLCl) is plotted along the right vertical axis. Yellow shading ("Level 1" in graph explanations) indicates periods of Level 1 pumping, blue shading ("PP" in graph explanations) indicates periods of pulse protection based on the $\mathrm{KLCl}$, and purple shading ("Offramp" in graph explanation) indicates pulse protection offramp periods. FPT, Sacramento River discharge at Freeport; WLK, Sacramento River discharge at Wilkins Slough; cfs, cubic foot per second. 
Water year: 2008
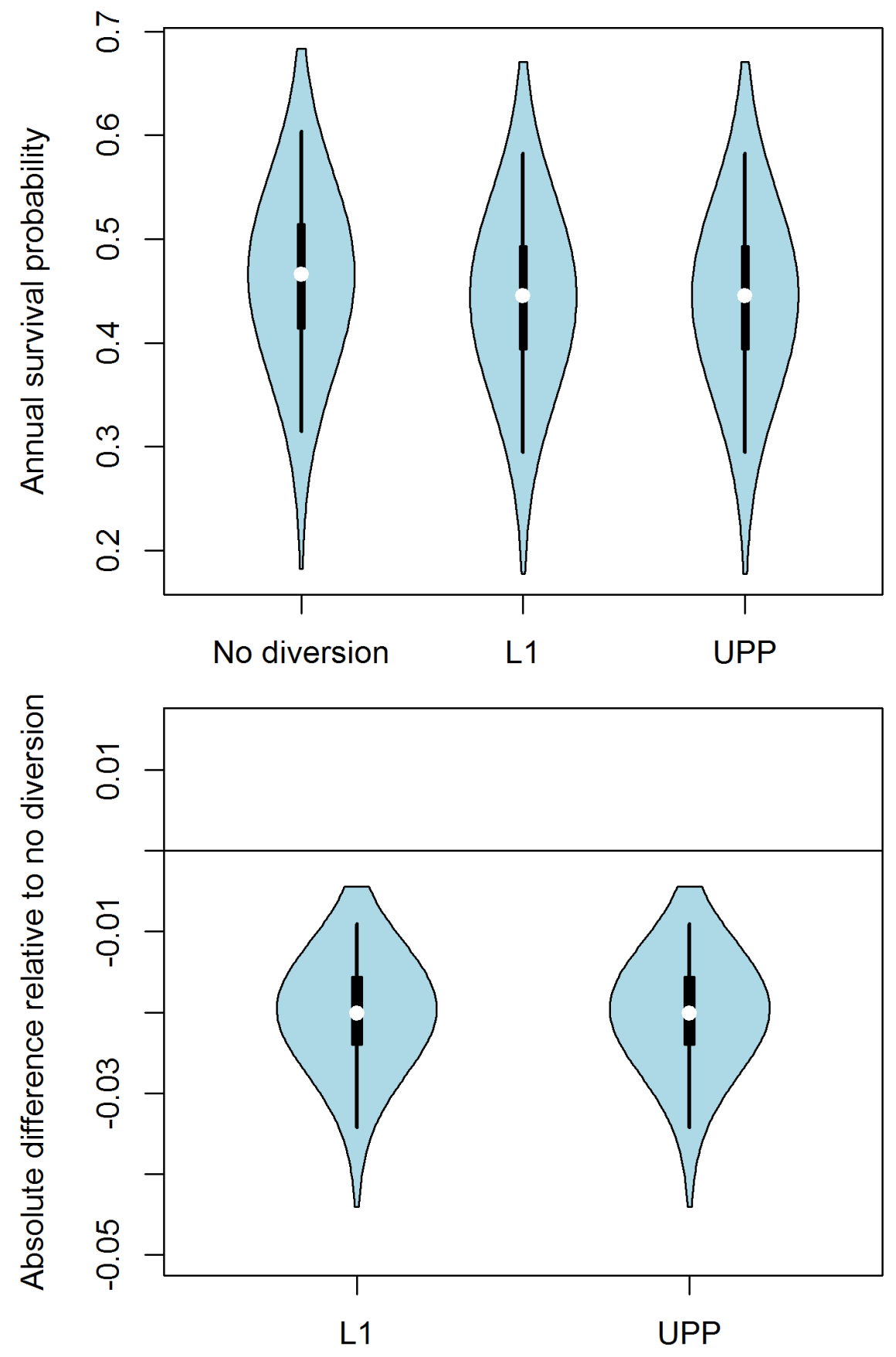

Figure 58. Violin plots showing posterior distributions of annual survival probability for Level 1 (L1) real-time operations and revised Unlimited Pulse Protection (UPP) real-time operations (top graph), and the difference in annual survival of each real-time scenario relative to the no diversion scenario (bottom graph), for water year 2008. Violins represent non-parametric kernel density estimates of the full posterior distributions, thin vertical lines represent the $95 \%$ credible intervals, thick vertical lines represent the 25 th-75th percentiles, and white dots represent the medians. 

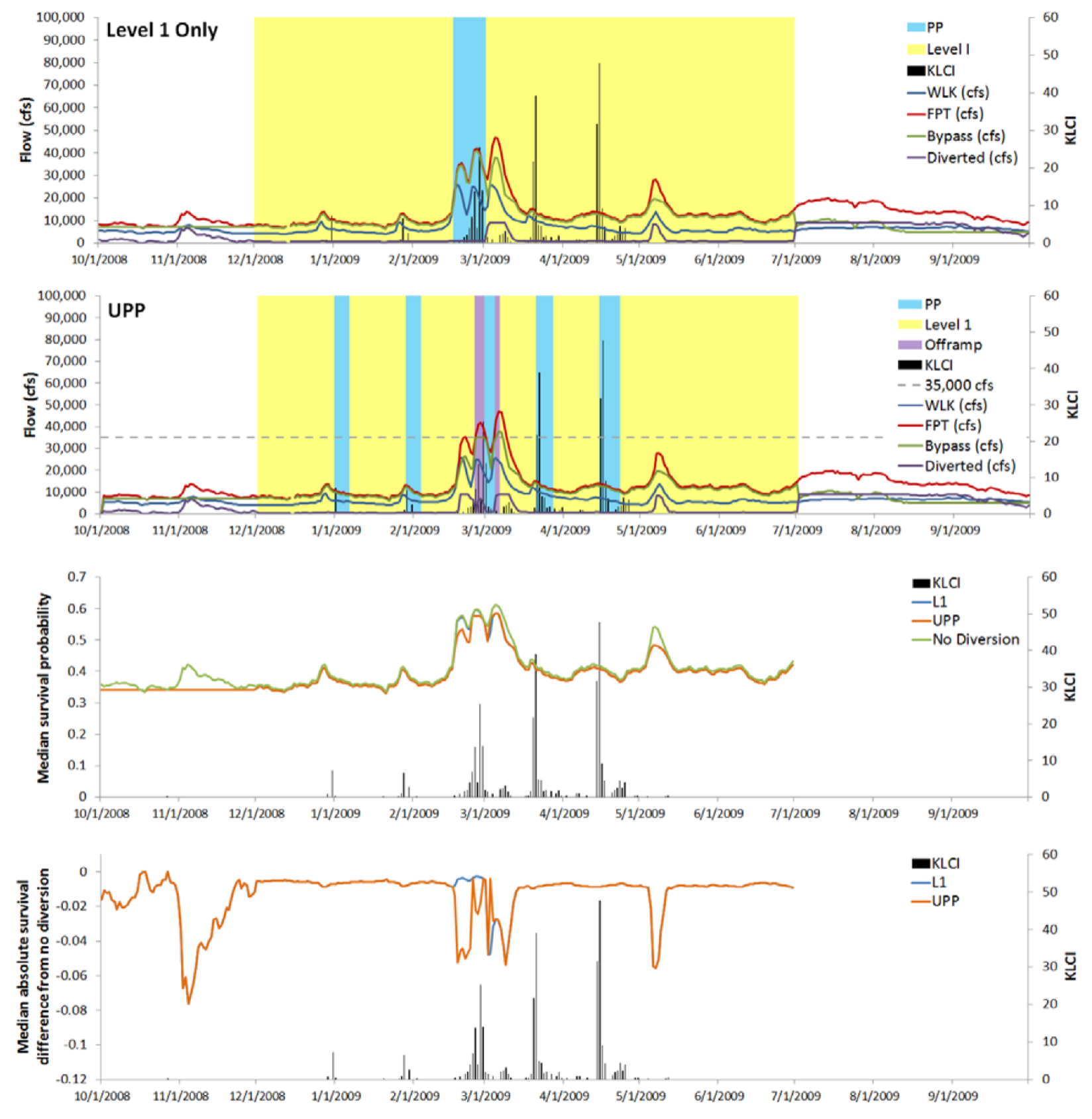

Figure 59. Graphs showing Level 1 (L1) real-time operations (top graph), revised Unlimited Pulse Protection (UPP) real-time operations (second graph from top;), median daily through-Sacramento-San Joaquin River Delta survival probability (third graph from top), and median daily difference in survival of each real-time scenario relative to the no diversion scenario (bottom graph), for water year 2009. The Knights Landing Catch Index (KLCl) is plotted along the right vertical axis. Yellow shading ("Level 1" in graph explanations) indicates periods of Level 1 pumping, blue shading ("PP" in graph explanations) indicates periods of pulse protection based on the $\mathrm{KLCl}$, and purple shading ("Offramp" in graph explanation) indicates pulse protection offramp periods. FPT, Sacramento River discharge at Freeport; WLK, Sacramento River discharge at Wilkins Slough; cfs, cubic foot per second. 
Water year: 2009
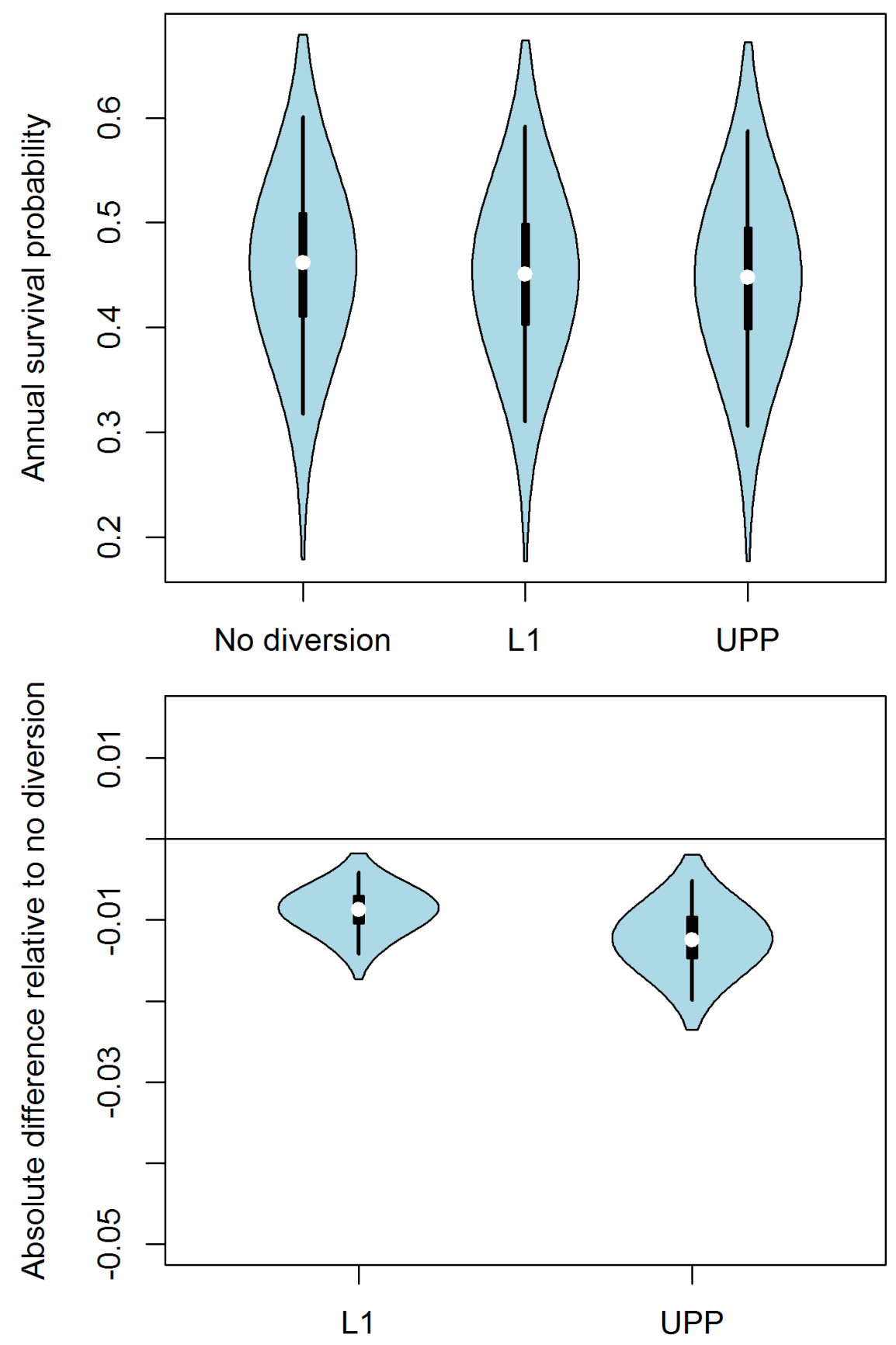

Figure 60. Violin plots showing posterior distributions of annual survival probability for Level 1 (L1) real-time operations and revised Unlimited Pulse Protection (UPP) real-time operations (top graph), and the difference in annual survival of each real-time scenario relative to the no diversion scenario (bottom graph), for water year 2009. Violins represent non-parametric kernel density estimates of the full posterior distributions, thin vertical lines represent the $95 \%$ credible intervals, thick vertical lines represent the 25 th-75th percentiles, and white dots represent the medians. 

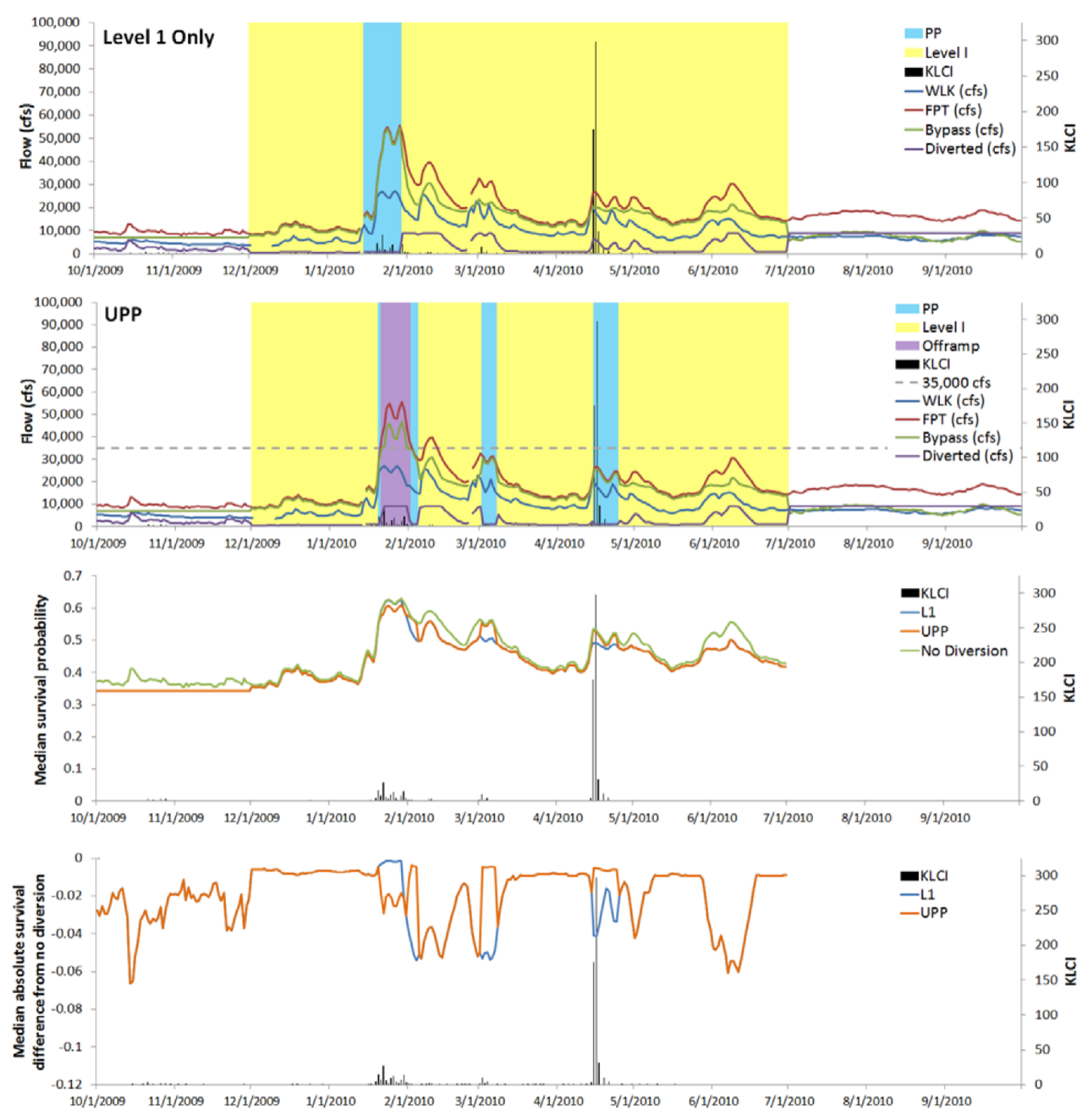

Figure 61. Graphs showing Level 1 (L1) real-time operations (top graph), revised Unlimited Pulse Protection (UPP) real-time operations (second graph from top), median daily through-Sacramento-San Joaquin River Delta survival probability (third graph from top), and median daily difference in survival of each real-time scenario relative to the no diversion scenario (bottom graph), for water year 2010. The Knights Landing Catch Index (KLCl) is plotted along the right vertical axis. Yellow shading ("Level 1" in graph explanations) indicates periods of Level 1 pumping, blue shading ("PP" in graph explanations) indicates periods of pulse protection based on the $\mathrm{KLCl}$, and purple shading ("Offramp" in graph explanation) indicates pulse protection offramp periods. FPT, Sacramento River discharge at Freeport; WLK, Sacramento River discharge at Wilkins Slough; cfs, cubic foot per second. 
Water year: 2010
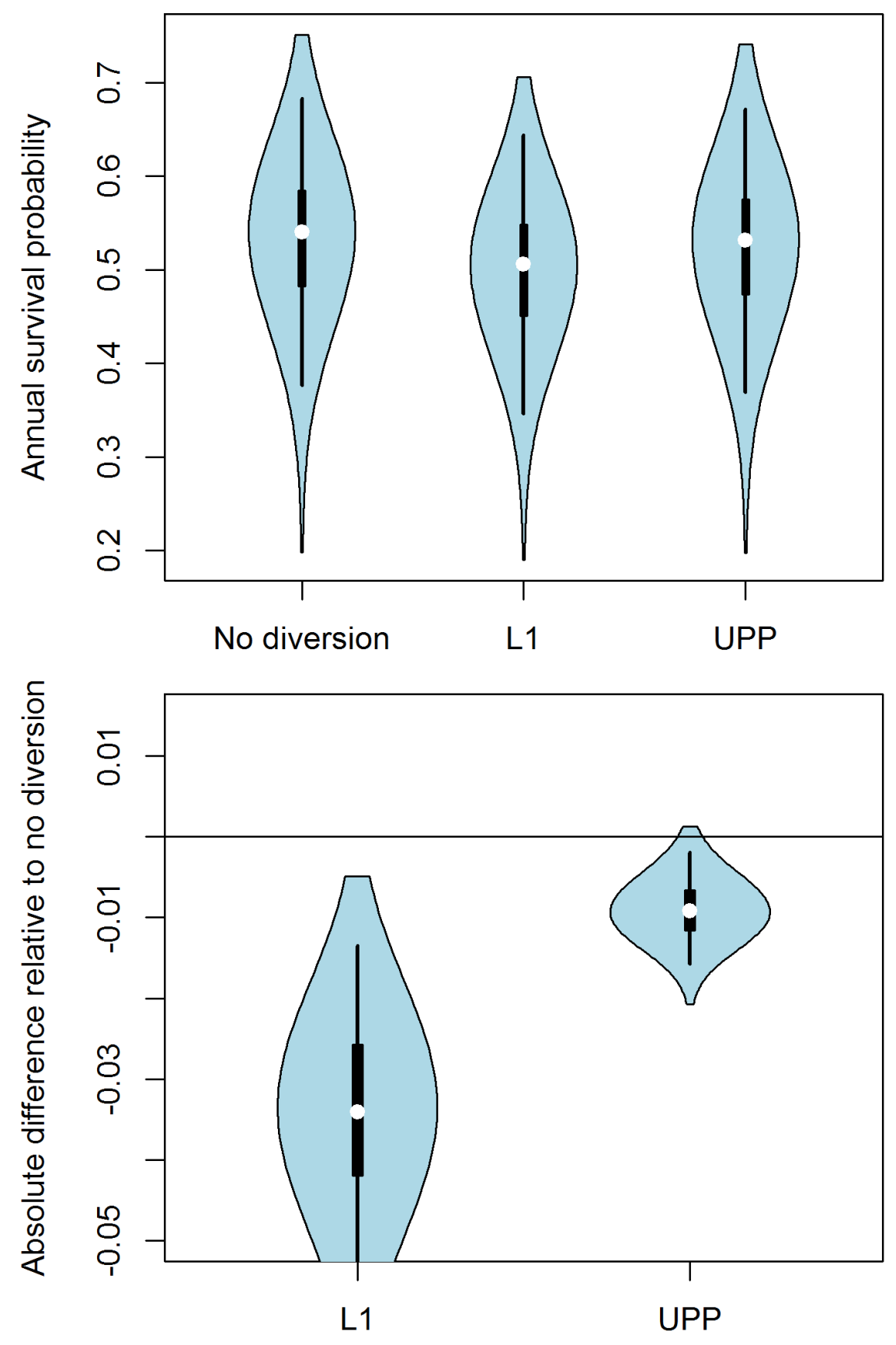

Figure 62. Violin plots showing posterior distributions of annual survival probability for Level 1 (L1) real-time operations and revised Unlimited Pulse Protection (UPP) real-time operations (top graph), and the difference in annual survival of each real-time scenario relative to the no diversion scenario (bottom graph), for water year 2010. Violins represent non-parametric kernel density estimates of the full posterior distributions, thin vertical lines represent the $95 \%$ credible intervals, thick vertical lines represent the 25 th-75th percentiles, and white dots represent the medians. 


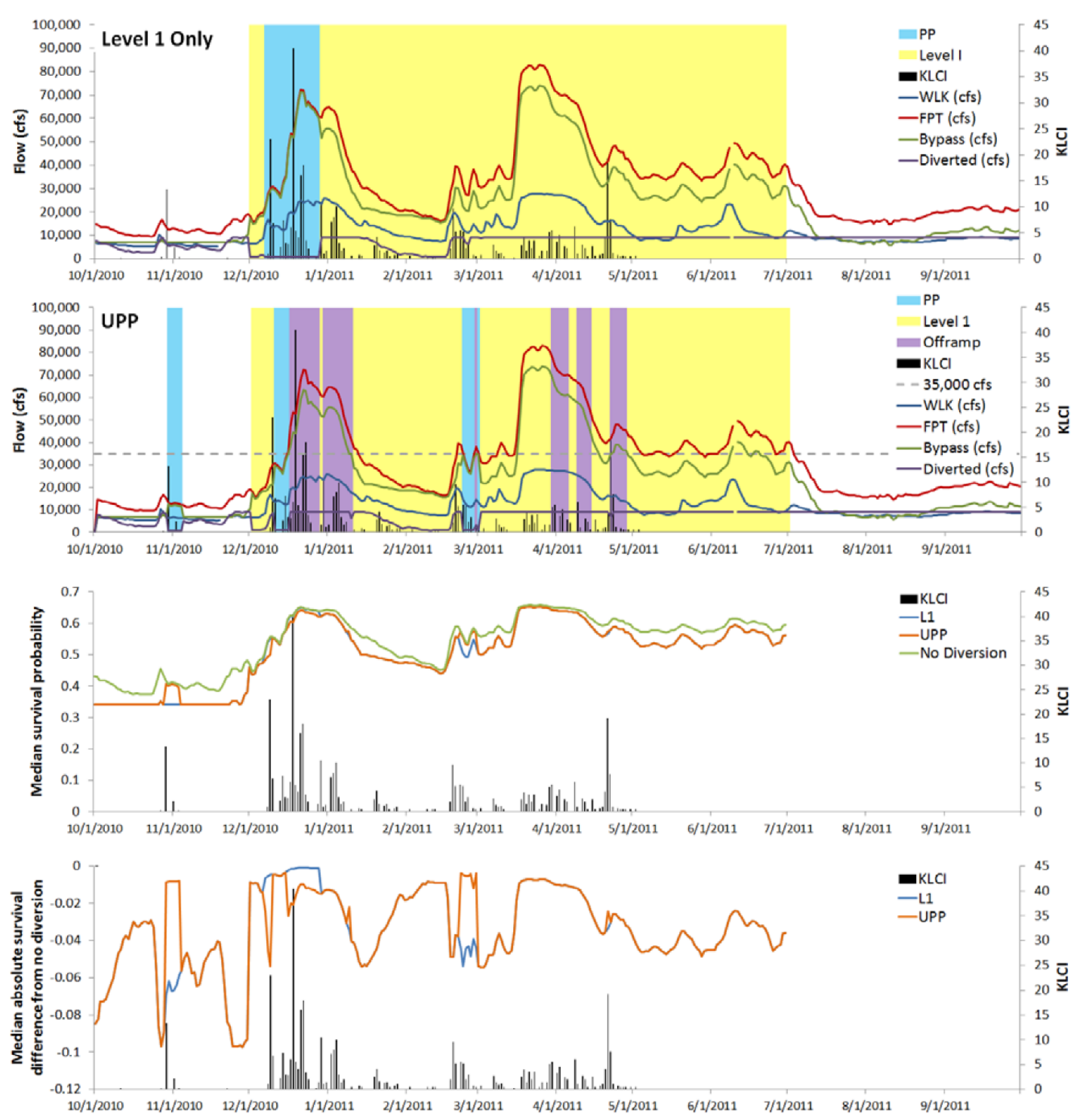

Figure 63. Graphs showing Level 1 (L1) real-time operations (top graph), revised Unlimited Pulse Protection (UPP) real-time operations (second graph from top), median daily through-Sacramento-San Joaquin River Delta survival probability (third graph from top), and median daily difference in survival of each real-time scenario relative to the no diversion scenario (bottom graph), for water year 2011. The Knights Landing Catch Index (KLCl) is plotted along the right vertical axis. Yellow shading ("Level 1" in graph explanations) indicates periods of Level 1 pumping, blue shading ("PP" in graph explanations) indicates periods of pulse protection based on the $\mathrm{KLCl}$, and purple shading ("Offramp" in graph explanation) indicates pulse protection offramp periods. FPT, Sacramento River discharge at Freeport; WLK, Sacramento River discharge at Wilkins Slough; cfs, cubic foot per second. 
Water year: 2011
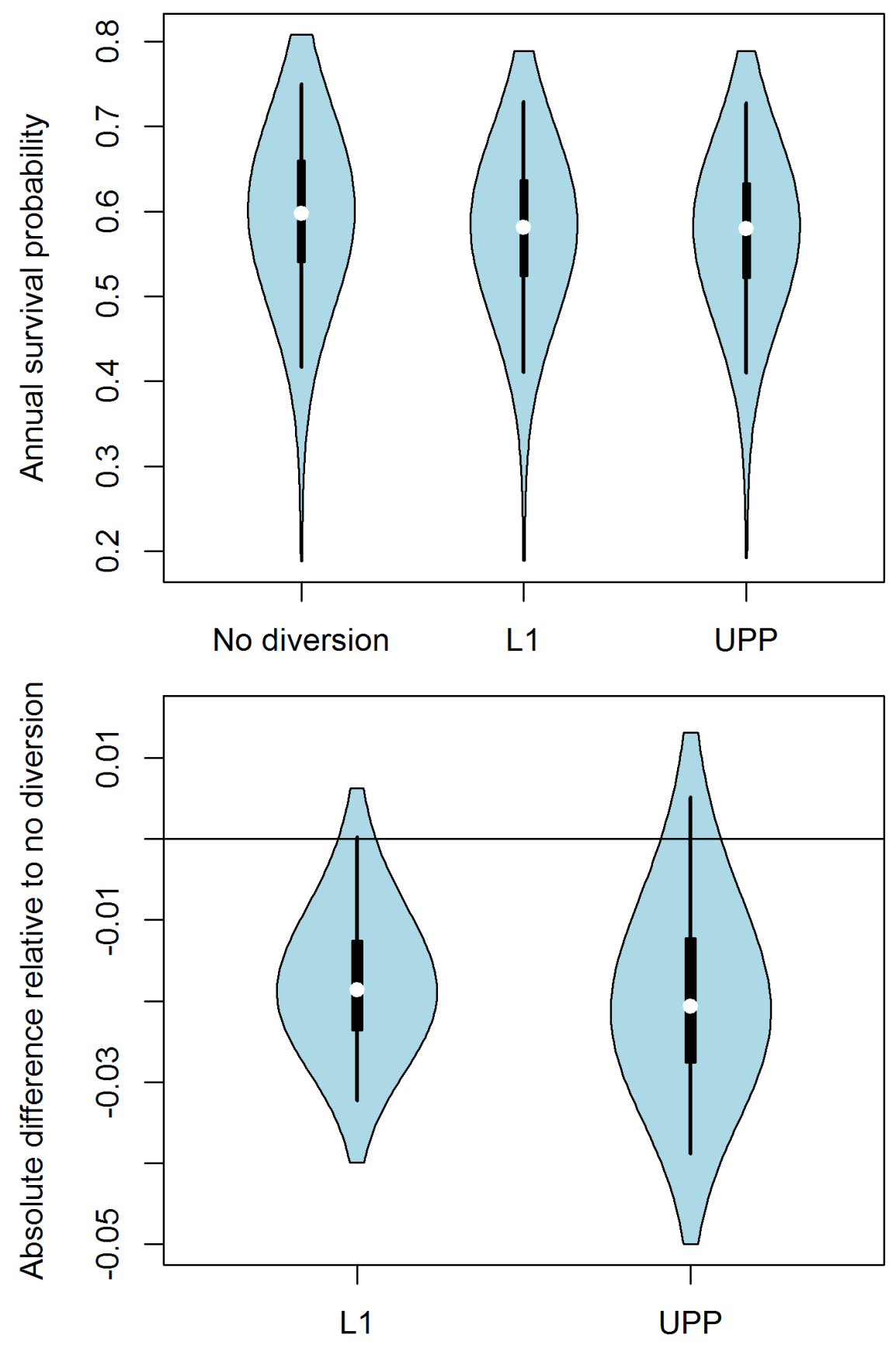

Figure 64. Violin plots showing posterior distributions of annual survival probability for Level 1 (L1) real-time operations and revised Unlimited Pulse Protection (UPP) real-time operations (top graph,) and the difference in annual survival of each real-time scenario relative to the no diversion scenario (bottom graph), for water year 2011. Violins represent non-parametric kernel density estimates of the full posterior distributions, thin vertical lines represent the $95 \%$ credible intervals, thick vertical lines represent the 25 th-75th percentiles, and white dots represent the medians. 


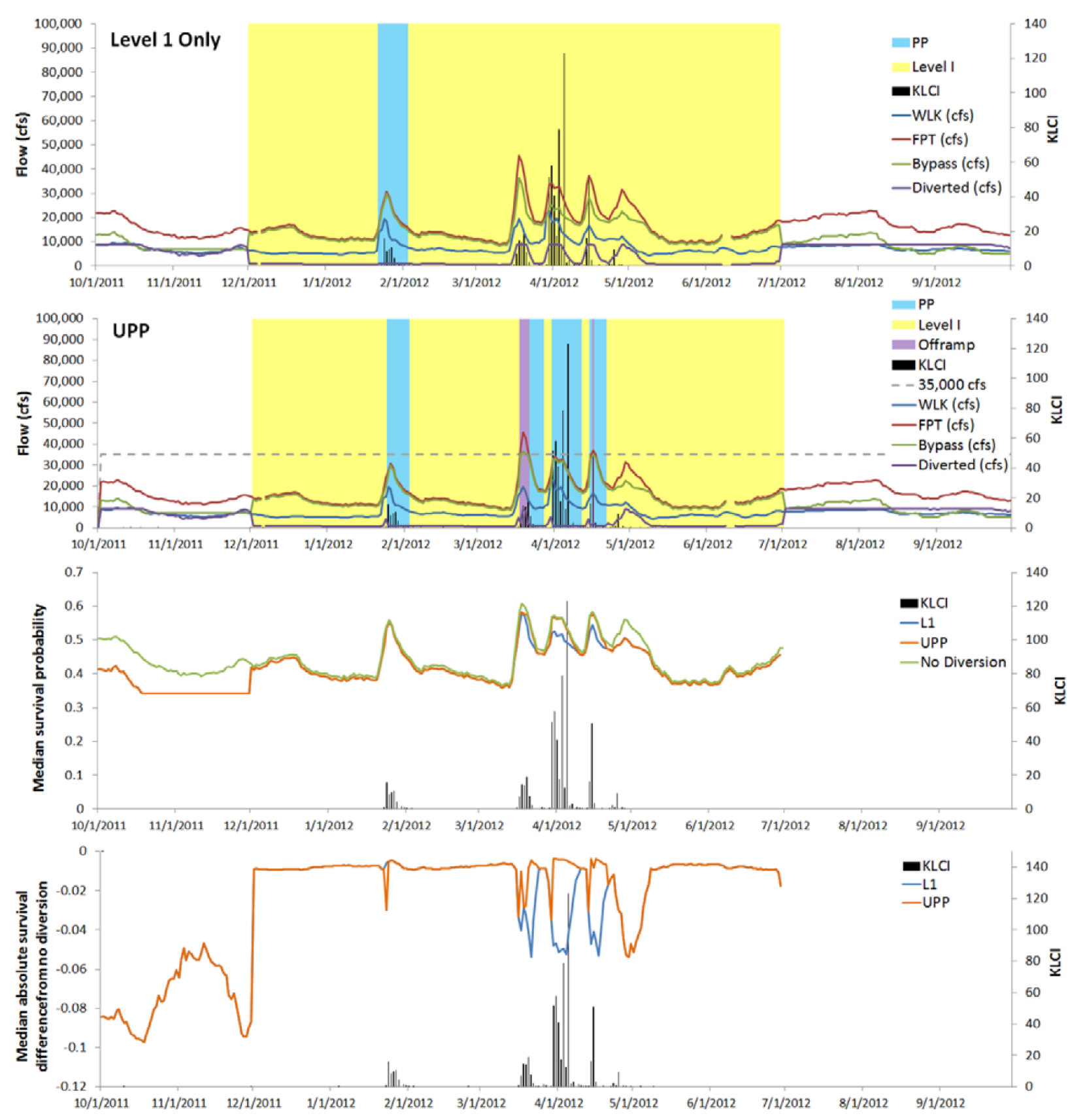

Figure 65. Graphs showing Level 1 (L1) real-time operations (top graph), revised Unlimited Pulse Protection (UPP) real-time operations (second graph from top), median daily through-Sacramento-San Joaquin River Delta survival probability (third graph from top), and median daily difference in survival of each real-time scenario relative to the no diversion scenario (bottom graph), for water year 2012. The Knights Landing Catch Index (KLCl) is plotted along the right vertical axis. Yellow shading ("Level 1" in graph explanations) indicates periods of Level 1 pumping, blue shading ("PP" in graph explanations) indicates periods of pulse protection based on the $\mathrm{KLCl}$, and purple shading ("Offramp" in graph explanation) indicates pulse protection offramp periods. FPT, Sacramento River discharge at Freeport; WLK, Sacramento River discharge at Wilkins Slough; cfs, cubic foot per second. 
Water year: 2012
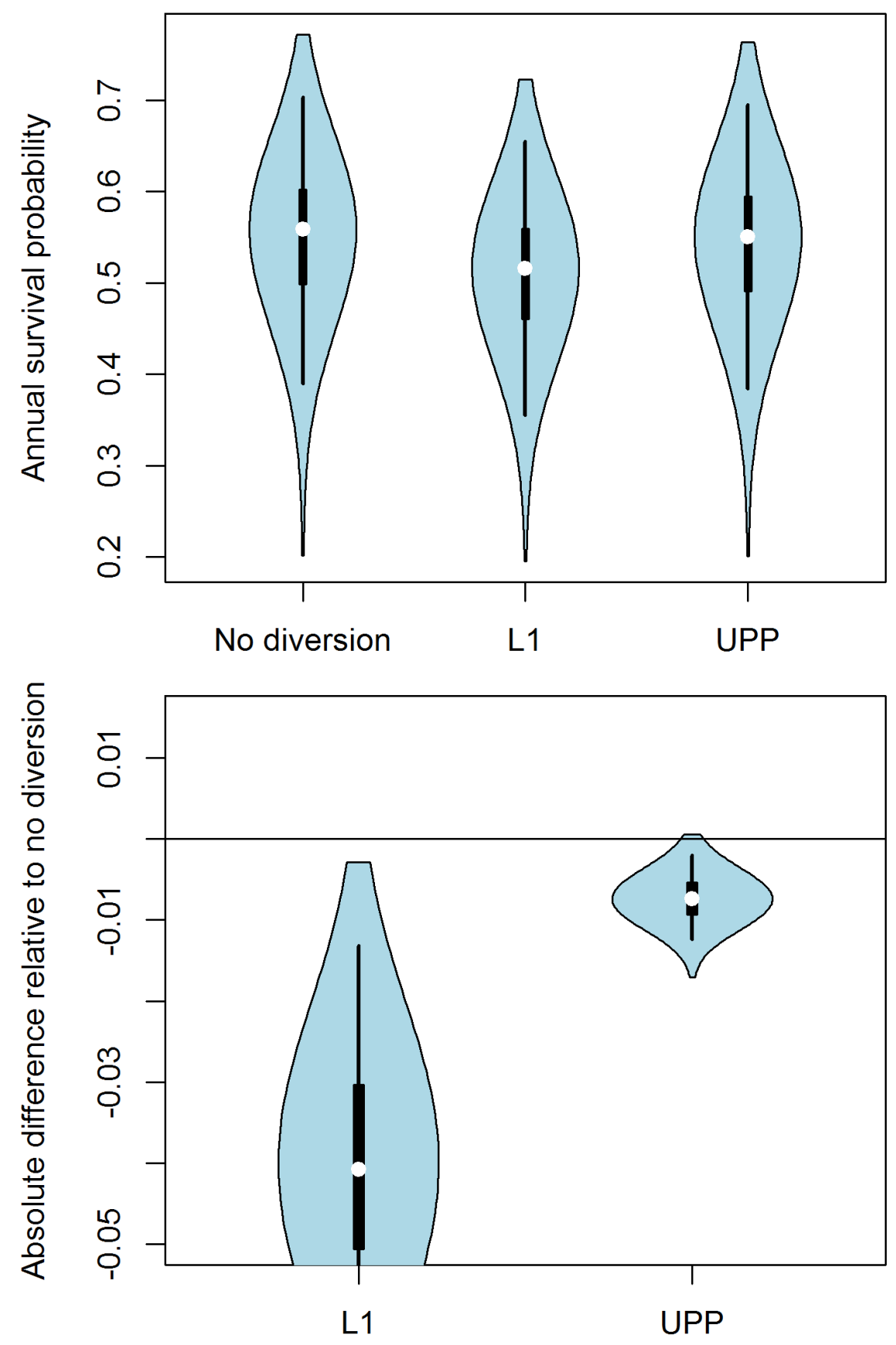

Figure 66. Violin plots showing posterior distributions of annual survival probability for Level 1 (L1) real-time operations and revised Unlimited Pulse Protection (UPP) real-time operations (top graph), and the difference in annual survival of each real-time scenario relative to the no diversion scenario (bottom graph), for water year 2012. Violins represent non-parametric kernel density estimates of the full posterior distributions, thin vertical lines represent the $95 \%$ credible intervals, thick vertical lines represent the 25 th-75th percentiles, and white dots represent the medians. 


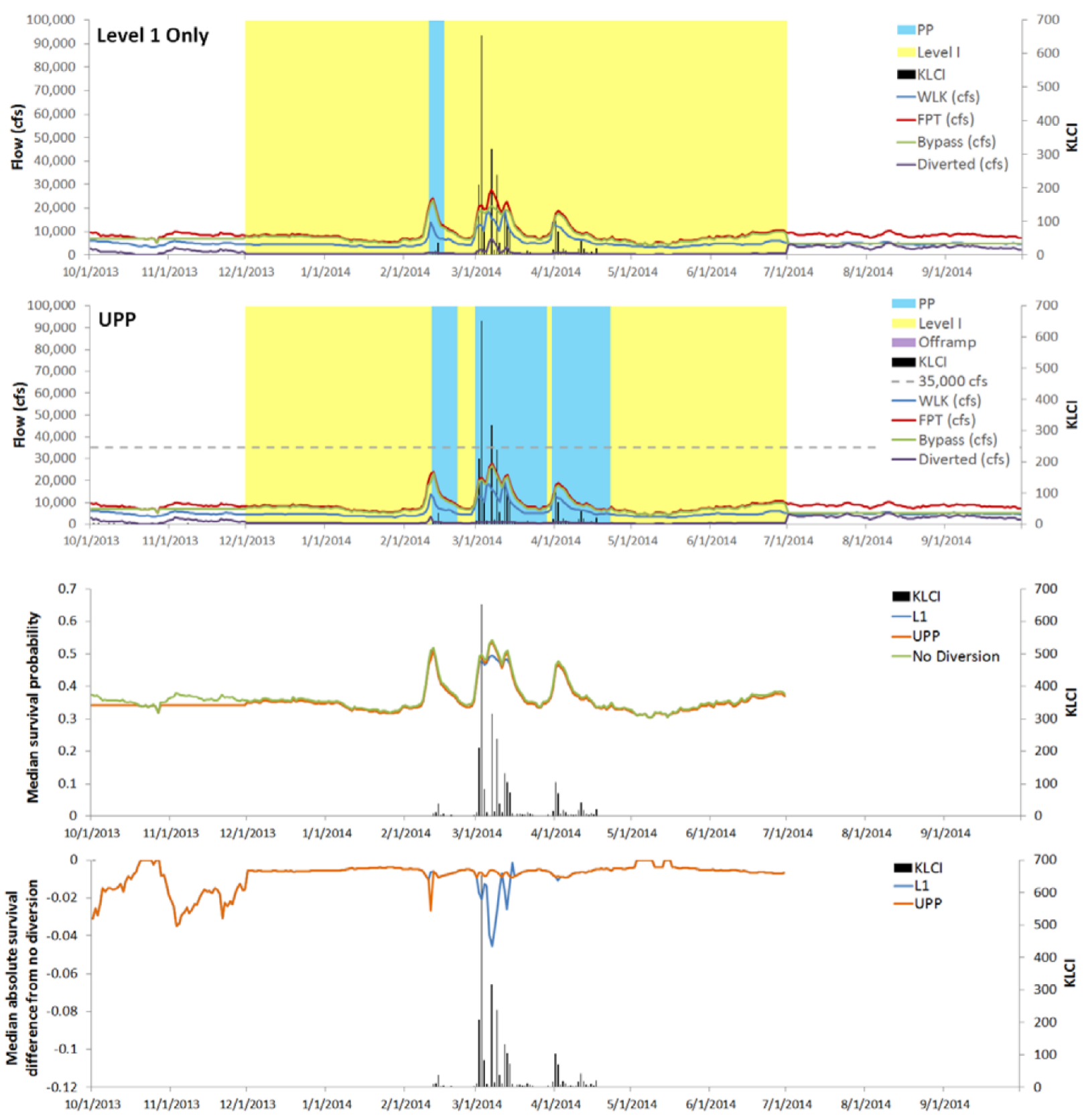

Figure 67. Graphs showing Level 1 (L1) real-time operations (top graph), revised Unlimited Pulse Protection (UPP) real-time operations (second graph from top), median daily through-Sacramento-San Joaquin River Delta survival probability (third graph from top), and median daily difference in survival of each real-time scenario relative to the no diversion scenario (bottom graph), for water year 2014. The Knights Landing Catch Index (KLCl) is plotted along the right vertical axis. Yellow shading ("Level 1" in graph explanations) indicates periods of Level 1 pumping, blue shading ("PP" in graph explanations) indicates periods of pulse protection based on the $\mathrm{KLCl}$, and purple shading ("Offramp" in graph explanation) indicates pulse protection offramp periods. FPT, Sacramento River discharge at Freeport; WLK, Sacramento River discharge at Wilkins Slough; cfs, cubic foot per second. 
Water year: 2014
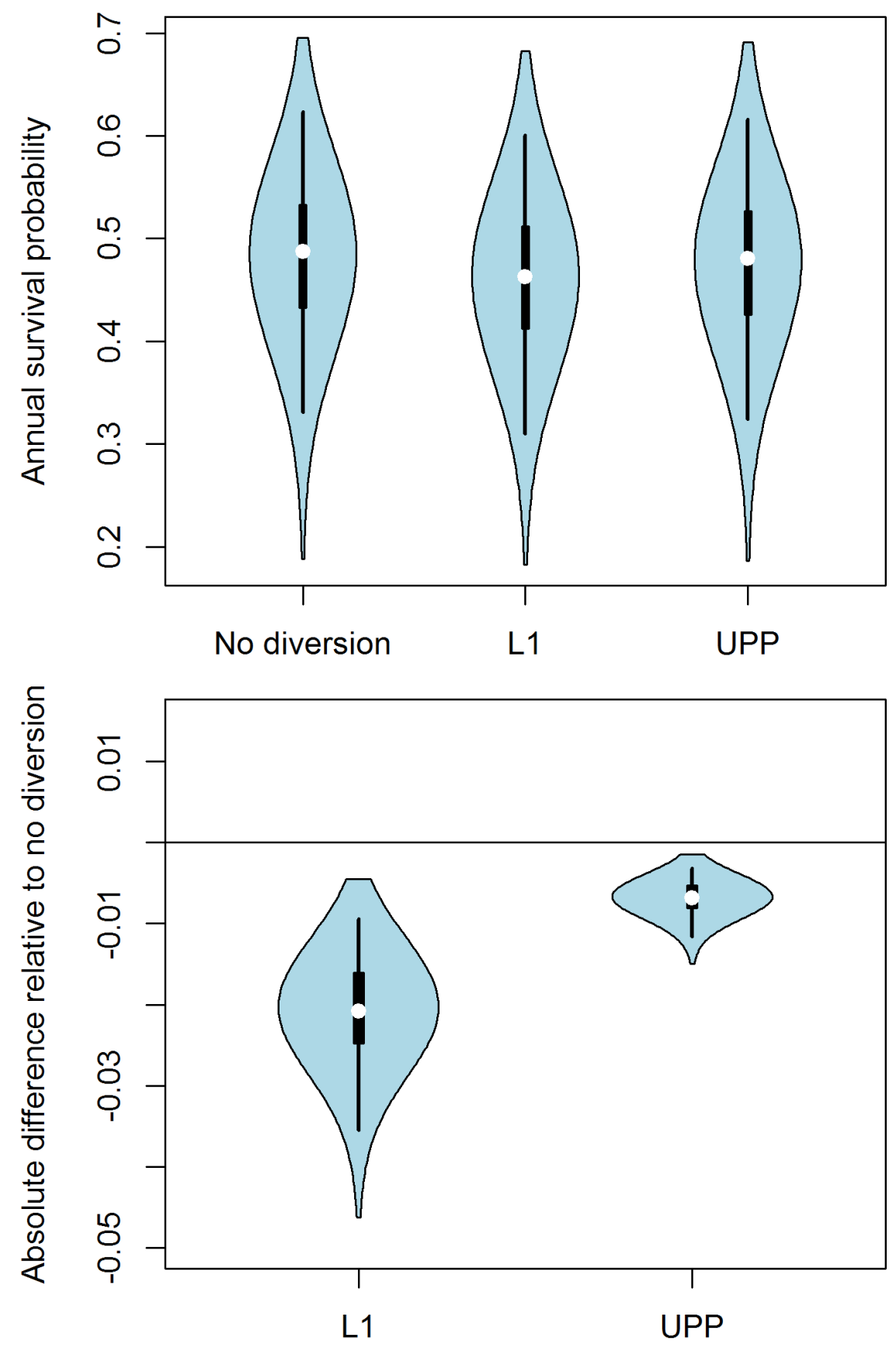

Figure 68. Violin plots showing posterior distributions of annual survival probability for Level 1 (L1) real-time operations and revised Unlimited Pulse Protection (UPP) real-time operations (top graph), and the difference in annual survival of each real-time scenario relative to the no diversion scenario (bottom graph), for water year 2014. Violins represent non-parametric kernel density estimates of the full posterior distributions, thin vertical line represent the $95 \%$ credible intervals, thick vertical lines represent the 25 th- 75 th percentiles, and white dots represent the medians. 


\section{Discussion}

We did four in-depth analyses that showed one common overarching finding-Diversion of water from the Sacramento River upstream of the Delta reduces survival of juvenile Chinook salmon migrating through the Delta. This finding should come as little surprise, however, given the positive relation between river flow and through-Delta survival (fig. 5). We identified flows at which the current bypass rules substantially decrease survival and identified considerable seasonal variation in the probability and magnitude of decrease in survival owing to NDD operation. Thus, we developed a quantitative approach for determining diversion rates that yield the same level of protection across the range of river flows. Although we identified negative effects on survival for the current bypass rules and the PA and L1 scenarios, real-time operations with unlimited pulse protection (the UPP scenario) resulted in high mean annual survival and little change in daily survival at times when pulses of juvenile salmon were entering the Delta.

Analysis of the bypass rule curves indicated that all rules but constant low-level pumping could lead to sizeable decreases in survival of as much as 6-10 percentage points at certain flows (fig. 9). Decreases in survival were minimal at the lowest flows of $5,000-15,000 \mathrm{ft}^{3} / \mathrm{s}$, but increased to a maximum at intermediate flows ranging from $20,000 \mathrm{ft}^{3} / \mathrm{s}$ to $30,000 \mathrm{ft}^{3} / \mathrm{s}$ before decreasing at higher flows. This pattern arises from the interaction between the rate of increase in diversion relative to the change in survival with increases in river flow. Diversions under most bypass rules are held to constant low-level pumping (maximum of $900 \mathrm{ft}^{3} / \mathrm{s}$ diversion) at flows $<15,000 \mathrm{ft}^{3} / \mathrm{s}$, minimizing survival decreases. At greater flows, diversions increase linearly until they reach the maximum diversion of $9,000 \mathrm{ft}^{3} / \mathrm{s}$. Over this range of flows, survival has the steepest rate of increase before leveling off (fig. 5). Therefore, increasing diversion over this range of flows results in a large decrease in survival owing to the steep slope of the survival curve (figs. 11-21).

The 82-year CalSim simulations showed in detail how routing, survival, and travel time vary when the bypass rules are applied in the context of system-wide water management and other regulatory constraints. Summarizing simulations over the 82 years, we noted a high probability that survival under the PA scenario was lower than under the NAA scenario, and that travel time was longer under PA relative to NAA in most simulation years. However, the largest survival differences between the PA and NAA scenarios occurred during October-November and May-June. Two factors led to larger survival differences during these periods. Less restrictive bypass rules resulted in lower survival. Second, more frequent operation of the DCC under the PA scenario led to large decreases in survival. Specifically, the largest decreases in daily survival between scenarios occurred during periods when the DCC was open under the PA scenario but closed under the NAA scenario (fig. 22, appendix 1). When the DCC is open, two factors interact to substantially reduce survival. First, opening the DCC increases the proportion of fish entering the interior Delta where survival is low (figs. 8 and 29, appendix 3). Second, opening DCC gates decreases survival of fish in the Sacramento River downstream of the DCC (see fig. 2, second graph from left). The bypass rules were designed to be most restrictive during the primary migration period when endangered winter- and spring-run juvenile salmon are migrating through the Delta (December-April). Nonetheless, juvenile salmon are present in the Delta during October -June, and our analysis shows that considerable decreases in survival could occur during October-November and May-June, with lower but less extreme decreases during other times of year (figs. 32 and 34). 
Results from our survival model were unavailable during development of the bypass rules, but had such a model been available, we show how it could have been used to shape NDD rule curves that (1) achieve the same level of protection across the range of river flows, and (2) account for uncertainty by specifying a low probability of exceeding a given decrease in survival. Regardless of the rule-curve scenario that we examined, to maintain a constant level of protection over the range of river flows requires increasing diversion at a rate considerably less than the rate of increase specified by the bypass rules (figs. 38-43). Although our scenarios indicate a slower rate of increase in diversion, we also determined that diversion could be higher than the L1 scenario diversion rates when flows are less than about $20,000 \mathrm{ft}^{3} / \mathrm{s}$, but increase more slowly (that is, lower diversion rates) at higher flows.

We also examined rule curves that resulted from the choice of criterion based on absolute compared to relative change in survival. Because through-Delta survival increases from about 0.35 to 0.65 over the range of flows, managers might wish to be more risk averse during low flows, or in other words, allow for a larger absolute decrease in survival at high flows when survival is high. Using a relative change in survival achieves this purpose because a constant relative decrease results in an increasing absolute change as survival increases (fig. 45, bottom graph).

Real-time operations, and particularly the UPP operations that protect an unlimited number of pulses, showed considerable promise in protecting juvenile salmonid populations. This analysis indicated that the highest catches occurred during flow pulses when survival was expected to be high. Annual survival, therefore, is weighted towards periods of high daily survival, resulting in a high annual survival. Furthermore, given the asymptotic shape of the flow-survival relations (fig. 5), where survival levels off at flows higher than about 35,000 ft $3 / \mathrm{s}$, NDD diversions above this level (that is, the "offramp" implemented under the UPP scenario) should have little effect on survival. Movement of fish during high flow periods (when survival is high and insensitive to changes in flow) and higher allowable diversions during these periods compared to other periods allow for both the protection of juvenile salmon and the diversion of water.

Although real-time operations seem to have a small effect on survival, many important caveats and assumptions should be considered. By weighting daily survivals by the Knights Landing Catch Index, our calculation of mean annual survival implicitly assumed that the true abundance of winterand spring-run sized fish was directly proportional to the catch index. However, juvenile trapping efforts often have very low capture probabilities ( $<1 \%$; Roberts, 2007), and capture efficiency can be influenced by environmental conditions (Cheng and Gallinat, 2004). Thus, true abundance may not be proportional to catch. For example, survival probabilities for days when there was 0 catch during the main migration season (December-April) contributed 0 to mean annual survival, even though some fish likely entered the Delta on these days. Furthermore, days with 0 catch often occurred during low flows when daily survival was low, thereby under-representing these days in the mean annual survival. 
Our analysis assumed no implementation error in the sense that pulses of fish at Knights Landing were protected perfectly by implementation of constant low-level pumping. Because Knights Landing is about $75 \mathrm{~km}$ upstream of the NDD, there is a time lag between pulses of fish at Knights Landing an NDD that could result in some pulses missing protective diversion rules by the time they pass the NDD. Because the travel time between locations is unknown, we assumed that fish pulses arrived at the NDD essentially on the same day as they passed Knights Landing. For future implementation of real-time operations, we suggest (1) moving trapping efforts closer to the NDD, (2) using absolute abundance as an operational trigger because catch may not be proportional to abundance, and (3) implementing regular trap efficiency trials and the associated statistical model to estimate capture probability and abundance.

Because our survival model is essentially a regression model, it has many important limitations regarding its application and inferences that can be drawn from it. First, care should be taken when extending inferences beyond the range of data used to fit the model. Observed flows for our analysis encompassed the 1st-95th percentiles of historical flow, bolstering inferences from the model (Perry and others, in press). Second, the model was fit to large hatchery-origin late-fall Chinook salmon smolts that migrated through the Delta during December-March, yet here we are extending inferences to all runs over the entire migration period. Thus, survival of other runs at other times of year could have a different response to the effects of NDD operations on survival. Third, because our model was fitted to juvenile salmon telemetry data during 2005-11, it is a representation of the Delta in its current state, not some future state. because our model characterizes the relation between Delta inflows and survival in the present-day Delta, our model would be insensitive to future changes to the Delta that modify the relation between inflows and survival. For example, Perry and others (in press) identified the strongest flow-survival relations in reaches that transitioned from bidirectional tidal flows at low inflows to unidirectional river flow at high inflow, implicating the tides as an important driver of the flow survival relation. Future sea level rise due to climate change would change tidal dynamics in the Delta, which in turn could modify the relation between inflow and survival. Our model is insensitive to these types of changes to a future Delta.

Given these caveats, our analyses were able to (1) provide a comprehensive assessment of California WaterFix to quantify relative changes in key population metrics between scenarios, (2) identify the magnitude of these changes at given inflows and given times of the year, and (3) offer quantitative approaches for shaping NDD operations. Ultimately, these analyses and others done for the California WaterFix Biological Opinion (National Marine Fisheries Service, 2017) helped to develop operational criteria, such as the UPP scenario, that minimize effects on survival (relative to other scenarios evaluated) while allowing operation of the NDD.

\section{Acknowledgments}

We would like to thank Yvette Redler and Cathy Marcinkevage of the National Marine Fisheries Service for providing guidance through this project, as well as for facilitating a stimulating collaborative work environment. 


\section{References Cited}

California Department of Water Resources, 2013, Bay Delta conservation Plan-Public draft: Prepared by ICF International for California Department of Water Resources, Sacramento, California, $1396 \mathrm{p}$.

California Department of Water Resources, 2016, 2014 Georgiana Slough floating fish guidance structure performance evaluation project report: California Department of Water Resources, BayDelta Office, Sacramento, California., 486 p., accessed November 22, 2017, at http://baydeltaoffice.water.ca.gov/sdb/GS/docs/Final\%20Report\%20October\%202016\%20Edition\% 20103116-signed.pdf.

Cheng, Y.W., and Gallinat, M.P., 2004, Statistical analysis of the relationship among environmental variables, inter-annual variability and smolt trap efficiency of salmonids in the Tucannon River: Fisheries Research, v. 70, nos. 2-3, p. 229-238, https://doi.org/10.1016/j.fishres.2004.08.005. del Rosario, R.B., Redler, Y.J., Newman, K., Brandes, P.L., Sommer, T., Reece, K., and Vincik, R., 2013, Migration patterns of juvenile winter-run-sized Chinook salmon (Oncorhynchus tshawytscha) through the Sacramento-San Joaquin Delta: San Francisco Estuary and Watershed Science, v. 11, no. 1, p. 1-22, https://doi.org/10.15447/sfews.2013v11iss1art3.

ICF International, 2016, Biological assessment for the California WaterFix: Prepared for the Bureau of Reclamation, Sacramento, California, ICF 00237.15., 62 p.

Kapahi, G., Baer, I., Farwell, J., Riddle, D., and Wilson, G., 2006, Water quality control plan for the San Francisco Bay/Sacramento-San Joaquin Delta Estuary: Sacramento, California, State Water Resources Control Board, 49 p.

King, R., Morgan, B., Gimenez, O., and Brooks, S., 2010, Bayesian analysis for population ecology: Boca Raton, Florida, CRC Press, 456 p.

Michel, C.J., Ammann, A.J., Lindley, S.T., Sandstrom, P.T., Chapman, E.D., Thomas, M.J., Singer, G.P., Klimley, A.P., and MacFarlane, R.B., 2015, Chinook salmon outmigration survival in wet and dry years in California's Sacramento River: Canadian Journal of Fisheries and Aquatic Sciences, v. 72, no. 11, p. 1749-1759, https://doi.org/10.1139/cjfas-2014-0528.

National Marine Fisheries Service, 2017, California WaterFix Biological Opinion: National Marine Fisheries Service Consultation Number WCR-2016-5506, accessed March 2, 2018, at http://www.westcoast.fisheries.noaa.gov/central_valley/CAWaterFix.html.

Newman, K.B., 2003, Modelling paired release-recovery data in the presence of survival and capture heterogeneity with application to marked juvenile salmon: Statistical Modelling, v. 3, no. 3, p. 157177, https://doi.org/10.1191/1471082X03st055oa.

Newman, K.B., and Rice, J., 2002, Modeling the survival of Chinook salmon smolts outmigrating through the lower Sacramento River system: Journal of the American Statistical Association, v. 97, no. 460, p. 983-993, https://doi.org/10.1198/016214502388618771.

Perry, R.W., 2010, Survival and migration dynamics of juvenile Chinook salmon (Oncorhynchus tshawytscha) in the Sacramento-San Joaquin River Delta: Seattle, University of Washington, School of Aquatic and Fishery Sciences, Ph.D. dissertation, 223 p.

Perry, R.W., Brandes, P.L., Burau, J.R., Klimley, A.P., MacFarlane, B., Michel, C., and Skalski, J.R., 2013, Sensitivity of survival to migration routes used by juvenile Chinook salmon to negotiate the Sacramento-San Joaquin River Delta: Environmental Biology of Fishes, v. 96, nos. 2-3, p. 381-392, https://doi.org/10.1007/s10641-012-9984-6.

Perry, R.W., Brandes, P.L., Burau, J.R., Sandstrom, P.T., and Skalski, J.R., 2015, Effect of tides, river flow, and gate operations on entrainment of juvenile salmon into the interior Sacramento-San Joaquin River Delta: Transactions of the American Fisheries Society, v. 144, no. 3, p. 445-455, https://doi.org/10.1080/00028487.2014.1001038. 
Perry, R.W., Pope, A.C., Romine, J.G., Brandes, P.L., Burau, J.R., Blake, A.R., Ammann, A.J., and Michel, C.J. (in press), Flow-mediated effects on travel time, routing, and survival of juvenile Chinook salmon in a spatially complex, tidally forced river delta: Canadian Journal of Fisheries and Aquatic Sciences, https://doi.org/10.1139/cjfas-2017-0310.

Perry, R.W., Romine, J.G., Adams, N.S., Blake, A.R., Burau, J.R., Johnston, S.V., and Liedtke, T.L., 2014, Using a non-physical behavioral barrier to alter migration routing of juvenile Chinook salmon in the Sacramento-San Joaquin River Delta: River Research and Applications, v. 30, p. 192-203.

Perry, R.W., Romine, J.G., Pope, A.C., and Evans, S.D., 2018, Effects of the proposed California WaterFix North Delta Diversion on flow reversals and entrainment of juvenile Chinook salmon (Oncorhynchus tshawytscha) into Georgiana Slough and the Delta Cross Channel, northern California: U.S. Geological Survey Open-File Report 2018-1028, 46 p., https://doi.org/10.3133/ofr20181028.

Perry, R.W., Skalski, J.R., Brandes, P.L., Sandstrom, P.T., Klimley, A.P., Ammann, A., and MacFarlane, B., 2010, Estimating survival and migration route probabilities of juvenile Chinook salmon in the Sacramento-San Joaquin River Delta: North American Journal of Fisheries Management, v. 30, no. 1, p. 142-156, https://doi.org/10.1577/M08-200.1.

Roberts, J., 2007, Timing, composition, and abundance of juvenile salmonid emigration in the Sacramento River near Knights Landing, October 2001-July 2002_Draft: California Department of Fish and Game, accessed March 2, 2018, at https://nrm.dfg.ca.gov/FileHandler.ashx?DocumentID=45739.

Romine, J.G., Perry, R.W., Pope, A.C., Stumpner, P., Liedtke, T.L., Kumagai, K.K., and Reeves, R.L., 2017, Evaluation of a floating fish guidance structure at a hydrodynamically complex river junction in the Sacramento-San Joaquin River Delta, California, USA: Marine and Freshwater Research, v. 68, no. 5, p. 878-888, https://doi.org/10.1071/MF15285. 


\section{Appendixes}

Appendixes 1-11 are Adobe Acrobat ${ }^{\circledR}$ files and are available for download at https://doi.org/10.3133/ofr20181078.

Appendix 1. Simulated Daily Survival by Year, No Action Alternative Compared to Proposed Action Scenarios, 1922-2003

Appendix 2. Simulated Daily Travel Time by Year, No Action Alternative Compared to Proposed Action Scenarios, 1922-2003

Appendix 3. Simulated Daily Routing by Year, No Action Alternative Compared to Proposed Action Scenarios, 1922-2003

Appendix 4. Simulated Route-Specific Survival by Year, No Action Alternative Compared to PA Scenarios, 1922-2003

Appendix 5. Simulated Route-Specific Travel Time by Year, No Action Alternative Compared to PA Scenarios, 1922-2003

Appendix 6. Simulated Daily Survival by Year, No Action Alternative Compared to Level 1 Scenarios, 1922-2003

Appendix 7. Simulated Daily Travel Time by Year, No Action Alternative Compared to Level 1 Scenarios, 1922-2003

Appendix 8. Simulated Daily Routing by Year, No Action Alternative Compared to Level 1 Scenarios, 1922-2003

Appendix 9. Simulated Route-Specific Survival by Year, No Action Alternative Compared to Level 1 Scenarios, 1922-2003

Appendix 10. Simulated Route-Specific Travel Time by Year, No Action Alternative Compared to Level 1 Scenarios, 1922-2003

Appendix 11. North Delta Diversion Rule Curve Optimization 
Publishing support provided by the U.S. Geological Survey

Science Publishing Network, Tacoma Publishing Service Center

For more information concerning the research in this report, contact the Director, Western Fisheries Research Center

U.S. Geological Survey

6505 NE 65th Street

Seattle, Washington 98115

https://wfrc.usgs.gov/ 
